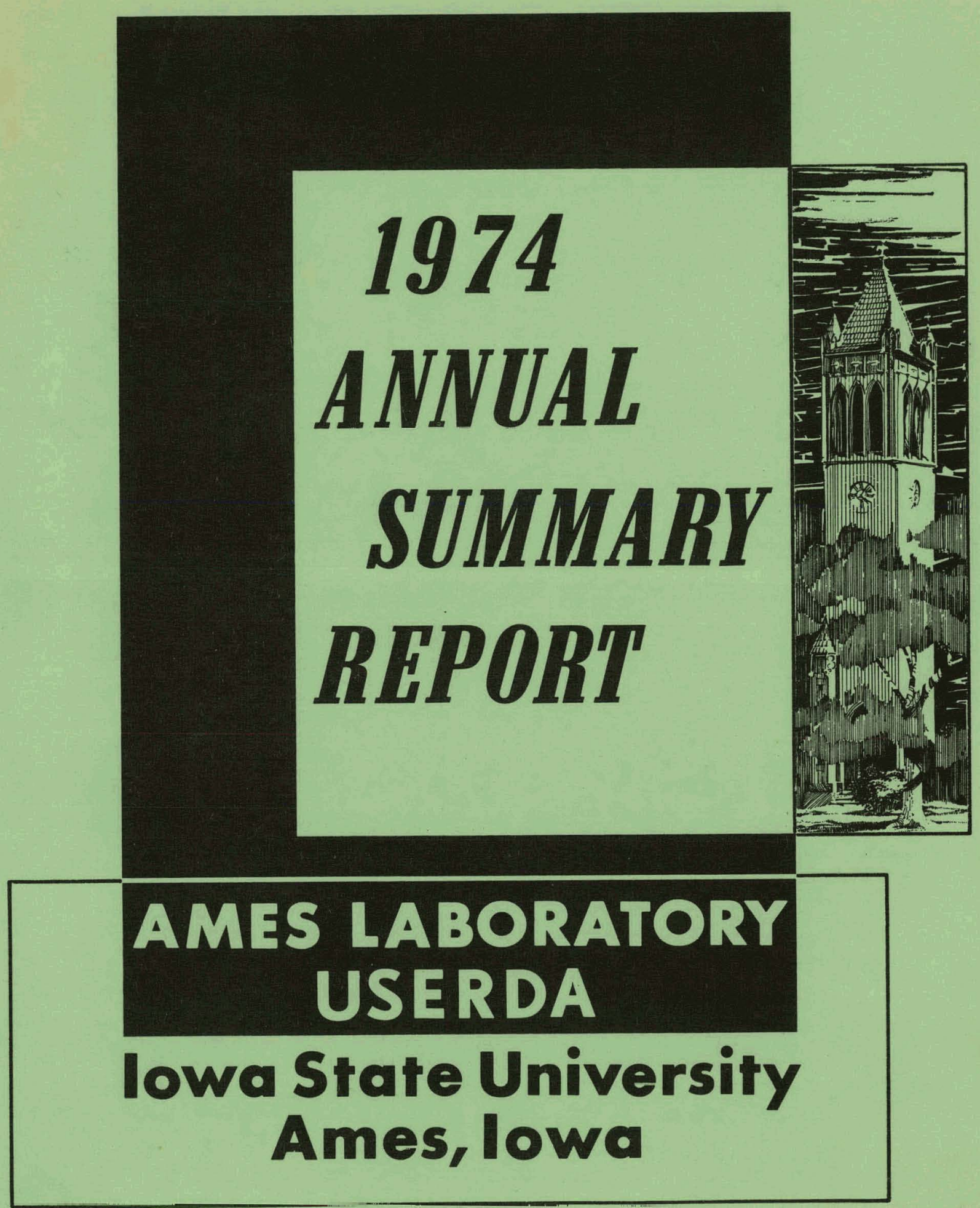

JULY 1975

MSTRIBUTraK OF THIS DOCUMENT UNLIMITE 


\section{DISCLAIMER}

This report was prepared as an account of work sponsored by an agency of the United States Government. Neither the United States Government nor any agency Thereof, nor any of their employees, makes any warranty, express or implied, or assumes any legal liability or responsibility for the accuracy, completeness, or usefulness of any information, apparatus, product, or process disclosed, or represents that its use would not infringe privately owned rights. Reference herein to any specific commercial product, process, or service by trade name, trademark, manufacturer, or otherwise does not necessarily constitute or imply its endorsement, recommendation, or favoring by the United States Government or any agency thereof. The views and opinions of authors expressed herein do not necessarily state or reflect those of the United States Government or any agency thereof. 


\section{DISCLAIMER}

Portions of this document may be illegible in electronic image products. Images are produced from the best available original document. 
This report was prepared as an account of work sponsored by the United States Government. Neither the United States nor the United States Energy Research and Development Administration, nor any of their employees, nor any of their contractors, subcontractors, or their employees, makes any warranty, express or implied, or assumes any legal liability or responsibility for the accuracy, completeness, or usefulness of any information, apparatus, product or process disclosed, or represents that its use would not infringe privately owned rights.

Available from: National Terhnical Information Service U. S. Department of Commerce P.O. Box 1553

Springfield, VA 22161

Price: Microfiche $\$ 2.25$

Printed Copy $\$ 5.25$ 
Distribution Category UC 2

General, Miscellaneous, and

Progress Reports (TID-4500)

\title{
1974 ANNUAL SUMMARY REPORT
}

\author{
HIGH ENERGY PHYSICS \\ NUCLEAR SCIENCES \\ MATERIALS SCIENCE \\ MOLECULAR SCIENCES
}

Ames Laboratory, USERDA

Iowa State University

Ames, Iow a 50010

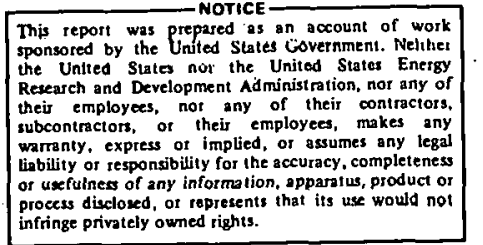

Date Published: July, 1975

Prepared for the

U. S. Energy Research and Development Administration

under Contract No. W-7405-eng-82 
THIS PAGE

\section{WAS INTENTIONALLY \\ LEFT BLANK}


PHYSICAL RESEARCH

\section{FOREW ORD}

This report consists of collections of abstracts of papers published during the previous calendar year in the areas of high energy physics, nuclear sciences, materials science and molecular sciences. These are arranged in accordance with the project titles used in the A.EC Schedule 189 Budget Proposals. The collection of abstracts therefore supplements the listing of papcre publiohed in the Schedule 189. 
Rocent reports in this sorios arc:

$\begin{array}{lll}\text { IS }-1500 & \text { IS }-2300 \\ \text { IS }-1600 & \text { IS }-2600 \\ \text { IS }-1900 & \text { IS }-2800 \\ \text { IS }-2.100 & \text { IS }=3300 \\ & \text { IS }-3500 & \end{array}$




\section{CONTENTS}

Activity Code

NT -01

NT -02

NT -03

NT $-03-01-0.1$

NT $-03-01-02$

NT $-03-01-03$

NT $-03-01-04$

NT $-03-02$

NT-03-02-01

NT $-03-02-02$
Activity

High Energy Physics

Experimental

Theory

Nuclear Sciences

Materials Science

Structure of Materials

Mechanical Properties

Physical Properties

Radiation Effects

Solid State Physics

Neutron Scattering

Experimental Physics

I. Electron Structure and Magnetic Properties of Solids

II. Nuclear Resonance in Solids

III. Superconductivity

IV. Thermodynamic and Transport Properties of Solids

V. Optical \& Spectroscopic Properties of Solids

VI. Rare Earth Metals Preparation

Theoretical Physics

I. Optical and Surface Physics

II. Superconductivity

III. Magnetic and Electrical Properties

Materials Chemistry
Page

1

1 
NT $-03-03-01$

NT $-03-03-02$

NT $-03-03-03$

NT -04

NT $-04-01$

NT-04-01-01

NT $-04-01-02$

NT $-04-02$

NT $-04-02-01$

NT $-04-03$

NT $-04-03-01$
Chemical Structure

59

I. X-Ray and Neutron Crystallography

59

II. Interactions in Solids

III. L ow Oxidation States in Solid and Molten Systems

IV. Chemistry of Heavy. Transition Metals

Engineering Chemistry

67

High Temperature and Surface Chemistry

69

I. High Temperature Chemistry

II. Surface Chemistry

Molecular Sciences

Radiation and Separations Research

Radiation Sciences

73

I. Photochemistry \& Spectroscopy . 73

II. Radiation \& Solid State Spectroscopy 75

Separations Research $\quad 77$

Chemical \& Geophysical Energy 81

Chemical Energy

81

1. Reaction Mechanisms of Inorganic and Bioinorganic Systems 81

II. Properties of Rare Earth Electrolytes 84

Molecular and Atomic Sciences 88

Chemical Physics

88

I. Crystallography of Organic and Biological Materials

II. Statistical Mechanisms of Gaseous Systems

III. Mass Spectroscopy, Ion Source Chemistry

IV. Molecular Bonding Theory 
NT $-04-03-03$

NT $-04-04$

NT-04-04-01
Analys is

I. Analytical Spectroscopy

101

II. Analytical Separations 107

III. Analytical Mass Spectroscopy

110

IV. Activation Analysis and Electroanalytical Chemistry

112

v. Lasers in Analytical Chemistry

112

Mathematical \& Computer Sciences.

112

Mathematical Sciences 


\title{
NT-01
}

\section{HIGH ENERGY PHYSICS}

\author{
Experimental
}

DESIGN AND PERFORMANCE OF THE MUL TIPARTICLE ARGO SPECTROMETER SYSTEM

E. W. Anderson, G. B. Collins, G. P. Fisher, E. Lazarus, K. M. Moy, A. Ramanauskas, P. Schübelin, R. Siemann, A. M. Thorndike, F. Turkot, L. von Lindern, T. S. Clifford, J. R. Ficenec, D. R. Gilbert, W. N. Schreiner, B. C. Stringfellow, W. P. Trower, A. R. Erwin, L. J. Gutay, E. Harvey, N. C. Hien, A. Laasanen, G. P. Larson, M. O'Neill, W. Selove, K. Stanfield and R. B. Willmann

Nucl. Instr. Methods 122: 587 (1974)

Abstract--The Multiparticle Argo Spectrometer System, MASS, consists of a magnetic vertex spectrometer, two external trigger spectrometers, an on-line monitoring system and an off-line data analysis chain. The performance of MASS has been evaluated from physics data taken in a study of $28.5 \mathrm{GeV} / \subseteq$ pp collisions covering a large range of transverse momentum.

THE ON-LINE SATELLITE/CENTRAL COMPUTER FACILITY OF THE MULTIPARTICLE ARGO SPECTROMETER SYSTEM E. W. Anderson, G. P. Fisher, N. C. Hien, G. P. Larson, A. M. Thorndike, F. Turkut, L. von Lindern, T. S. Clifford, J. R. Ficenec and $W$. P. T rower

Nucl. Instr. Methods 122: 479 (1974)

Abstract--An on-line satellite/central computer facility has been developed at Brookhaven National Laboratory as part of the Multiparticle Argo Spectrometer System (MASS). This facility consisting of a PDP-9 and a CDC-6600, has been successfully used in a study of proton-proton inte ractions at $28.5 \mathrm{GeV} / \underline{c}$. 
STUDY OF PRODUCTION MECHANISMS AT LARGE TRANSVERSE MOMENTUM IN pp $\rightarrow$ pp $\pi^{+} \pi^{-}$AT $28.5 \mathrm{GeV} / \underline{\mathrm{c}}$

E. W. Anderson, J. R. Ficenec, D. R. Gilbert, L. J. Gutay, A. Laasanen, A. Ramanauskas, P. Schübelin and F. Turkot

Lett. al Nuovo Cimento, Serie 2, 11: 491 (1974)

Abstract- -We have a) isolated a low-mass $\Delta^{++} \pi^{-}$enhancement, probably the $\mathcal{P}_{*(1688)}$ at large $\underline{p} \perp$; b) found a sample of events where the large transverse momentum of the proton is balanced by a single meson, c) observed strong indication for the isoscalar dominance of the pomeronnucleon $\underline{t}$-channel scattering amplitude at large $\mathrm{p} \perp$.

DESIGN AND DEVELOPMENT OF A 1.5 METER STREAMER CHAMBER SYSTEM

A. Abashian, N. Beamer, B. Eisenstein, J. D. Hansen, W. Mollet, G. R. Morris, T. O'Halloran, J. R. Orr, D. Rhines, P. Schultz, P. Sokolsky, S. J. Prunster, J. Watson and M. Buttram

Nucl. Instr. Methods 115: 445 (1974)

Abstract--A $1.5 \mathrm{~m} \times 1.0 \mathrm{~m} \times 0.6 \mathrm{~m} \mathrm{Ne}-\mathrm{He}$ streamer chamber and high voltage pulsing system capable of $1.0 \mathrm{MV}$ pulses with widths continuously variable from 10 to $20 \mathrm{~ns}$ has been developed by a University of Illinois - ANL group. The design and construction of the de fast charge regulator, Marx generator, Blumlein pulse shaping network, transmission line, and chamber are described. Studies on the effects of increasing field emission and injection of free electrons into the pulse shaping network gap on pulse amplitude stability are reported. Under normal operating conditions, pulse amplitude stability of $2-3 \% \mathrm{rms}$ has been achieved. Photographic and pulse monitoring systems are described and operating experience over two experimental runs is summarized. 
*ANAL YSIS OF p̄p ELASTIC SCATTERING USING TWO COHERENT EXPONENTIALS

H. B. Crawley, N. W. Dean, E. S. Hafen, W. J. Kernan, and F. Ogino Phys. Rev. D 9: 189 (1974)

Abstract--Published data from many groups on pp elastic scattering at twenty-eight laboratory momenta have been analyzed with a parametrization corresponding to two coherent interfering exponentials. The data from almost all of these experiments can be adequately represented by this parametrization. In most of the experiments, the data are such that the fit does not uniquely determine all five parameters with reasonable errors. In fits to at least eight experiments, the parameters are well determined. Using these parameters as guides, attempts are made to reduce the total number of parameters and still fit all the data.

* COHERENT EXPONENTIALs IN p̈p ELASTIC SCATtERING H. B. Crawley, N. W. Dean, and W. J. Kernan

Phys. Rev. D 9: 3029 (1974)

Abstract--It is shown that three coherent exponentials can represent the entire center-of-mass angular distribution in pp elastic scattering for the most accurate available experiments. The parametrization is significantly better determined if the ratios of the slopes of the exponentials are constrained. The most effective constraints are those corresponding to a simple absorption picture in which the absorbing (Pomeron) amplitude is only half as steep in $\underline{t}$ as the unabsorbed amplitude.

*also listed under theory, page 5. 
MEASUREMENT OF THE $\pi^{-}$p ELASTIC SCATTERING CROSS SECTION NEAR $180^{\circ}$ BETWEEN 600 AÑD $1280 \mathrm{MeV} / \mathrm{c}$

T. J. Richards, D. G. Crabb, R. Keller, J. R. O'Fallon, R. J. Ott, J. Trischuk, J. Va'vra, and L. S. Schroeder

Phys. Rev. D 10: 45 (1974)

Abstract--Differential cross sections for $\pi^{-} \mathrm{p}$ elastic scattering over the angular range $155^{\circ}$ to $177^{\circ}$ in the center-of-mass system have been measured at 33 incident pion momenta in the range 600 to $1280 \mathrm{MeV} / \mathrm{c}$. The experiment, which was performed at the Bevatron at the Lawrence Berkeley Laboratory, employed a liquid hydrogen target, a double-arm spectrometer, and standard counter techniques to detect the elastic events. The data from this experiment are compared to all other published data in this momentum region. the over-all agreement is good. The data of this experiment are also compared with the results of the recent phase-shift analysis by Almehed and Lovelace. In the momentum region between 700 and $900 \mathrm{MeV} /$ c, the slope of the backward angular distribution goes rapidly through zero from negative to positive, and the magnitude of the differential cross section falls by more than a factor of 10. Momentum-dependent structure is seen in the extrapolated differential cross sections at $180^{\circ}$. Two prominent dips in the $180^{\circ}$ differential cross sections appear at 880 and $1150 \mathrm{MeV} /$ c. This structure is discussed in terms of a direct-channel resonance model that assumes only resonant partial waves are contributing to the cross sections for large scattering angles. 


\section{Theory}

ANAL YSIS OF p̄p ELASTIC SCATTERING USING TWO COHERENT EXPONENTIALS

H. B. Crawley, N. W. Dean, E. S. Hafen, W. J. Kernan, and F. Ogino Phys. Rev. B 9: 189 (1974)

See abstract under Experimental, page 3 .

COHERENT EXPONENTIALS IN p̄p ELASTIC SCATTERING

H. B. Crawley, N. W. Dean, and W. J. Kernan

Phys. Rev. D 9: 3029 (1974)

See abstract under Experimental, page 3 .

DOUBLE-CHARGE-EXCHANGE REACTIONS AND REGGE-REGGE CUTS IN A DUAL REGGE MODEL

D. W. Duke and N. W. Dean

Phys. Rev. D 10: 1481 (1974)

Abstract--A model which previously achieved a good quantitative description of 19 different $0^{-\frac{1}{2}}+0^{-\frac{1}{2}}$ reactions is extended to doublecharge-exchange reactions. The underlying mechanism is double Regge exchange, calculated in an SU(3)-symmetric dual absorptive model. The results depend on whether a nonet or an octet of mesons is assumed in the intermediate state; strong theoretical reasons for favoring a nonet are given. The amplitudes obtained in the previous model produce good quantitative agreement with recent data on $\pi^{-} \underline{\mathrm{p}} \rightarrow \underline{\mathrm{K}}^{+} \Sigma^{-}, \underline{\mathrm{K}}^{-} \mathrm{p} \rightarrow \pi^{+} \Sigma^{-}$, and $\underline{\mathrm{K}}{ }^{-} \mathrm{p} \rightarrow$ $\underline{\mathrm{K}}^{+} \mathrm{\Xi}$ - forward differential cross sections. 
MINIMAL REGGE MODEL FOR MESON-BARYON SCATTERING: DUALITY, SU(3), AND PHASE-MODIFIED ABSORPTIVE CUTS

S. E. Egli, D. W. Duke, and N. W. Dean

Phys. Rev. D 9: 1365 (1974)

Abstract--A model is presented which incorporates ecomonically all of the modifications to simple SU(3)-symmetric dual Regge-pole theory which are required by existing data on $0^{-\frac{1}{2}}+0^{-\frac{1}{2}}+$ processes. The basic assumptions are no-exotics duality, minimally broken SU(3) symmetry, and absorptive Regge cuts phase-modified by the Ringland prescription. We first describe qualitatively how these assumptions suffice for the description of all measured reactions, and then present the results of a detailed fit to 1987 data points for 18 different reactions.

POLARIZATION OF ELECTRONS IN SCREENED COULOMB SCATTERING F. L. Ridener, Jr., and R. H. Good, Jr.

J. Math. Phys. 15: 1071 (1974)

Abstract--In this paper the effects of screened-Coulomb scattering on electron polarization are calculated. The results apply to elastic electron scattering by light atoms at moderate energies. The calculation is carried out to second order in $\alpha \underline{Z}$; in this order the change in magnitude of the polarization first occurs. For arbitrary initial polarization, the final polarization vector is expressed explicitly as a function of initial polarization, momentum, and scattering angle. The effects of screening on polarization is discussed. In the low energy region, a few hundred eV, there is a significant effect on the output polarization of an input unpolarized beam. 
NEUTRON-PROTON FORM FACTORS. II C. L. Hammer, T. A. Weber, and V. S. Zidell Phys. Rev. D 9: 158 (1974)

Abstract--In a recent letter we suggested that the momentum dependence of the exact meson propagator may be responsible for the dipolelike behavior of the nucleon electromagnetic form factors over the limited range of data available. In this paper we extend the analysis to include more than one vector-meson propagator, and, by assuming a simplified form for the imaginary part of the level shift, we calculate the form factors explicitly. The nucleon electromagnetic form-factor data are fitted for momentum transfer to $2 \mathrm{GeV} / \underline{c}$ assuming just one isovector-vector meson and two isoscalar-vector mesons. The resulting fit is much better than that obtained using the dipole formula, and min $\chi^{2}$ occurs for values of the masses and widths of the vector mesons close to the experimental values of the $\rho$, $\omega$ and $\varphi$ resonances. The six independent meson-nucleon coupling constants are determined. Their values are consistent with the assumption that the nucleon charge and the magnetic moment distributions are extended, that is, that there are no hard-core contributions to the form factors. This assumption completely determines the isovector coupling constants and reduces the number of independent coupling constants to two. The pion and kaon charge form factors, as deduced from the nucleon charge form factors assuming universality, are compared with the available data. The pion form factors fit the data in both the spacelike and the timelike regions, including the resonarice shape for the $\rho$ contribution to the pion form factor. The kaon formfactor data disagree with the assumption of universality in both the spacelike and timelike regions. 
REMARKS ON THE KLAUDER PHENOMENON

B. DeFacio and C. L. Hammer

J. Math. Phys. 15: 1071 (1974)

Abstract--An elementary discussion is given of a phenomenon discovered by Klauder. In Klauder's phenomenon $\underline{\mathrm{H}}=\underline{\mathrm{H}}_{0}+\lambda \underline{\mathrm{V}}$ does not converge to $\underline{\mathrm{H}}_{0}$. as the positive real parameter $\lambda \rightarrow 0^{+}$. We discuss domain questions of the operators, and also operator forms and operator extensions. The implications of this penomenon for "gauge" theories" are given, and new examples, which include the massless limit for particles of arbitrary spin and an integral operator, are given.

UNST ABLE GOLDSTONE BOSONS AND THE ELIMINATION OF SCALAR PARTICLES FROM GAUGE THEORIES

C. L. Hammer and B. DeFacio

Phys. Rev. D 10: 1225 (1974)

A.bstract--One of the key ingredients in the gauge field theories which unify electromagnetism and weak interactions is spontanenus symmetry breaking. A source of instability is given for the Goldstone bosons and the details of the procedure for taking a quotient space and eliminating certain negative metric and/or unstable fields are given. It is then shown that a suitable symmetry breaking combined with unstable Goldstone bosons can lead to massive vector bosons without any superfluous massless scalar bosons. The gauge transformation properties of the "in" fields are also discussed.

PATH INDEPENDENCE AND CHARGE QUANTIZATION

D. K. Ross

J. Phys. A: Math., Nucl. Gen. 7: 705 (1974)

Abstract--It is shown that is quantum electrodynamics is assumed to be manifestly gauge independent and path independent, then electric charge must'be quantized. 


\section{NT-02 \\ NUCLEAR SCIENCES}

DECAYS OF MASS-SEPARATED ${ }^{138} \mathrm{Xe}$ and ${ }^{138} \mathrm{Cs}$ G. H. Carlson, W. L. Talbert, Jr., and J. R. McConnell Phys. Rev. C 9: 283 (1974)

$$
\text { Abstract--The } \beta \text { and subsequent } \gamma \text { decays of }{ }^{138} \mathrm{Xe} \text { and }{ }^{138} \mathrm{Cs} \text { were }
$$
investigated using the on-line isotope separator system TRISTAN at the Ames Laboratory research reactor. $\mathrm{Ge}(\mathrm{Li}) \gamma$-ray singles and $\mathrm{Ge}(\mathrm{Li})$ $\mathrm{Ge}(\mathrm{Li}) \gamma-\gamma$ coincidence measurements were used to construct level schemes for ${ }^{138} \mathrm{Cs}$ and ${ }^{138} \mathrm{Ba}$. For the decay of ${ }^{138} \mathrm{Xe}, 94$ of 99 observed $\gamma-\mathrm{ray}$ transitions have been placed in a level scheme for ${ }^{138} \mathrm{Cs}$ with 27 excited states. For the decay of ${ }^{138} \mathrm{Cs}, 82$ of 86 observed $\gamma$ rays are placed in a level scheme for ${ }^{138}$ Ba with 35 excited states. Ge(Li)-plastic coincidence measurements gave $\underline{Q}$ values of $2.83 \pm 0.08 \mathrm{MeV}$ and $5.29 \pm 0.07$ $\mathrm{MeV}$ for ${ }^{138} \mathrm{Xe}$ and ${ }^{138} \mathrm{Cs}$, respectively. Spin and parity assignments have been deduced using $\gamma$-ray transition rates, $\beta$-decay logft values, and other information existing in the literature. Interpretation of some of the energy levels is made from a shell-model viewpoint.

INTERNAL CONVERSION COEFFICIENT MEASUREMENTS FOR TRANSITIONS IN ${ }^{140}$ CS FROM THE DECAY OF ${ }^{140} \mathrm{Xe}$ J. P. Adams, F. K. Wohn, W. L. Talbert, Jr., W. C. Schick, Jr., and J. R. McConnell

Phys. Rev. C 10: 1467 (1974)

Abstract--The internal conversion coefficients (ICC) of 18 transitions in the decay of ${ }^{140} \mathrm{Xe}$ have been measured by the normalized electronto- $\gamma$-ray ratio method using $\mathrm{Si}(\mathrm{Li})$ and $\mathrm{Ge}(\mathrm{Li})$ detectors. Mass-separated sources of ${ }^{140} \mathrm{Xe}$ were obtained from the TRISTAN on-line isotope separator facility. The ICC were used to deduce the multipolarities of the transitions. 
Tentative spin-parity assignments have been made for 14 levels in ${ }^{140} \mathrm{Cs}$ from consideration of the transition multipolarities and logft values deduced from the results of a previous $\gamma$-ray decay study.

LEVELS IN ${ }^{140}$ Ba POPULATED IN THE DECAY OF $64-\mathrm{sec}^{140} \mathrm{Cs}$ W. C. Schick, Jr., and W. L. Talbert, Jr.

Phys. Rev. C 9: 2328 (1974)

$$
\text { Abstract--The } y \text {-ray decay of } 64-\mathrm{sec} \text { fission-product }{ }^{140} \mathrm{Cs} \text { has }
$$

been studicd using the TRISTAN on-line isotope-separator system. Ge(Li) detector singles and $\mathrm{Ge}(\mathrm{Li})-\mathrm{Ge}(\mathrm{Li})$ coincidences were performed. $154 \mathrm{Y}$ ray transitions were assigned to a level scheme for ${ }^{140} \mathrm{Ba}$ with 30 definite and 13 tcntative excited levels. Tentative spin and parity assignmonts were made for some of these levels. The relationship between ${ }^{140} \mathrm{Ba}$ and the other even $\mathrm{Ba}$ isotopes is discussed, and an interesting similarity with ${ }^{134} \mathrm{Ba}$ is noted.

A MAGNETIC SPECTROMETER SYSTEM FOR ON-LINE STUDIES OF $\beta$ RAYS AND INTERNA.L CONVERSION ELECTRONS OF SHORT - LIVED MASS-SEPARATED ACTIVITIES

J. K. Halbig, F. K. Wohn, and W. L. Talbert Jr. Rev. Sci. Instrum. 45: 789 (1974)

Abstract--A. $\pi \sqrt{ } 2$ high-resolution magnetic spectrometer has recently become operational at the TRISTAN on-line isotope separator facility. The design and operational modes of the spectrometer have been developed especially for on-line studies of short-lived mass-separated fission product activities. The spectrometer configuration is described, with particular emphasis on the magnetic field control and stabilization, the data collection modes and techniques developed to study nonequilibrium source activities, and the stabilization of the ion-beam deposit position by use of a split-tape ion-beam collector. 
MANY - PARTICLE STATES OF THE ANISOTROPIC OSCILLATOR J. P. Draayer and S. A. Williams

Phys. Rev. C 10: 901 (1974)

Abstract--The invariance under canonical transformations of the fundamental Cartesian coordinates and conjugate momenta commutators is used to show that the state labeling schemes of Elliott and Moshinsky are applicable to the case of many particles in an anisotropic harmonic oscillator potential. The relationship of the states obtained to the group theoretically equivalent isotropic harmonic oscillator states is investigated. The results reveal explicitly the collective nature of the particle-hole. structure induced by the deformation. 


\section{THIS PAGE \\ WAS INTENTIONALLY \\ LEFT BLANK}


$\mathrm{NT}-03$

\title{
NT-03
}

\section{MATERIALS SCIENCE \\ NT-03-01}

\section{Metallurgy and Ceramics}

\author{
NT-03-01-01
}

\section{Structure of Materials}

DIFFUSION OF METALLIC SOLUTES IN VANADIUM USING SPARK SOURCE MASS SPECTROMETRY A.S THE METHOD OF ANALYSIS

F. A. Schmidt, R. J. Conzemius, O. N. Carlson and H. J. Svec Anal. Chem. 46 : 810 (1974)

Abstract--The diffusion coefficients of iron, niobium, nickel, silicon, and titanium in vanadium metal were determined at 1600,1700 , and $1800^{\circ} \mathrm{C}$ using a spark source mass spectrometric technique to trace the concentration profiles. Samples containing both a single solute and several solutes were studied and the results compared. The diffusion coefficients obtained for an element when it was the single additive were about the same as when it was present as one of several solutes. In all samples, nickel diffused al the fastest rate, followed by iron, 'l'he diffusion rates of niobium, silicon, and titanium were slower at each temperature but not in any particular order. Because of the high sensitivity of the mass spectrometric method of analysis, the diffusing solute could be present in low concentrations of the couple. This represents a distinct advantage of the present method because the activity of the additive in dilute solution is decreased and any solute-solute interactions are minimized. 
SOLID SOLUBILITIES OF OXYGEN, CARBON AND NITROGEN IN YTTRIUM O. N. Carlson, R. R. Lichtenberg and J. C. Warner

J. Less-Common Metals 35: 275 (1974)

Abstract--The solid solubilities of oxygen, carbon and nitrogen in yttrium metal have been investigated and a partial diagram is proposed for the Y-YN system. The temperature dependence of the solubility of each solute in $\alpha$ yttrium was fitted empirically to Arrhenius-type equations, and the heats of solution for the co-existing oxide, carbide or nitride phase were found to be $6.8 \pm 0.4,8.0 \pm 1.0$ and $11.6 \pm 1.3 \mathrm{kcal} / \mathrm{mole}$, respectively.

STUDIES ON UPGRADING OF AUTOMOTIVE SCRAP BY VACUUM MELTING AND ELECTROSLA.G REMELTING

O. N. Carlson, F. A. Schmidt, J. K. McClusky, C. V. Owen, R. R. I,ichtenberg, and R. E. Shaw

Proc. Fourth Mineral Waste Utilization Symposium, sponsored by the U. S. Bureau of Mines and IIT Research Institute, Chicago, Illinois May $7-8,1974$, pp. $397-408$

Abstract--The technical feasibility of removing deleterious impurities, principally copper, tin, and chromium, from automotive scrap steel by various vacuum melting procedures and also by electroslag remelting was evaluated. Reduced-pressure melting studies included the use of nonconsumable electrode arc melting, vacuum induction, vacuum arc, and electron beam melting. The effects of such variables as temperature, time, pressure, and carbon content on the rates of evaporation of these impurities from molten iron are described. The copper and tin contents are readily decreased to acceptable levels by either electron beam or induction melting. Chromium can also be vaporized out of steel but it is first necessary to reduce the carbon concentration to rather low levels. Attempts tu upgrade scrap steel by vacuum arc or nonconsumable electrode reduced pressure melting were unsuccessful. 
Slags of different composition were evaluated as extractants of impurity elements from steel by electroslag melting. Chromium, tin, and aluminum were successfully removed from scrap steel by electroslag melting but efforts to develop a suitable extractant for copper were unsuccessful.

A procedure was developed whereby a high grade stainless steel can be prepared from auto scrap by a single induction melting step.

\section{CAPILLARITY EFFECT AT AN $\alpha / \beta$ BRA.SS INTERFACE}

E. P. Simonen and R. Trivedi

Metal Science 8: 274 (1974)

Abstract--The nonideality parameter changes by a factor of three when $\beta$-brass undergoes order-disorder transformation. This change in nonideal parameter affects appreciably the curvature-dependent equilibrium concentrations at an $\alpha: \beta$ interface. Detailed numerical calculations on the capillarity effects are carried out and it is shown that the equilibrium concentration can be linearly related to the interface curvature at any given temperature. The variation is found to be much larger for a dis ordered $\beta$-phase compared to that for an ordered $\beta$-phase.

IMPORTANCE OF DENDRITIC GROWTH DURING SOLIDIFICATION OR CASTINGS

R. Trivedi

J. Sci. \& Ind. Res. 32: 696 (1973)

Abstract--Recent developments in solidification studies are applied to characterize the structure and segregation patterns of cast metals. It. is shown that the equiaxed zone, inverse segregation and microsegregation are a direct consequence of the fact that the solid-liquid interface is 
dendritic in nature. The reasons for the existence of dendritic interface are given and a discussion is presented on the application of the basic solidification theories to the freezing of a liquid so as to gain an appreciation for various physical parameters which are important in casting.

ON THE KINETIC EXPRESSION FOR THE GROWTH OF PRECIPITATE PLATES

W. P: Bosze and R. Trivedi

Met. Trans. 5: 511 (1974)

Abstract-- The Widmanstätten or platelike morphology is observed in a great number of. alloy systems of importance in metallurgy, and the influence of this morphology on the mechanical properties of alloys is quite significant. Thus, many kinetic studies have been made to understand the physical phenomena controlling the growth of such a precipitate morphology. Of the various kinetic models available so far, the model proposed by Trivedi is the most rigorous one which assesses the relative contributions of diffusion, surface energy and interface kinetic processes during the growth of a platelike morphology. The main purpose of this communication is to show that under most experimental conditions the Trivedi expression can be greatly simplified to give a clear insight into the interdependence of the growth rate, radius of curvature and supersaturation.

LEED STUDY OF SOLID SURFACES: ADSORPTION OF OXYGEN ON V(100) SUREACH:

S. R. Srinivasan, S. K. Sreeharsha, and R. Trivedi Indian J. Tech. 11: 530 (1973)

Abstract--The adsorption characteristics of oxygen on a vanadium (100) surface have been investigated using the low energy electron diffraction technique. The presence of ordered atomic arrangement corresponding 
to $(1 \times 1)$ and $(2 \times 2)$ patterns on the surface has already been reported in literature. The present study shows the existence of another ordered structure, which is between these two structures. The analysis and indexing of the diffraction pattern which corresponds to this intermediate structure have been carried out to determine the relative position of the oxygen and vanadium atoms on the surface, and this ordered arrangement of atoms on the surface has been confirmed by laser simulation of the observed diffraction pattern.

TEMPERATURE DISTRIBUTION AROUND A MOVING CYLINDRICAL SOURCE

R. Trivedi and S. R. Srinivasan

J. Heat Transfer Trans. ASME 96 Series C: 427 (1974)

Abstract--Temperature distributions around moving point and line sources have been obtained by Rosenthal and the importance of such an analysis in understanding many practical problems in welding and solidification is well established in literature. Many important problems, however, involve moving sources or sinks which are finite in size. In this communication, therefore, the Rosenthal treatment is extended to obtain temperature distribution around a moving source whose shape corresponds to a circular cylinder of infinite height and radius $\underline{R}$.

\section{NT-03-01-02}

\section{Mechanical Properties}

ELASTIC PROPERTIES OF POLYCRYST ALLINE MONOCLINIC $\mathrm{Sm}_{2} \mathrm{O}_{3}$ O. Hunter, Jr., H. J. Korklan, and R. R. Suchomel

J. Am. Ceram. Soc. 57: 267 (1974)

Abstract--The elastic properties of polycrystalline monoclinic

$\mathrm{Sm}_{2} \mathrm{O}_{3}$ were measured in the range from room temperature to $1400{ }^{\circ} \mathrm{C}$ 
and over the porosity range from $1.9 \%$ to $38 \%$ by the sonic resonance method.

Young's modulus, E, and shear modulus, G, are given as a function of temperature, $\mathrm{T}^{\circ} \mathrm{C}$, by

$$
\begin{aligned}
& E=1097.0-0.1051 \mathrm{~T} \\
& G=421.1-0.0759 \mathrm{~T}
\end{aligned}
$$

for a specimen with $10.8 \%$ porosity. A specimen with $1.9 \%$ porosity showed a hysteresis in its temperature-moduli curves. As a function of porosity the moduli are given by

$$
\begin{aligned}
& E=1450.4(1-2.028 P) \\
& G=547.5(1-1.978 P)
\end{aligned}
$$

The Debye temperature was found to be $360 \mathrm{~K}$.

RESIDUAL RESISTIVITY AND A.GING-CLUSTERING EFFECTS OF CuRICH C.,1 =Ni AT,T, OYS

S. Legvold, D. T. Peterson, P. Burgardt, R. J. Hofer, B. Lundell,

T. A. Vyrostek and H. Gärtner

Phys. Rev. B 9: 2386 (1974)

For abstract, see NT-03-02-02, Experimental Physics, page 32.

SUPER CONDUCTING CRITICAL FIELD CURVES FOR Th-U

H. L. Watson, D. T. Peterson, and D. K. Finnemore

K. D. Timmerhaus, W. J. O'Sullivan, E. F. Hammel, eds. Low

Temperature Physics LT 13, Vol. 2 (New York, Plenum Publishing Corp., 1974) pp. 590-592.

For abstract, see NT-03-02-02, Experimental Physics, page 36.

THE EFFECT OF ZIR CONIUM ON THE STRENGTH OF THORIUM D. T. Peterson and D. C. Zabel

Met. Trans. 5: 1173 (1974)

Abstract--The flow stress of thorium-zirconium alloys containing up to 12 at. pet zirconium was studied over a range of temperatures and 
strain rates. It was found that the flow stress could be analyzed as the sum of a thermally activated and an athermal component. The thermally activated component was nearly the same in the base metal and the zirconium alloys. The major effect of zirconium was a considerable increase in the athermal component. The magnitude of this increase was directly proportional to the zirconium content. Zirconium also retarded the recovery and recrystallization processes.

MECHANICAL PROPERTIES OF POLYCRYSTALLINE DYSPROSIUM FROM $78 \mathrm{TO} 750 \mathrm{~K}$

C. V. Owen and T. E. Scott

J. Less-Common Metals 37: $353^{\circ}$ (1974)

Abstract--The flow-stress temperature dependence, strain-rate sensitivity, strain-hardening exponent and ductility of dysprosium were determined from 78 to $750 \mathrm{~K}$ at strain rates of $0.005,0.01,0.10$ and 1.0 $\min ^{-1}$. The results are presented and similarities of some of the results to those obtained for other rare-earth metals are discussed.

\section{NT-03-01-03}

\section{Physical Properties}

MEASUREMENT OF OXYGEN DIFFUSION IN $\mathrm{Dy}_{2} \mathrm{O}_{3} \mathrm{AND} \mathrm{Gd}_{2} \mathrm{O}_{3} \mathrm{BY}$ STUDYING IIIGI -TEMPIRATURE OXIDATION OF THE METALS D. B. Basler and M. F. Berard

J. Am. Ceram. Soc. 57: 447 (1974)

A.bstract--Studies of the oxidation of Gd and Dy at $\underline{P}_{02}$ 's from $10^{-0.3}$ to $10^{-14.5}$ atm and temperatures from $727^{\circ}$ to $1327^{\circ} \mathrm{C}$ indicate both semiconducting and ionic-conducting domains in the sesquioxides formed. At higher temperatures, where dense coarse-grained oxide layers developed, the rate of oxidation in the high- $\underline{\mathrm{P}}_{02}$ semiconducting domain yielded oxygen diffusion coefficients by $\mathrm{Dy}_{2} \mathrm{O}_{3}$ in excellent agreement with literature values derived from oxidation of partially reduced 
oxide single crystals. Under the same conditions, the oxidation of Gd yielded oxygen diffusion coefficients in cubic $\mathrm{Gd}_{2} \mathrm{O}_{3}$. At lower temperatures, porous scales were formed, and apparent diffusion coefficients derived from oxidation rates show a smaller temperature dependence than the high temperature data. At low $\underline{\mathrm{P}}_{02}$, the oxides behave as ionic conductors, and metal oxidation rates result in estimates of the electronic contribution to the electrical conductivity of the order of $10^{-6}$ to $10^{-7} \Omega^{-1} \mathrm{~cm}^{-1}$. VARIATION WITH CHEMICAL ORDER OF SPIN COUPLING IN NiPt C. W. Chen, J. D. Greiner, and R. W. Buttry Magnetism and Magnetic Materials - 1973, held in Boston, Mass. (New York, American Institute of Physics, 1974) p. 432.

Abstract--The effect of chemical order on the coupling mode of spins in NiPt was studied by measurements of magnetic susceptibility, magnetization, and electrical resistance. Ferromagnetic and antiferromagnetic couplings were detected in the disordered and ordered states, respectively. These results confirm a previous report by Watanabe and Miyahara. The present study, however, obtained a lower $(98$ versus $136 \mathrm{~K}$ ) Curie temperature and a different mean atomic moment in the ferromagnetic structure. Irradiation of the ordered alloy by fast neutrons tends to destroy the antiferromagnetism, which eventually disappears when the irradiation fluence reaches $4 \times 10^{18}$ neutrons $(E \geq 1 \mathrm{MeV})$ per $\mathrm{cm}^{2}$. Irradiation of the disordered alloy, on the other hand, causes peculiarities in the temperature dependence of susceptibility. Evidence for the existence of superparamagnetism in the irradiated samples is described. The complex magnetic behavior of INiFt resembles that of FePt 3 strikingly. 
COMMENTS ON "LATTICE PARAMETERS OF COMPOUNDS OF THE TYPE R. E. $(\mathrm{Zn}){ }_{5}$ HAVING THE CaCu $\left.{ }_{5} \underline{(D}_{2} \underline{d}\right)$ ST RUCTURE"

J. Mason

J. Less-Common Metals 37: 387 (1974)

Abstract--A critical examination of some recent experimental evidence for the existence of a series of R.E. $Z_{n_{5}}$ compounds (R.E. = Ce, $\mathrm{Pr}, \mathrm{Nd}, \mathrm{Sm}, \mathrm{Gd}, \mathrm{Dy}$ and $\mathrm{Er})$ of the $\mathrm{CaCu}_{5}\left(\underline{D}^{2} \underline{\mathrm{d}}^{2}\right)$ type structure has been made. This examination includes a review of the pertinent literature, a detailed comparison of the observed and calculated $x$-ray powder diffraction data and an examination of the lattice dimensions as a function of ionic radius of the rare earth element. It is concluded that $\mathrm{Pr}, \mathrm{Nd}, \mathrm{Sm}$, $G d, D y$ and $E r$ do not form compounds of the $\mathrm{CaCu}{ }_{5}$ type structure with zinc.

CRYSTAL STRUCTURES OF $\mathrm{ThBr}_{4}$ POLYMORPHS J. T. Mason, M. C. Jha, D. M. Bailey, and P. Chiotti J. Iress-Common Metals 35: 331 (1974)

Abstract--Thorium tetrabromide has two polymorphic forms with a transformation temperature of $426 \pm 5^{\circ} \mathrm{C}$ and a melting temperature of $678 \pm 5^{\circ} \mathrm{C}$. The space group symmetry of the high-temperature form, $B-\mathrm{ThBr}_{4}$, has been confirmed as $I_{1} /$ amd by single-crystal X-ray diffraction techniques. The lattice parameters were measured as $\underline{a}=8.934 \pm$ 0.003 and $\underline{c}=7.964 \pm 0.001 \AA$. The calculated $X$-ray density is $5.76 \mathrm{~g} / \mathrm{cm}^{3}$ and the measured density is $5.70 \mathrm{~g} / \mathrm{cm}^{3}$. The structure of the low-temperature form, $\alpha-\operatorname{ThBr}_{4}$, has space group symmetry $\underline{I}_{1} / \underline{\text { a. A }}$ A complete structure determination was made from single-crystal $\mathrm{X}$-ray diffraction intensities. There are four molecules of. $\mathrm{ThBr}_{4}$ per unit cell. With the origin at $\vec{l}$ the thorium atoms are in set (4a) with positions $0, \frac{1}{4}, \frac{1}{8}$ and the biumine atoms are in set (16́f) with positions $0.3378,0.412 \%, 0.1998$. 
The lattice parameters are $\underline{a}=6.737 \pm 0.001$ and $\underline{c}=13.601 \pm 0.003 \AA$. The calculated $\mathrm{X}$-ray density is $5.94 \mathrm{~g} / \mathrm{cm}^{3}$ and the measured density is $5.84 \mathrm{~g} / \mathrm{cm}^{3}$.

CRYSTAL STRUCTURES OF ThCl 4 POLYMORPHS J. T. Mason, M. C. Jha, and P. Chiotti

J. Less-Common Metals 34: 143 (1974)

Abstract--Thorium tetrachloride has been shown to possess two polymorphic forms. The crystal structure of the $B$ form, stable above $405^{\circ} \mathrm{C}$ has been well established by Mooney and by Mucker et al. to be tetragonal with space symmetry $\underline{I}_{1}{ }_{1} /$ amd and lattice parameters $\underline{a}=8.486$ and $\underline{c}=7.465 \AA$. The low-temperature $\alpha$ form has becn shown to be tetragonal with space symmetry $\underline{I}^{4} 1$ / $\underline{a}$ with $\underline{a}=6.408 \pm 0.001$ and $\underline{c}=12.924 \pm$ $0.003 \AA$. If the thorium atoms are located at the four-fold set $(4 a)$ with positions $0, \frac{1}{4}, \frac{1}{8}$, the chlorine atoms reside in the general 16 -fold set with $\underline{x}=0.353, \underline{y}=0.483$ and $\underline{z}=0.202$. These parameters are an average of the parameters determined from single-crystal data, diffractometer powder data and Debye-Scherrer powder data. The calculated density is $4.68 \mathrm{~g} / \mathrm{cm}^{3}$ which compares favorably with the measured value of $4.64 \mathrm{~g} / \mathrm{cm}^{3}$. Both the $\alpha$ and $B$ forms contain four $\mathrm{ThCl}_{4}$ units per unit cell. In both structures the thorium atoms a re surrounded by a coordination polyhedron of eight chlorine atoms.

NEW INTEGRATION OF THE GIBBS-DUHEM EQUATION AND APPLICATION OF PHASE RELATIONS AND THERMODYNAMICS TO FUEL REPRO CESSING

P. Th intt.i

J. Nucl. Mater. 51: 178 (1974)

Abstract--The application of phase relations and the rmodynamic properties to the design of fused salt and liquid metal processes for the separation of fission product elements from nuclear fuel materials is 
described. Processes can be designed to extract minor components from a fuel material without drastically altering its character or state of aggregation. It is possible to effectively transport solutes from one liquid metal or alloy to a second liquid metal or alloy by bringing the two in contact with an appropriate fused salt. Alternatively it is possible to transport solutes between two liquid salt phases by bringing them in mutual contact with an appropriate alloy. A process for extracting uranium from a thoriaurania solid solution powder by reactions in a fused salt medium is described. The value of the activity coefficient of any particular solute at infinite dilution is an important parameter in determining the ultimate degree of separation to be expected in a given process. Interpolation functions for evaluating the properties of dilute solutions are examined and a new integration of the Gibbs-Duhem equation for binary alloys is developed. The method described lends considerable versatility to the types of curves or functions which can be integrated to yield data for a second component in a binary solution.

CERIUM

K. A. Gschneidner, Jr.

ח. M. Considine, ed., Chemical and Process Technology Encyclopedia (New York, McGraw-Hill, 1974) pp. 248-50

Abstract--The chemical, metallurgical and physical properties of cerium are reviewed, with special emphasis being placed on the unusual electronic behavior of elemental cerium. Ore sources, chemical processing and the uses of cerium and its compounds are also discussed. 
CONCERNING 'ANOTHER INDICATED PHASE TRANSFORMATION IN YTTERBIUM'

B. J. Beaudry and K. A. Gschneidner, Jr.

Solid State Comm. 15: 791 (1974)

Abstract--Experimental data are presented which show the 'new phase transformation in ytterbium' reported by Hurd and Alderson is probably due to hydrogen contamination in their 'high purity' ytterbium.

THE HEAT CAPACITY OF B-CERIUM BETWEEN 1. 5 AND $23 \mathrm{~K}$

D. C. Koskimaki and K. A. Gschneidner, Jr.

Phys. Rev. B 10: 2055 (1974)

Abstract--The lieal capacity of single-phase $B$-cerium has becn determined between 1.5 and $23 \mathrm{~K}$ with special emphasis on the shape of the antiferromagnetic ordering peak. It is concluded that separate ordering occurs at 12.45 and $13.7 \mathrm{~K}$ for the two types of site symmetry. The lower-temperature peak is thought to be associated with ordering of the cubic sites and the upper peak with the ordering of the hexagonal sites. An analysis of the various contributions to the heat capacity is made. The magnetic heat capacity between 1.5 and $2.3 \mathrm{~K}$ exhibits an expunential behavior, yielding an energy gap of $2.92 \mathrm{~K}$, and between 3.5 and $6.5 \mathrm{~K}$ it exhibits a $\mathrm{T}^{3}$ behavior.

HIGH - TEMPERATURE ENTHALPIES AND STANDARD GIBBS FREE ENERGIES OF FORMA.TION OF THE EUROPIUM CHAL COGENIDES: EuO, EuS, EuSe, AND EuTe O. D. McMasters, K. A. Gschneidner, Jr., E. Kaldis and G. Sampietro J. Chem. Thermodynamics 6: 845 (1974)

Abstract--The enthalpies of EuO, EuS, EuSe, and EuTe were measured from 300 to $1725 \mathrm{~K}$ by using a copper-block drop calorimeter. High temperature values of $\underline{C}_{\mathrm{p}}^{\circ}(\underline{T}), \underline{S}^{\circ}(\underline{T})$, and $-\left\{\underline{G}^{\circ}(\underline{T})-\underline{H}^{\circ}(298.15 \mathrm{~K})\right\} / \underline{T}$, were calculated from the enthalpies together with the published low-temperature heat capacity for EuO and EuS and estimated entropies at $298.15 \mathrm{~K}$ 
for EuSe and EuTe. The enthalpies of formation of EuO, EuS, and EuSe, at $298.15 \mathrm{~K}$, were reevaluated and the standard Gibbs free energies of formation of all four compounds were calculated as a function of temperature.

THE LANTHANUM-INDIUM SYSTEM

O. D. McMasters and K. A. Gschneidner, Jr. J. Less-Common Metals 38: 137 (1974)

A.bstract--Differential thermal, X-ray diffraction and metallographic methods have been used to establish the lanthanum-indium phase diagram. Eutectic reactions occur at $742^{\circ} \mathrm{C}$ and 13.5 at. $\%$ In, at $1086^{\circ} \mathrm{C}$ and 54.0 at. $\% \mathrm{In}$, at $1120^{\circ} \mathrm{C}$ and 71.2 at. $\% \mathrm{In}$, and at $155^{\circ} \mathrm{C}$ and greater than 99.5 at. $\%$ In. A eutectoid reaction at $702^{\circ} \mathrm{C}$ and 8.1 at. $\%$ In develops as a result of indium additions for the $861^{\circ} \mathrm{C} \gamma-\beta$ transformation of lanthanum. The intermetallic compounds, $\mathrm{La}_{3} \mathrm{In}, \mathrm{La} \mathrm{I}_{2} \mathrm{In}$, and $\mathrm{LaIn}_{2}$, decompose peritectically at 816,955 , and $1153^{\circ} \mathrm{C}$, respectively. LaIn, $\mathrm{La}_{3} \mathrm{In}_{5}$, and $\operatorname{LaIn}_{3}$ melt congruently at 1125,1185 and $1140^{\circ} \mathrm{C}$, respectively. Another compound is believed to exist in the temperature range $905-1073^{\circ} \mathrm{C}$ between 50 and 60 at. $\%$ In. Crystallographic data are given for most of these compounds. The maximum solid solubility of In in B-La is 3.5 at. $\%$ In and that in $\gamma-\mathrm{La}$ is 10.2 at. $\%$ In.

Thermodynamic analyses of the La-rich and of the La-In system were made, and activities, activity coefficients and partial molal free energies were derived for liquid lanthanum and $\gamma-L a$. These data verify the close similarity of the La-In and Pr-Tl systems for the liquid $\approx \gamma-L a$ (or B-Pr) transformation. But they also show that there is a significant difference for the $\gamma-\mathrm{La}$ (or $\beta-\mathrm{Pr}) \rightleftarrows \beta-\mathrm{La}$ (or $\alpha-\mathrm{Pr}$ ) transformation which is not evident from a visual examination of the two diagrams. The existence of $\mathrm{LaIn}_{2}$ with the $\mathrm{CeCu}_{2}$-type structure is discussed in view of the present understanding of the nocurrence of this structure type. 
PREPARATION OF SINGLE PHASE $B$ AND $\alpha$ CERIUM SAMPLES FOR LOW TEMPERATURE MEASUREMENTS

D. C. Koskimaki, K. A. Gschneidner, Jr. and N. T. Panousis

J. Crystal Growth 22: 225 (1974)

Abstract--A method for preparing close to $100 \% \beta$ cerium is reported. The method involves repeated steps of thermal cycling cerium samples between room temperature and liquid helium temperature followed by annealing for long periods at $75^{\circ} \mathrm{C}$. The preparation of single phase $\alpha$ cerium by using a pressure-cooling-depressurizing cycle is described.

TRANSITION INTO A MAGNETIC STATE WITHOUT MAGNETIC SCAT TERING IN A RARE EARTH SYSTEM: CeA.l 3

A. S. Edelstein, C. J. Tranchita, O. D. McMasters and K. A. Gschneidner, Jr.

Solid State Comm. 15: 81 (1974)

Abstract--Susceptibility measurements on $\mathrm{CeAl}_{3}$ down to $0.5 \mathrm{~K}$ show both the absence of magnetic urdering dind a celuced effective monent such as found in dilute Kondo alloys. The resistance decreases a factor of 30 below the maximum at $\underline{T}=37 \mathrm{~K}$ and the magneto resistance which is negative above $0.5 \mathrm{~K}$ apparently becomes positive for $\underline{T}<0.5 \mathrm{~K}$.

\section{YTTF.R RIIUM}

K. A. Gschneidner, Jr.

D. M. Considine, ed., Encyclopedia on Chemical and Process Technology (New York, McGraw-Hill, 1974) pp. 1173-5

Abstract--The chemical, metallurgical and physical properties of ytterbium are reviewed. Ore sources, chemical processing and the uses of ytterbium and its compounds are also described. 
ELASTIC CONSTANTS OF SOME MAl $_{2}$ SINGLE CRYSTALS R. J. Schiltz Jr. and J. F. Smith

J. Appl. Phys. 45: 4681 (1974)

Abstract--Elastic constants of single crystals of the cubic Laves phases $\mathrm{CaAl}_{2}, \mathrm{YAl}_{2}, \mathrm{LaAl}_{2}$, and $\mathrm{GdAl}_{2}$ have been measured over the temperature range $4.2-300 \mathrm{~K}$. The ferromagnetic transition in $\mathrm{GdAl}_{2}$. near $170 \mathrm{~K}$ is evident by changes in slope in plots of the three independently measured elastic constants of $\mathrm{GdAl}_{2}$ as functions of temperature. Debye temperatures at $0 \mathrm{~K}$ were evaluated as $474 \mathrm{~K}$ for $\mathrm{CaAl}_{2}, 484 \mathrm{~K}$ for $\mathrm{YAl}_{2}, 374 \mathrm{~K}$ for $\mathrm{LaAl}_{2}, 399 \mathrm{~K}$ for magnetically disordered $\mathrm{GdAl}_{2}$ and 406 $\mathrm{K}$ for magnetically ordered $\mathrm{GdAl}_{2}$. It was inferred from the data that the valence electron distributions in nonsuperconducting $\mathrm{YAl}_{2}$ and $\mathrm{GdAl}_{2}$ are much alike, but the valence electron distribution in superconducting $\mathrm{LaAl}_{2}$ is significantly different. Thus the results support a theoretical calculation indicating an admixture of $4 \mathrm{f}$ character into the valence bands of LaAl $_{2}$

A TECHNIQUE FOR VERIFYING THE ALIGNMENT OF LARGE SINGLE CRYSTALS J. D. Greiner and D: M. Bailey

Rev. Sci. Instrum. 45: 1032 (1974)

Abstract--A procedure is presented for verifying the alignment of a crystal surface with respect to the $x$-ray beam in the back-reflection Laue technique. The procedure involves the use of a $\mathrm{NaCl}$ reference crystal attached to the surface of interest. Application to the determinatiun of the orientation of a skew surface is discussed.

THERMODYNAMIC PROPERTIES OF BINARY THORIUM SYSTEMS

J. F. Smith

J. Nucl. Mater. 51: 136 (1974)

Abstract--The available thermodynamic data for binary metallic systems of thorium have been critically reviewed. Data for the Th-O and 
Th-F systems have been included rather arbitrarily because of the importance of such data in deriving thermodynamic functions from equilibrium studies. Data for 53 intermediate phases in 19 binary systems are included. Within a given system, bits of information were evaluated with consistency as the paramount criterion and with reliability of experimental technique as the secondary guideline.

ROTATION BETWEEN MICROGRAPHS FROM THE SCANNING ELECTRON MICROSCOPE AND ELECTRON CHANNELLING PATTERNS

C. G. van Essen and J. D. Verhoeven

J. Phys. E: Sci. Instr. p. 768 (1974)

A.bstract--When a large single crystal is examined in the scanning electron microscope, micrograph and electron channelling pattern (ECP) may be obtained simultaneously. When obtaining the selected area ECP of a small crystal, a separate micrograph must be taken. Relating the ECP to the micrograph in either case, the crystallographic direction of the centre of the micrograph is correctly indicated by the pole direction of the centre of the ECP. But the directions of planes with normals orthogonal to the optic axis may not be correctly indicated, errors of up to $30^{\circ}$ having been measured. The error may occur in any scanning electron microscopy with a double-deflection scan system, whether above or below the final lens, and is due to a relative rotation of the planes of the upper and lower scan deflections. The error can be eliminated by using a single scan deflection, as in the deflection-focusing method of obtaining selected-area ECPs. 
$\mathrm{NT}-03$

\section{NT-03-01-04}

\section{Radiation Effects}

STRAIN AGING IN IRRADIATED VANADIUM CONTAINING OXYGEN

M. S. Wechsler and R. Bajaj

Scripta Met. 8: 885 (1974)

Abstract--Polycrystalline vanadium tensile samples were ir radiated in the Ames Laboratory Research Reactor to a fluence of $1.2 \times 10^{19}$ neutrons/ $\mathrm{cm}^{2}(\mathrm{E}>1 \mathrm{Mev})$ at $105^{\circ} \mathrm{C}$. The samples contained three levels of oxygen: 60,200 , and $640 \mathrm{wt}$. ppm. Unirradiated and irradiated samples were subjected to a series of load-unload-age-reload tests at room temperature and a strain rate of $1.7 \times 10^{-4} \mathrm{sec}^{-1}$. The aging treatments were performed is othermally at $175^{\circ} \mathrm{C}$, at which temperature strain aging due to oxygen in vanadium is known to occur. The results of the strain aging tests indicate that longer aging times are necessary to produce strain aging in the irradiated samples than in the unirradiated ones. This is interpreted to suggest that oxygen impurity atoms migrate at first to radiation-produced defect clusters in the irradiated material. The oxygen atoms migrate to dislocations only after the defect clusters become saturated with oxygen and therefore the oxygen atoms participate in strain aging later than is the case for the unirradiated material. This mechanism for the retardation of strain aging due to oxygen in vanadium is consistent with earlier observations of State III annealing and radiation-anneal hardening, which we re also attributed to oxygen migration to radiation-produced defect clusters. 
NT -03

\section{NT-03-02}

\section{Solid State Physics}

\section{NT-03-02-01}

\section{Neutron Scattering}

MICROSCOPIC CALCULATION OF PHONON SPECTRUM OF KCL AND $\mathrm{KBr}$

N. Wakabayashi and S. K. Sinha

Phys. Rcv. B 10: 745 (1974)

Abstract--A microscopic calculation is performed of the phonon spectrum of the alkali halide crystals $\mathrm{KCl}$ and $\mathrm{KBr}$ in the approximation where the dielectric matrix is assumed to be of separable form. The calculations involve two adjustable microscopic parameters. Reasonable agreement with experiment is obtained. A detailed discussion is also given of the microscopic treatment of effective charges and overlap interactions in ionic crystals. It is shown how qualitative conclusions regarding the nature of the overlap forces may be drawn from a simple consideration of the nature of the valence- and conduction-band orbitals.

NEUTRON DIFFRACTION STUDY OF THE MAGNETIC STRUCTURE OF ERDIUM

M. Habenschuss, C. Stassis, S. K. Sinha, H. W. Deckman, and F. H. Spedding

Phys. Rev. B 10: 1020 (1974)

Abstract--The magnetic structurc of high "purity eingle cryctalo of erbium has been studied by neutron-diffraction techniques. Although the general characteristics of the magnetic structure of erbium have been found to be in agreement with earlier measurements, several interesting new features have been observed. At $84.4 \mathrm{~K}$ the $\subseteq$-axis moment orders 
in a sinusoidally modulated magnetic structure with wave vector along the $\underline{c}$ axis, and develops higher-order harmonics as the temperature is decreased below the Neel point. The third-and fifth-order modulations of the c-axis moment were of measurable intensity at temperatures as high as 75 and $55 \mathrm{~K}$, respectively. Higher-order harmonics up to the 17 th order have been observed as the temperature was decreased down to $22 \mathrm{~K}$. A.t $52.4 \mathrm{~K}$ the basal-plane moment was found to order in a spiral with wave vector equal to that of the $\underline{c}$-axis moment. Third-and fifth-order harmonics of the basal-plane moment were observed between approximately 50 and $18 \mathrm{~K}$. At $18 \mathrm{~K}$ a transition to a ferromagnetic spiral structure was observed; significant hysteresis effects were observed in the vicinity of this transition temperature. Significant short-range-order effects have been observed above the Néel and the basal-plane-ordering temperatures. The temperature dependence of the wave vector of the magnetic structure was found to exhibit a number of anomalies associated with commensurability of the magnetic periodicity with that of the lattice. The basic features of the temperature dependence of the wave vector are in good agreement, in the (84-18) K temperature region, with the Elliott-Wedgewood theory. The temperature dependence of the $\underline{c}$ - and $\underline{\text { a-axis }}$ lattice constants has been measured and found to exhibit significant magnetostriction effects.

NEUTRON DIFFRACTION BY PERFECT CRYSTALS C. Stassis and J. A. Oberteuffer

Phys. Rev. B 10: 51.92 (1974)

Abstract--The dynamical theory of neutron diffraction has been formulated to include the reflected waves from the boundaries of a crystal. This formulation allows a unified treatment of the neutron optical and 
diffraction phenomena in crystals. It is shown that the neutron propagation in the crystal is determined by two structure factors characterizing the lattice: the total structure factor and the structure factor of the neutronspin-neutron-orbit interaction. Diffraction by a parallel crystal plate has been studied in considerable detail. It has been found that for a definite neutron-spin orientation, the diffracted and transmitted beams are modulated by six terms periodic in the thickness of the crystal. The period of the dominant term, in this Pendellösung fringe structure, has been calcula- ' ted in several cases of experimental importance. If the glancing angle of incidence substantially exceeds the critical angle for total reflection, the results are identical with those obtained by a simple extension, to the neutron case, of the $x$-ray dynamical theory. The diffraction by a magnetized crystal has been examined in some detail and it is shown that measurement of the Pendellösung periods for the two neutron-spin orientations may be used to determine both the nuclear and magnetic neutron scattering amplitude.

\section{NT-03-02-02}

\section{Experimental Physics}

I. Electronic Structure and Magnetic Properties of Solids RESIDUAL RESISTIVITY AND A.GING-CLUSTERING EFFECTS OF CuRICH Cu-Ni ALLOYS

S. Legvold, D. T. Peterson, P. Burgardt, R. J. Hofer, B. Lundell, T. A. Vyrostek, and H. Gärtner

Phys. Rev. B 9: 2386 (1974)

Abstract--The residual resistivities of copper-nickel alloys with nickel concentrations ranging from 20 ppm to 44 at. $\%$ and the observation of $\mathrm{Ni}$-cluster growth at room temperature on one sample are reported. 
From samples arc-melted over a Cu hearth, wires $1 \mathrm{~mm}$ in diameter were drawn, annealed at $800^{\circ} \mathrm{C}$ for 3 days and quenched in ice water. Pieces of wire adjacent to the samples were used for chemical analysis on the 3-44 at. \% samples and parts of the samples were used for spectrophotometric analysis on the dilute alloys. Results show that the resistivity at 4. $2 \mathrm{~K}$ over the concentration range studied is given by $\rho-\rho_{\mathrm{Cu}}(4.2 \mathrm{~K})=$ 1. $112 \underline{x}(\mu \Omega \mathrm{cm} /$ at. $\% \cdot \mathrm{Ni})$, where $\underline{x}$ is the nickel concentration in at. \%. By chance the electrical resistivity from 1.3 to $300 \mathrm{~K}$ of samples of $\mathrm{Cu}_{1-\mathrm{x}^{-}}$ $\mathrm{Ni}_{\underline{x}}(\underline{x}=0.32$ and 0.44$)$ were remeasured after they had been on the shelf at room temperature for 3 years. The new results showed that the electrical resistivity of the $\underline{x}=0.44$ sample had changed quite markedly. The sample was then reannealed at $800^{\circ} \mathrm{C}$ and quenched in ice water, and the resistivity was measured for the third time. The sample again took on nearly the same character it had originally displayed. The nature of the change of resistivity with shelf time suggests that $\mathrm{Ni}$-cluster growth at room temperature occurred.

\section{Nuclear Resonance in Solids}

\section{DEUTERON QUADRUPOLE COUPLING TENSORS IN SOLIDS}

\section{R. G. Barnes} Proceedings of a Symposium on Nuclear Quadrupole Resonance. Advances in Nuclear Quadrupole Resonance held at Queen Elizabeth College, University of London, September 1972, (1974) p. 335

Abstract--This review touches on several representative applications of the study of deuteron quadrupole coupling tensors to problems in the physics and chemistry of the organic solid state. Emphasis is given to the effective utilization of the spectra of polycrystalline samples (powder 
NT -03

spectra) in such studies, in the hope that these methods will gain more widespread application and prove productive in respect to other investigations.

NUCLEAR MAGNETIC RESONANCE STUDY OF THE TRANSITION METAL MONOBORIDES. II. NUCLEAR ELECTRIC QUADRUPOLE AND MAGNETIC SHIFT PARAMETERS OF THE METAL NUCLEI IN VB, CoB, AND NbB R. B. Creel, S. L. Segel, R. J. Schoenberger, R. G. Barnes, and D. R. Torgeson

J. of Chem. Phys. 60: 2310 (1974)

A.bstract--Measurements are reported of the nuclear electric quadrupole interaction parameters (coupling constant and asymmetry) and the several anisotropic Knight shift parameters of the ${ }^{51} \mathrm{~V},{ }^{59} \mathrm{Co}$, and ${ }^{93} \mathrm{Nb}$ nuclear magnetic resonance spectra in $\mathrm{VB}, \mathrm{CoB}$, and $\mathrm{NbB}$ monoborides, respectively. A detailed account is given of the method of extracting these parameters from the experimental spectra. The quadrupole coupling constants and asymmetry parameters are ${ }^{51} \mathrm{VB}, 1.75 \mathrm{MHz}$, $0.95 ;{ }^{59} \mathrm{CoB}, 25.2 \mathrm{MHz}, 0.74$; and ${ }^{93} \mathrm{NbB}, 20.4 \mathrm{MHz}, 0.065$. The isotropic components of the Knight shifts are all positive: ${ }^{b I^{1}} \mathrm{VB}, 0.32 \%$; ${ }^{b 4} \mathrm{CoB}$, $0.69 \%$; and ${ }^{93} \mathrm{NbB} ; 0.24 \%$. Despite the close similarity in the structures of these compounds, neither the quadrupole nor Knight shift parameters scale in a simple manner with the nuclear properties. Thus, even in the cases of $\mathrm{VB}$ and $\mathrm{NbB}$, it appears that a rigid-band type approximation furnishes a poor description of the actual changes in the electronic structure. 
III. Superconductivity

NUCLEATION OF VORTICES IN THE SUPERCONDUCTING MIXED STATE: NASCENT VORTICES

B. L. Walton, B. Rosenblum, and F. Bridges

Phys. Rev. Lett. 32: 1047 (1974)

Abstract--Evidence is presented that the mixed-state order param-

eter at surfaces parallel to the magnetic field is strongly modulated. The minima of this modulation act as the nucleation and denucleation sites for vortices.

PHASE TRANSITION AT $\underline{H}_{c l}$ FOR SUPERCONDUCTING Nb AND V J. J. Wollan, K. W. Haas, J. R. Clem, and D, K. Finnemore Phys. Rev. 10: 1874 (1974)

Abstract--Magnetization curves for $\mathrm{V}$ and $\mathrm{Nb}$ have been studied to look for a first-order transition at $\underline{\mathrm{H}}_{\underline{\mathrm{c}} 1}$ and to determine the temperature interval in which the interaction between quantized vortices is attractive. Both the $\mathrm{Nb}$ sample with resistivity ratio of $\Gamma \approx 1000$ and the $\mathrm{V}$ sample with $\Gamma \approx 1500$ show a very sharp rise in magnetic induction at $\underline{H}_{\underline{c}} l$ which is reminiscent of a first-order transition. The values of vortex spacing derived from the magnitude of this abrupt rise agree well with the decoration technique at $1.2 \mathrm{~K}$ and the neutron-diffraction technique at $4 \mathrm{~K}$. As the temperature increases, the magnetic-induction curves near $\underline{\mathrm{H}}_{\underline{c}}$ retain the same shape for all temperatures up to reduced temperatures above 0.95. Hence there is no evidence in the magnetization data for a changeover from an attractive to a repulsive interaction in this temperature range. The detailed shape of the phase-transition curves near $\underline{H}_{\underline{c}}$ agrees fairly well with model calculations which include only bulk pinning. 
SUPERCONDUCTING CRITICAL FIELD CURVES FOR Th-U

H. L. Watson, D. T. Peterson and D. K. Finnemore

K. D. Timmerhaus, W. J. O'Sullivan and E. F. Hammel, eds., Low

Temperature Physics-LT 13, Vol. 2 (New York: Plenum Publishing Corp., 1974) p. 590

Abstract--The superconducting critical fields for two Th-U alloys containing 0.05 and 0.10 at. $\% \mathrm{U}$ have been measured to an accuracy of $1 \%$ in the temperature range from the transition temperature to $0.30 \mathrm{~K}$. Results indicate that the $U$ impurity is indeed weakly magnetic as predicted by the localized spin fluctuation model. Experimental critical field curves lie between the Bardeen-Cooper-Schrieffer theory for nonmagnetic impurities and the Abrikosov-Gor'kov theory for paramagnetic impurities with the full moment at all temperatures.

SURFACE SUPERCONDUCTIVITY IN NIOBIUM AND NIOBIUM-TANTALUM ALLOYS

J. R. Hopkins and D. K. Finnemore

Phys. Rev. B 9: 108 (1974)

Abstract--The critical field for surface superconductivity, $\underline{H}_{\underline{c}} 3^{\text {, }}$ and the upper bulk critical field, $\underline{H}_{\underline{C}}$, have been measured as a function of temperature and mean free path for $\mathrm{Nb}$ and $\mathrm{Nb}(\mathrm{Ta})$ alloys in an attempt to study the spatial variations of the superconducting interaction constant $\underline{N}(0) \underline{V}$ near a vacuum-metal interface. At temperatures below $\underline{T} / \underline{T}_{\underline{c}}=$ 0.85 , the pure-Nb sample shows $\underline{\mathrm{H}}_{\underline{c} 3} / \underline{\mathrm{H}}_{\underline{c}}$ values well above 1.695 , as predicted by $\mathrm{Hu}$ and Korenman for the limit of long electronic mean free path. As the mean free path decreases, there is a regular depression of $\underline{\mathrm{H}}_{\underline{c}} 3 / \underline{\mathrm{H}}_{\mathrm{c}}$ toward 1.695. At temperatures above $\underline{\mathrm{T}} \underline{\underline{T}}_{\underline{c}}=0.85$, however, there are striking deviations from the theory which may arise because the interaction constant is slightly depressed at the surface. A model calculation by $\mathrm{Hu}$ shows that changes in $\underline{N}(0) \underline{\mathrm{V}}$ at the surface of $0.7 \%$ for pure $\mathrm{Nb}$ and $1.6 \%$ for $\mathrm{Nb}-1.0$-at. $\%$. Ta can account for the experimental results. 
ENHANCEMENT OF THE SUPER CONDUCTING TRANSITION TEMPERATURE NEAR A. PHASE INSTABILITY IN Na ${ }_{\underline{x}} \mathrm{WO}_{3}$
H. R. Shanks

Solid State Comm. 15: 753 (1974)

Abstract--The superconducting transition temperature of tetrag-

onal I sodium tungsten bronze $\left(\mathrm{Na} \mathrm{WO}_{3}\right)$ has been found to increase rapidly as the $x$-value is decreased to the metal-semiconductor phase transition. It is suggested that a soft mode instability is responsible for the increased electron-phonon interaction near the phase transition.

IV. Thermodynamic and Transport Properties of Solids

A COMPARISON OF CALCIUM SULFATE DIHYDRATE GROWN IN CLAY GELS AND IN SODIUM SILICATE GELS

R. D. Cody and H. R. Shanks

J. Crystal Growth 23: 275 (1974)

A.bstract--A comparison of crystals of calcium sulfate dihydrate grown in two different gel media, sodium silicate gel and bentonite clay gel, shows that the two media affect crystal habit and surface topography differently. Those crystals grown in silica gel at $40^{\circ} \mathrm{C}$ and $\mathrm{pH} 7.5$ consist of elongated prisms, exhibit relatively smooth crystal faces, and are often twinned. Crystals grown in bentonite gel at the same temperature and similar $\mathrm{pH}$ tend to be tabular, exhibit a wide variety of kinks, steps, and pits on their surfaces, and are never twinned under our experimental conditions. A comparison of the bentonite-grown crystals with those commonly found in nature shows that bentonite resembles natural sediments in its effects on the growll habil of gypsum. 
THE GROWTH OF MAGNESIUM GERMANIDE CRYSTALS

H. R. Shanks

J. Crystal Growth 23: 190 (1974)

Abstract--Large high purity single crystals of the semiconductor $\mathrm{Mg}_{2} \mathrm{Ge}$ have been grown by a modified Bridgman method. Crystals grown from stoichiometric melts were p-type with carrier concentrations at

$77 \mathrm{~K}$ of about $10^{16} / \mathrm{cm}^{3}$ and Hall mobilities near $1100 \mathrm{~cm}^{5} / \mathrm{V}$ sec. Excess magnesium placed in the melt acted as a donor and produced $n$-type material. Carrier concentrations of the compensated $n$-type material could be obtained ranging from $5 \times 10^{14}$ to $5 \times 10^{17} / \mathrm{cm}^{3}$ at $77 \mathrm{~K}$. Mobilities for the $\mathrm{n}$-type material were somewhat higher at about $1600 \mathrm{~cm}^{5} / \mathrm{V}$ sec than for the $p=$ type erystals.

HEAT CAPACITY OF APIEZON N GREASE FROM 1 TO $50 \mathrm{~K}$ A. J. Bevolo Cryogenics 14: 661 (1974)

Abstract--The low temperature heat capacity of Apiezon $\mathrm{N}$ grease has been measured and compared to that of Apiezon T. The latter grease has a linear term in its heat capacity while the former does not, in spite of the fact that they both have nearly identical terms. It is recommended that for very low temperature cryostats (below $4 \mathrm{~K}$ ) Apiezon $\mathrm{N}$ be used rather than Apiezon $T$ because of its lower heat capacity.

HEAT CAPACITY OF HEXAGONAL TUNGSTEN BRONZES A. J. Bevolo, H, R. Shanks, P. H. Sidles, and G. C. Danielson Phys. Rev. B 9: 3220 (1974)

Abstract--The heat capacity of four hexagonal tungsten bronzes $\left(\mathrm{K}_{\underline{x}} \mathrm{WO}_{3}, \mathrm{Rb}_{\underline{x}} \mathrm{WO}_{3}, \mathrm{Cs}_{\underline{x}} \mathrm{WO}_{3}\right.$, and $\left.\mathrm{Tl}_{\underline{x}} \mathrm{WO}_{3}\right), \mathrm{WO}_{3}$, and cubic $\mathrm{Na} \underline{\mathrm{WO}}_{3}$ have been measured from 1 to $55 \mathrm{~K}$. The excess heat capacity reported by King et al. for $\mathrm{Rb}_{\underline{x}} \mathrm{WO}_{3}$ and attributed to an Einstein mode is also present 
in $\mathrm{K}_{\underline{x}} \mathrm{WO}_{3}, \mathrm{Cs}_{\underline{x}} \mathrm{WO}_{3}$, and $\mathrm{Tl}_{\underline{x}} \mathrm{WO}_{3}$. The values of $\underline{x}$ determined from the excess heat capacity agree reasonably well with the nominal composition having $\underline{x}=0.33$. The Einstein temperatures $\Theta_{\underline{E}}$ for the metal ions vibrating in the channels formed by the six-membered rings of $\mathrm{WO}_{6}$ octahedra were found to be $58 \mathrm{~K}$ for $\mathrm{Rb}, 70 \mathrm{~K}$ for $\mathrm{Cs}$, and $38 \mathrm{~K}$ for $\mathrm{Tl}$. Two unexplained peaks in the heat capacity of $\mathrm{K}_{\underline{x}}$ WO $_{3}$ near $20 \mathrm{~K}$ precluded an accurate determination of $\Theta_{\underline{E}}$ for this tungsten bronze, but $\Theta_{\underline{E}}$ is estimated to be between 60 and $90 \mathrm{~K}$. The magnitudes of the Einstein temperatures can be understood in terms of the masses and ionic radii of the metal ions. All four hexagonal tungsten bronzes are superconductors. Measurements of the heat capacity with a magnetic field showed $\mathrm{Rb}_{\underline{x}} \mathrm{WO}_{3}$ to be a type-I superconductor, but $\mathrm{K}_{\underline{x}} \mathrm{WO}_{3}$ to be a type-II superconductor.

HEAT CAPACITY OF RUBIDIUM TUNGSTEN BRONZE

W. E. Kienzle, A. J. Bevolo, G. C. Danielson, P. W. Li, H. R. Shanks, and P. H. Sidles

K. D. Timmerhaus, W. J. O'Sullivan and E. F. Hammel, eds., Low Temperature Physics-LT 13, Vol. 3 (New York: Plenum Publishing Corp., 1974) p. 408

A.bstract--Heat capacity measurements were made from 1 to $16 \mathrm{~K}$ on samples of hexagonal rubidium tungsten bronze $\left(\mathrm{Rb}_{\underline{x}} \mathrm{WO}_{3}\right)$ which were prepared by two different methods, electrolysis and solid state reaction. All samples exhibited a superconducting transition near $2 \mathrm{~K}$. A magnetic field of a few hundred gauss was adequate to suppress the transition temperature below $1 \mathrm{~K}$. For all samples, C/T_increased more rapidly than $\mathrm{T}^{2}$ above $4 \mathrm{~K}$. For $\mathrm{Rb}_{0.30} \mathrm{WO}_{3}$, prepared by solid state reaction, $\gamma$ was 2.35 mjoules $/$ mole $K^{2}$ and $\theta_{\rho}$ was $311 \mathrm{~K}$. For all samples prepared by electrolysis a large additional non-linear contribution was observed which precluded the direct determination of $\gamma$ and $\theta_{\rho}$. 
SPECIFIC HEAT OF $2 \mathrm{H} \mathrm{NbSe}_{2}$

A. J. Bevolo and H. R. Shanks

J. A.ppl. Phys. 45: 4644 (1974)

Abstract--The specific heats of four samples of $2 \mathrm{H} \mathrm{NbSe}_{2}$ have been measured in the temperature range from 1 to $54 \mathrm{~K}$. No anomalous behavior was found near $40 \mathrm{~K}$ where $\mathrm{x}-\mathrm{ray}, \mathrm{NMR}$, and Hall-effect measurements have indicated the presence of a phase transition. An upper limit of 0.3 $\mathrm{J} / \mathrm{mole} \mathrm{K}$ has been placed on the magnitude of any anomaly in the heat capacity associated with this transition. Measurements of a high-purity stoichiometric $2 \mathrm{H} \mathrm{NbSe}{ }_{2}$ sample gave a superconducting transition temperature of $7.23 \mathrm{~K}$, a specific heat jump $(\Delta \mathrm{C})$ in zero field of $240 \mathrm{~mJ} / \mathrm{mole} \mathrm{K}$, and a Debye temperature of $204 \mathrm{~K}$. A deviation from the usual $\mathrm{T}^{3}$ behavior for the lattice contribution to the heat capacity was observed and assumed to be due to the two-dimensional layer structure of the compound. Our best estimate for the electronic coefficient of specific heat $(\gamma)$ is about $10 \pm 5 \mathrm{~mJ} / \mathrm{mole} \mathrm{K}^{2}$. Based on the values for $\underline{T}_{\underline{c}}$ and $\Delta \underline{C}$, the value for $\gamma$ calculated from BC'S theory is $23 \mathrm{~mJ} / \mathrm{mole}^{7}$ for $2 \mathrm{H} \mathrm{NbSe}{ }_{2}$ which is in disagreement with our estimated value for $\gamma$ by a factor of 2 .

THERMAL CONDUCTIVITY OF MAGNESIUM PLUMBIDE J. J. Martin and $H$. K. Shanks J. Applied Phys. 45 : 2428 (1974)

Abstract-- The thermal conductivity of a semimetal $\mathrm{Mg}_{2} \mathrm{~Pb}$ single crystal has been measured from 2 to $200 \mathrm{~K}$. A.t low temperatures thermal conduction is by phonons limited by phonon scattering from the heavy hole Fermi surface. At higher temperatures the thermal conductivity contains both electronic and phonon contributions. A comparison of the thermal conductivity of $\mathrm{Mg}_{2} \mathrm{~Pb}$ with the thermal conductivities of the related semi- 
conductors, $\mathrm{Mg}_{2} \mathrm{Si}, \mathrm{Mg}_{2} \mathrm{Ge}$ and $\mathrm{Mg}_{2} \mathrm{Sn}$, indicates that there is a significant bipolar contribution to the electronic the rmal conductivity.

TWO DIMENSIONAL KOHN ANOMALY IN NbSe 2 N. Wakabayashi, H. G. Smith and H. R. Shanks Phys. Lett. 50A: 367 (1974)

Abstract--Phonon dispersion curves for several low frequency branches in the layered compound $\mathrm{NbSe}_{2}$ have been measured. The results indicate the possible existence of a two dimensional Kohn anomaly in this material.

VISUAL EFFECTS OF SWITCHING IN 0.15 As-0.12 Ge-0.73 Te GLASS D. E. Eckels, P. H. Sidles, and G. C. Danielson J. Appl. Phys. 45: 3005 (1974)

Abstract--Bulk samples of 0.15 As-0.12 Ge-0.73 Te glass were switched electrically with a voltage slightly above the threshold voltage. For a probe separation of $1.4 \mathrm{~mm}$ and the sample at room temperature, the threshold voltage is $150 \mathrm{~V}$. The visual effects of switching were studied using 11000 -frames/sec cinematography. When $152 \mathrm{~V}$ was applied between two probes on the sample's surface, a filament appeared between the two probes $0.62 \mathrm{msec}$ before the sample switched. The filament at the time of formation was narrow but later widened as current continued to flow through the filament after switching had occurred. The appearance of the filament before the sample switched and the subsequent widening of the filament both indicate that in this experiment switching was the result of a predominantly thermal mechanism. 
EXPERIMENTAL COMPRESSIONS FOR NORMAL HYDROGEN AND NORMAL DEUTERIUM TO 25 kbar A.T $4.2 \mathrm{~K}$

M. S. Anderson and C. A. Swenson

Phys. Rev. B 10: 5184 (1974)

Abstract--The piston-displacement technique has been used to determine the pressure-volume relations for normal hydrogen $\left(\underline{\mathrm{n}}-\mathrm{H}_{2}\right)$ and normal deuterium $\left(\underline{\mathrm{n}}-\mathrm{D}_{2}\right)$ at pressures to $25 \mathrm{kbar}$ at $4.2 \mathrm{~K}$. The accuracy of the relative compressions $\underline{V} / \underline{V}_{0}$ ranges from $\pm 10^{-3}$ at low pressures to $\pm 3 \times 10^{-3}$ at $25 \mathrm{kbar}$. The data, especially for $\underline{\mathrm{n}}-\mathrm{H}_{2}$, agree well with earlier 20 -kbar results, and the extrapolated $\underline{P}=0$ bulk moduli, $1.70 \pm 0.06 \mathrm{kbar}$ for $\underline{\mathrm{n}}-\mathrm{H}_{2}$ and $3.15 \pm 0.06 \mathrm{kbar}$ for $\underline{\mathrm{n}}-\mathrm{D}_{2}$, are consistent with recent ultrasonic data. The shapes of the presisurevolume relations resemble more closely those for the helium isotopes than those for the heavier-rare-gas solids, and suggest that the twobody repulsive interaction for hydrogen molecules (and helium atoms) varies more slowly with intermolecular spacing than that for the heavierrare-gas atoms. These experiments also give maximum values for the pressure-dependent shear yield stress of solid hydrogen.

LINEAR-THERMAL-EXPANSION MEASUREMENTS ON POTASSIUM METAL FROM 2 TO $320 \mathrm{~K}$ D. R. Schouten and C. A. Swenson Hhys. Kev. B 10: 2175 (1974)

A.bstract--A differential capacitance dilatometer has been used to obtain linear-thermal-expansion measurements on free-standing samples of high-purity.potassium metal from 2 to $320 \mathrm{~K}$. The low-temperature results are consistent with a free-electron calculation of the electronic contribution to the thermal-expansion coefficient, while the lattice contribution can be represented by a Grüneisen parameter $\gamma$ which varies 
slowly with temperature from approximately 0.90 at $\underline{T}=0$ to 1.24 near the melting point, in agreement with $\gamma^{\prime}$ s as calculated from high-pressure elastic-constant data. Slight inconsistencies ( $1 \%$ or so) were found for temperatures between 20 and $30 \mathrm{~K}$, and between 100 and $200 \mathrm{~K}$, which are believed to be traceable to the thermal history of the samples. A summary of existing bulk-modulus data is given for use with the $\gamma$ calculations. The data are normalized to published bulk-density measurements at $300 \mathrm{~K}$, and the resulting $\underline{T}=0$ molar volume $\left(43.21 \pm 0.02 \mathrm{~cm}^{3} /\right.$ mole) can be used with the free-electron model to calculate a de Haas-van Alphen frequency which is in excellent agreement with direct determinations. When the smoothed linear-thermal-expansion coefficients are used to calculate $\underline{C}_{\underline{V}}^{\text {lat }}(T)$ from published results for $\underline{C}_{p}(T)$, anharmonic effects ( $\underline{\mathrm{C}}_{\mathrm{V}}$ proportional to $\underline{\mathrm{T}}$ ) are evident above $100 \mathrm{~K}$, while vacancy effects become important above $250 \mathrm{~K}$.

THERMAL EXPANSIONS OF HIGH-PURITY AND OH ${ }^{-}$-DOPED NaCl AT TEMPERATURES BELOW $30 \mathrm{~K}$

C. R. Case, II and C. A. Swenson

Phys. Rev. B 9: 4506 (1974)

Abstract--A variable transformer dilatometer has been used to obtain linear thermal-expansion coefficients for temperatures from 2 to $30 \mathrm{~K}$ for single crystals of pure $\left(\mathrm{OH}^{-}\right.$-free) $\mathrm{NaCl}$ and for $\mathrm{NaCl}$ crystals which contained 6.5 and $80 \mathrm{ppm}$ of $\mathrm{OH}^{-}$substitutional impurities. The thermal expansions of the pure sample are well behaved, with a Grüneisen parameter which agrees well with the elastic-constant value (1.06) below $6 \mathrm{~K}$, and which shows a pronounced minimum near $15 \mathrm{~K}$. A relatively large anomalous contribution to the thermal-expansion coefficient of the 80-ppm sample increases with decreasing temperature and has a magnitude which is ten times that of the pure sample at $2.25 \mathrm{~K}$. These large 
excess thermal expansions are similar in form to heat-capacity contributions which can be calculated from published energy-level diagrams for $\mathrm{OH}^{-}$in $\mathrm{NaCl}$. The corresponding Grüneisen parameter for this impurity system is quite large $(-40)$, and hence provides a direct confirmation that tunneling must be involved in any description of the thermodynamic properties of these impurity states.

\section{Optical and Spectroscopic Properties of Solids}

ELECTROREFLECTANCE OF GaP TO $27 \mathrm{eV}$

D. E. Aspnes and C. G. Olson

Phys. Rev. Lett. 33: 1605 (1974)

Abstract--We report the first electroreflectance spectra obtained above $7 \mathrm{eV}$. The large number of new critical points observed includes a group in the energy range above $20 \mathrm{eV}$ which occurs between the $3 \underline{d}$ valence bands, derived from the deep-lying Ga 3 d core levels, and the $s^{3}$ conduction bands. The resolution, currently limited by the monochromator band pass, enables us to resolve directly the $0.50 \pm 0.03 \mathrm{eV}$ spin-orbit splitting of the Ga 3 d core levels for the first time.

MATRIX ELEMEÑT DEPENDENCE OF OPTICAL EXCITATION AND AUGER DECAY OF 5d CORE HOLES IN $\mathrm{Bi}_{2} \mathrm{Te}_{3}$

Z. Hurych, J. C. Shaffer, D. L. Davis, T. A. Knecht, G. J. Lapeyre, P. L. Gobby, J. A. Knapp, and C. G. Olson

Phys. Rev. Lett. 33: 830 (1974)

Abstract--The spectral dependence of the Auger component of the uv photoemission and the far-uv reflectance show that the optical excitation of $5 d$ core states cannot be described in terms of simple density of states indicating that matrix element effects must be included. 
OPTICAL PROPERTIES OF V, Ta, AND MO FROM 0. 1 TO $35 \mathrm{eV}$ J. H. Weaver, D. W. Lynch, and C. G. Olson

Phys. Rev. B 10: 501 (1974)

Abstract--The absorptivity or reflectivity of crystals of $\mathrm{V}, \mathrm{Ta}$, and Mo was measured from 0.1 to $35 \mathrm{eV}$. The data were Kramers-Kronig analyzed to determine the dielectric functions. The inadequacy of a simple Drude model to describe absorption at low energy is discussed. Structure in the dielectric functions is discussed in terms of direct interband transitions which extend to about $18 \mathrm{eV}$. Features below $6 \mathrm{eV}$ are attributed to transitions near $\Sigma, \underline{G}$, and perhaps along $\underline{P}(\underline{D}) \underline{N}$ for $V, T a$, and Mo, with additional transitions in Mo from the $\Delta$ portion of the Brillouin zone. High-lying energy bands are identified as giving rise to high-energy structure in the dielectric functions. Results obtained previously for $\mathrm{Nb}$ are reviewed and compared. The electron-energy-loss functions were calculated and are discussed in terms of volume and surface plasmons. These metals all exhibit two volume and two surface plasmons.

\section{TEMPERATURE DEPENDENCE OF THE $\underline{K}$ ABSORPTION EDGE OF} LITHIUM C. Kunz, H. Petersen, and D. W. Lynch

Phys. Rev. Lett. 33: 1556 (1974)

Abstract--The shape of the $\underline{K}$ absorption edge of Li has been measured at $293,373,443$, and $-480 \mathrm{~K}$ (liquid) by photoyield methods. Unpublished transmission data on the shape of the edge at and below room temperature have been reanalyzed. There is a marked increase of the width of the edge with increasing temperature above $293 \mathrm{~K}$, indicating that the lattice plays a major role in the broadening of the edge. 
TEMPERATURE-MODULATED REFLECTANCE OF GOLD FROM 6 TO $35 \mathrm{eV}$

C. G. Olson, M. Piacentini, and D. W. Lynch

Phys. Rev. Lett. 33: 644 (1974)

Abstract--The thermoreflectance spectrum of gold has been measured in the $6-35-\mathrm{eV}$ region at about $200 \mathrm{~K}$ by using synchrotron radiation. Considerable sharp structure exists throughout this region, showing that lifetime broadening is not large enough to preclude the extension of high-resolution modulation techniques to at least $3 b \mathrm{eV}$. 'Ihe structure arises from interband transitions of the $5 \underline{d}$ electrons and from plasmons.

TEMPERATURE MODULATION OF THE OPTICAL TRANSITIONS IN VOLVING THE FERMI SURFACE IN AG: EXPERIMENTAL R. Rosei, C. H. Culp and J. H. Weaver Phys. Rev. B 10: 484 (1974)

Abstract--Thermoreflection and thermotransmission measurements were made on thin semitransparent films of Ag at about 320, 120, and $15 \mathrm{~K}$ in the range $3.40-4.40 \mathrm{eV}$. The results are in fairly good agreement with the theory presented in the preceding paper but show that thin metal films evaporated on amorphous substrates become strained upon cooling to low temperature. The onset of the $\underline{L}_{3} \rightarrow \underline{L}_{2}^{\prime}\left(\underline{\underline{E}}_{F}\right)$ transition is found to be at $4.03 \mathrm{eV}$, while the onset of the $\underline{L}_{2}{ }^{\prime}\left(\underline{E}_{F}\right) \rightarrow \underline{L}_{1}$ transition occurs at $3.87 \mathrm{eV}$.

VACUUM-ULTRA.VIOLET OPTICAL PROPERTIES OF SINGLE-CRYSTAL CADMIUM C. G. Olson and D. W. Lynch

Phys. Rev. B 9: 3159 (1974)

Abstract--The reflectivity of single-crystal Cd has been measured between 350 and $2500 \AA$ using synchrotron radiation. The data have been Kramers-Kronig analyzed and corrections for an overlayer of CdO discussed. 
The imaginary part of the dielectric constant exhibits a sharp rise at about $9.35 \mathrm{eV}$ due to the onset of transitions from the top of the 4 d bands to the Fermi level. These transitions persist, with structure, to high energy, only about a third of their oscillator strength being used by 30 eV. The bulk and surface plasmon energies are found to be 8.80 and $7.30 \mathrm{eV}$.

\section{Rare Earth Metals Preparation}

THE Gd-Yb AND Lu-Yb PHASE SYSTEMS

B. J. Beaudry and F. H. Spedding

Met. Trans. 5: 1631 (1974)

Abstract--The Gd-Yb and Lu-Yb phase systems were established by thermal analysis, $\mathrm{x}$-ray diffraction, metallography, electron microprobe and chemical analyses. The solubility of $\mathrm{Yb}$ in $\alpha$-Gd ranges from 6.5 at. pet at $500^{\circ} \mathrm{C}$ to 19.0 at. pct at $1161^{\circ} \mathrm{C}$. The addition of $\mathrm{Yb}$ to Gd lowers the $B$ (bcc) to $\alpha$ (hcp) transformation temperature to an inverse peritectic reaction at 20.0 at. pct $\mathrm{Yb}$ and $1161^{\circ} \mathrm{C}$. The addition of $\mathrm{Yb}$ to Gd lowers the melting point of Gd to a monotectic horizontal at $1183^{\circ} \mathrm{C}$ which extends from 21.0 to 71.0 at. pct Yb. The monotectic composition is 49.0 at. pct $\mathrm{Yb}$. The solid solubility of $\mathrm{Gd}$ in $\mathrm{Yb}$ ranges from 0.2 at. pct at $500^{\circ} \mathrm{C}$ to 2.3 at. pet at $819^{\circ} \mathrm{C}$. The melting point of $\mathrm{Yb}$ is raised from $816^{\circ} \mathrm{C}$ to $819^{\circ} \mathrm{C}$ by the addition of Gd while the $\gamma$ (bcc) to $B$ (fcc) transformation temperature of $\mathrm{Yb}$ is lowered from $796^{\circ} \mathrm{C}$ to $780^{\circ} \mathrm{C}$ by the addition of Gd. The solubility of $\mathrm{Yb}$ in solid Lu ranges from 6.0 at. pct at $800^{\circ} \mathrm{C}$ to 15 at. pct at $1530^{\circ} \mathrm{C}$. The addition of $\mathrm{Yb}$ to Lu lowers the melting point of $\mathrm{Lu}$ to a monotectic horizontal at $1530^{\circ} \mathrm{C}$ which extends 
from 15 to 90 at. pct Yb. The monotectic composition is approximately 30 at. pct $\mathrm{Yb}$. The solid solubility of Lu in $\mathrm{Yb}$ ranges from less than 0.1 at. pct at $500^{\circ} \mathrm{C}$ to 0.3 at. pct at $817^{\circ} \mathrm{C}$. The addition of Lu raises the melting point of $\mathrm{Yb}$ to $817^{\circ} \mathrm{C}$ and also raises the $B$ (fcc) to $\gamma$ (bcc) transformation temperature to $798^{\circ} \mathrm{C}$.

HIGH TEMPERATURE ENTHALPIES AND RELATED THERMODYNAMIC FUNCTIONS OF THE TRIFLUORIDES OF Sc, Ce, Sm, Eu, Gd, Tb, Dy, Er, Tm, AND Yb

F. H. Spedding, B. J. Beaudry, D. C. Henderson and J. Moorman

J. Chem. Phys. 60: 1578 (1974)

Abstract--The high temperature enthalpies of high purity $\mathrm{ScF}_{3}$, $\mathrm{CeF}_{3}, \mathrm{SmF}_{3}, \mathrm{GdF}_{3}$ (redetermined), $\mathrm{TbF}_{3}, \operatorname{DyF}_{3}, \mathrm{ErF}_{3}, \operatorname{Tm} \mathrm{F}_{3}$, and $\mathrm{YbF}_{3}$ were measured from 100 to $1600^{\circ} \mathrm{C}$ and $\mathrm{EuF}_{3}$ from 100 to $975^{\circ} \mathrm{C}$. The thermal data for the other fluorides in the rare earth series were reported earlier from this laboratory. The heat capacity, enthalpies of transition and fusion, and related thermodynamic functions were calculated. The smoothed values of $\underline{H}^{\circ}{ }_{T}-\underline{H}^{\circ} 298.15, \underline{C}^{\prime} \underline{S}^{\circ} \underline{T}-\underline{S}^{\circ} 298.15$, and $-\underline{F}^{\circ} \underline{T}^{-}$ $\underline{\mathrm{H}}^{\circ} 298.15^{1 / \mathrm{T}}$ are tabulated at $100^{\circ}$ intervals. The melting points, transition temperatures, and lattice parameters of the high purity fluorides prepared in this study were determined.

THE LATTICE PARAMETERS OF La, Ce, Pr, Nd, Sm, Eu AND Yb B. J. Beaudry and P. E. Palmer J. Less-Common Metals 34: 225 (1974)

A.bstract--Lattice parameters of La, Ce (B and $\gamma), \operatorname{Pr}, \mathrm{Nd}, \mathrm{Sm}$, $\mathrm{Eu}$ and $\mathrm{Yb}$ were determined on well-characterized high-purity metals in the form of small-grained wires. The effect of sample preparation on the lattice parameters of the se metals is discussed. A method to obtain crystallographically-pure polycrystalline d.h. c. p. lanthanum is presented. 


\title{
NT-03-02-03 \\ Theoretical Physics
}

\author{
I. Optical and Surface Physics
}

THEORY OF DYNAMICAL PROPERTIES OF DIELECTRIC SURFACES K. L. Kliewer and R. Fuchs

S. A. Rice and I. Prigogine, eds., Advances in Chemical Physics Vol. 27: Aspects of the Study of Surfaces (New York: John Wiley and Sons, Inc., 1974) pp. 355-541

Abstract-- The theory of surface phonons is reviewed and an extensive discussion of the deeply penetrating surface phonons in polar materials is presented for a variety of geometries. This and related sections, in which a continuum theory is used, include discussions of damping effects, doped polar semiconductors, magnetic field effects, and non-cubic crystals among others. For large wavevectors a continuum theory is not valid; either a nonlocal dielectric theory or a fully atomistic theory must be used. Both types of theory are discussed and their applicability demonstrated for metals and nonpolar semiconductors as well as polar materials. Experimental techniques for studying surface phonons are discussed as are a large number of experimental results.

THEORY OF THE OPTICAL PROPERTIES OF SMALL CUBES R. Fuchs Phys. Lett. 48A: 353 (1974)

Abstract--The optical properties are determined for small cubes composed of a homogeneous isotropic material with a dielectric function $\epsilon(\omega)$. 
COMPTON-EFFECT CROSS SECTION FOR 'IHE ELECTRON GAS:

COLLECTIVE TO SINGLE-PARTICLE TRANSITION

K. L. Kliewer and H. Raether

J. Phys. C: Solid State Phys. 7: 689 (1974)

Abstract--Calculations, within the SCF approximation, of the scattering cross section for the production of elementary excitations of the electron gas by high-energy photons are presented. The manner in which the cross section, dominated by plasmons at small momentum transfer, develops single-particle character with increasing momentum transfer is emphasized. It is shown that collective effects persist to wavevectors of the order of $6 \underline{k}_{F}$, where $\underline{k}_{F}$ is the magnitude of the Fermi wavevector. This corresponds to a wavevector of about $9 q_{c}$ for a high electron-density gas $\left(\underline{r}_{s} \sim 2\right)$ and $6 \underline{q}_{C}$ for a low electron-density gas $\left(\underline{r}_{s} \sim 5\right)$, with $q_{c}$ the critical wavevector at which the onset of Landau damping occurs.

NONLOCAL EFFECTS IN PHOTOEMISSION STUDIES WITH NONNORMAL I. Y IN GIDENT IIGHT

K. L. Kliewer

Phys. Rev. Lett. 33: 900 (1974)

Abstract-- The local theory for the photoyield resulting from $\mathrm{p}-$ polarized light incident upon a half-space photoemitter is reviewed and generalized to include nonlocal effects. Local and nonlocal yields for the electron gas are presented for frequencies above the plasma frequency. The nonlocal yields are substantially higher than the corresponding local yields and it is shown that this enhancement involves nondirect electronic transitions associated with both plasmons and single-particle excitations. 
REFLECTION SPECTROSCOPY ON MONOCLINIC CRYSTALS E. E. Koch, A. Otto and K. L. Kliewer

Chem. Phys. $\underline{3}: 362$ (1974)

Abstract--The properties of the dielectric tensor of a monoclinic crystal are reviewed and the nature of transverse excitations is pointed out. Reflection equations for normal incidence on the $(010)$ plant and (001) plane are presented, by use of which full information on all tensor components may be obtained from reflection measurements and KramersKronig analysis. A reflection equation for oblique incidence on faces $\left(\underline{h}_{1}, O, \underline{h}_{3}\right)$ with plane of incidence $(010)$ and transverse magnetic polarization allows the comparison of reflectance spectra calculated from the dielectric tensor components with respective experimental spectra. Simple model calculations related to exciton structures in molecular crystals and quasi one-dimensional materials are displayed.

\section{Superconductivity}

MAGNETIC COUPLING IN SUPERPOSED TYPE-II SUPERCONDUCT ING FILMS

J. W. Ekin, B. Serin and J. R. Clem

Phys. Rev. B 9: 912 (1974)

Abstract--A study has been made of the magnetic-coupling properties of vortex arrays in a dc superconducting transformer composed of two oxygen-doped aluminum films separated by a thin insulating layer. By doping to the appropriate level, very small depinning currents have been achicved, making possible an investigation of the vortex-coupling characteristics in a low-current regime free of heating instabilities. Measurements of the system's $\underline{V}-I$ characteristics have been obtained at currents more than an order of magnitude greater lhail the current at which the 
two vortex lattices cease to move at the same velocity. A simple periodiccoupling-force model has been used to generate theoretical V-I curves which are found to compare well with the experimental data. Values of the magnetic interaction force coupling the two vortex arrays have been determined as a function of temperature and intervortex spacing, and are compared with theory.

MAGNETIC FLUX STRUCTURES IN SUPERCONDUCTORS-A CONFERENCE SUMMARY

R. P. Huebener and J. R. Clem

Rev. Modern Phys. 46: 409 (1974)

Abstract--The proceedings of the International Conference on Magnetic Structures in Superconductors held at Argonne National Laboratory, Argonne, Illinois on 5-8 September 1973 are reviewed and summarized. Recent experimental and theoretical developments in the field of magnetic flux structures in both type-I and type-II superconductors are described, current research directions are discussed, and expected future developments are outlined.

\section{A. MODEL FOR FLUX PINNING IN SUPERCONDUCTORS}

J. R. Clem

K. D. Timmerhaus, W. J. O'Sullivan and E. F. Hammel, eds., Low Temperature Physics-LT 13 Vol. 3 (New York: Plenum Publishing Corp., 1974) p. 102

Abstract--In order to describe some of the important aspects of the interaction of fluxoids with surfaces and large defects in type II superconductors, we consider here an idealized flux-pinning model which treats bulk pinning as arising from a sequence of surface pinning events. To develop this model, we first discuss surface pinning in some detail. We then introduce the model, derive an expression for the critical current density, and, finally, discuss some of its implications. 
THEORY OF MAGNETICALLY COUPLED TYPE-II SUPERCONDUCTING FILMS

J. R. Clem

Phys. Rev. B 9: 898 (1974)

Abstract--The current-voltage characteristics of a magnetically coupled pair of infinite type-II superconducting films of finite thickness, separated by an insulating layer, are calculated. The main features of

the time-averaged primary and secondary flux-flow voltages $\underline{\bar{V}}_{\underline{p}}$ and $\underline{\bar{V}}_{\underline{s}}$ versus the primary and secondary currents $I_{\mathrm{P}}$ and $I_{s}$ are found to depend upon only five parameters: the primary and secondary critical depinning currents $I_{p c}$ and $I_{s c}$, the primary and secondary flux-flow resistances $\underline{R}_{p}$ and $\underline{R}_{\underline{s}}$, and a coupling current $\underline{I}_{0}$, which is proportional to the maximum coupling force exerted on a secondary fluxoid by the displaced primaryfluxoid lattice. Model calculations of the current-voltage characteristics are performed to illustrate predicted behavior under varying strengths of current, pinning, and coupling.

\section{Magnetic and Electrical Properties}

AU.GMENTED-PLANE-WAVE CALCULATION OF. INDIRECT-EXCHANGE MATRIY ELEMENTS FOR GADOLINIUM

B. N. Harmon and A. J. Freeman

Phys. Rev. B 10: 4849 (1974)

Abstract--The exchange matrix elements between a local $4 \underline{f}$ moment and the conduction electrons (Ruderman-Kittel-Kasuya-Yosida exchange) have been calculated for paramagnetic gadolinium metal using nonrelativistic augmented-plane-wave wave functions. The magnitude of the matrix elements is found to be largest for $\underline{d}$-like conduction electrons and is quite sensitive to their angular distribution. Because of band crossings, which cause rapid changes in wave-function character, 
the matrix elements cannot be well described as slowly varying functions of $\vec{q}=\overrightarrow{k^{\prime}}-\vec{k}$.

CHARGE-DENSITY - WAVE STATE IN VS

S. H. Liu

Phys. Rev. B 10: 3619 (1974)

Abstract-- The crystallographic phase transition in the compound VS is explained in terms of the formation of a charge-density-wave (CDW) state. In an attempt to neutralize the çharge density of the elertron gas, the positive ions shift in position and produce a superlattice strurture. In VS it is found to be energetically favorable for the superlattice to have a periodicity which is commensurate with the undistorted lattice, as found experimentally. The elementary excitations in the CDW state contain an acoustic-plasmon branch which is mixed with the transverse-optical phonons.

ELECTRONIC STRUCTURE OF VS

W. B. England, S. H. Liu and H. W. Myrnn J. Chem. Phys. 60: 3760 (1974)

Abstract--Energy bands, density of states, Fermi surfaces, and wavefunction populations are calculated for VS in the hexagnnal phase. Purely metallic, mixed metal-nonmetal, and purely nonmetallic bands are observed. The Fermi level intersects the almost pure vanadium 3 d bands so the compound should exhihit electrical conductivity like typical $\underline{d}$ band metals. The vanadium $\underline{s}$ and $p$ and sulfur $\mathrm{p}$ bands are hybridized and lie well below the Fermi energy, and they give rise to the strong covalent bonds and the nonmetallic mechanical properties of the compound. 
ENERGY BANDS, FERMI SURFACE AND LATTICE INSTABILITY IN VS S. H. Liu, W. B. England and H. W. Myron

Solid State Comm. 14: 1003 (1974)

Abstract-- The energy bands of vanadium monosulfide have been calculated by the KKR method in the muffin-tin approximation. The Fermi surface is very complicated, but there are two nearly cylindrical sheets of nearly equal cross-sections centered around $\Gamma$ and $\underline{M}$ respectively. We suggest that this Fermi surface feature can support a charge-density-wave (CDW) state in the conduction electron system at low enough temperatures, and the formation of the $\mathrm{CDW}$ explains the lattice phase transition in this compound.

SPIN-POLARIZED ENERGY - BAND STRUCTURE, CONDUCTION-ELECTRON POLARIZATION, SPIN DENSITIES, AND THE NEUTRON MAGNETIC FORM FACTOR OF FERROMAGNETIC GADOLINIUM

B. N. Harmon and A. J. Freeman

Phys. Rev. B 10: 1979 (1974)

Abstract--Conduction-electron polarization, spin densities, and neutron magnetic scattering in ferromagnetic Gd metal were studied using the spin-polarized augmented-plane-wave (APW) method in a warpedmuffin-tin-potential formulation. The spin-up and spin-down bands were found to be very similar in shape to the bands from a paramagnetic calculation, with the exchange splitting proportional to the amount of $\underline{d}$ character in the bands. It was also found that the conduction-electron spin density determined from the APW wave functions is of mostly d character. This dominance of the $\underline{d}$-like wave functions for the spin-dependent interactions is explained by (i) the much greater overlap of the $4 \underline{f}$ states with the $\underline{d}$-like wave functions as compared to the $\underline{s}-\underline{p}$ wave functions; (ii) the nearly complete d character of the bands in the region of the Fermi surface. 
The magnetic form factor was calculated from the conduction-electron spin density and compared with the recent neutron magnetic-form-factor measurement of Moon, Koehler, Cable, and Child. The calculated spin density was found to have the same shape as the "diffuse" density derived by Moon et al. (including a negative but much smaller in magnitude spin density at the $\subseteq$ site in the unit cell). After the inclusion of core-polarization effects we conclude that large nonspherical contributions with $\underline{Y}_{33^{-}}$ $\underline{Y}_{3-3}$, and $\underline{Y}_{40}$ angular dependence are needed to explain the experimental results.

TECHNIQUE FOR RAPID SOLUTION OF THE APW SECULAR EQUATION B. N. Harmon and D. D. Koelling J. Phys. C: Solid State Phys. 7: L2 10 (1974)

Abstract--A modification of the standard variational procedure used in the APW method is presented. The new procedure allows rapid solution of the secular equation and yields correctly normalized wavefunctions. Since several minor complications can arise, a detailed description of the method is given.

DIELECTRIC FUNCTION AND PHONON SPECTRUM OF GREY TIN R. P. Gupta, S. K. Sinha, J. P. Walter and Marvin L. Cohen Solid State Comm. 14: 1313 (1974)

Abstract--The dielectric function of $\alpha$-Sn has been evaluated from a. pseudopotential calculation of the valence electron wavefunctions and energy bands. The result is used, together with an approximate method of calculating the inverse of the dielectric function matrix, lo calculate the phonon dispersion curves. Fairly good overall agreement with the experimental dispersion curves has been obtained. 
MICROSCOPIC THEORY OF DIELECTRIC SCREENING AND LATTICE DYNAMICS. I. LOCAL-FIELD CORRECTIONS AND DIELECTRIC CONSTANTS

S. K. Sinha, R. P. Gupta and D. L. Price

Phys. Rev. B 9: 2564 (1974)

Abstract--We show how local-field corrections in solids may be treated by a very general factorization scheme for $\in\left(\vec{Q}, \overrightarrow{Q^{\prime}}\right)$ from which practically all existing models of dielectric screening and lattice dynamics may be derived as special cases, including the shell model, the breathingshell model, and the bond-charge model, as well as generalizations of these models which result from the introduction of a "screening medium." The latter arise naturally in our formalism from a portion of $\in\left(\vec{Q}, \vec{Q}^{\prime}\right)$ which is purely diagonal. It is shown that the formalism also allows for charge-transfer and multipole effects. In this first paper we derive explicit expressions for the elements of $\epsilon\left(\vec{q}+\vec{G}, \vec{q}+\vec{G}^{\prime}\right)$ and its inverse and show that they have the correct analytic behavior as $\vec{q} \rightarrow 0$. For insulators of cubic and tetrahedral symmetry, explicit microscopic expressions are derived for the high-frequency dielectric constant $\epsilon_{\infty}$, thus realizing a generalization of the Lorentz-Lorenz formula, and for the local fleld produced by dil applied field.

MICROSCOPIC THEORY OF DIELECTRIC SCREENING AND LATTICE DYNAMICS. II. PHONON SPECTRA. AND EFFECTIVE CHARGES D. L. Price, S. K. Sinha and R. P. Gupta Phys. Rev. B 9: 2573 (1974)

Abstract--The factorization scheme for treating dielectric screening in solids, introduced in a previous paper, is here used to calculate the dynamical matrix for the phonon frequencies and eigenvectors. By considering the limit as $\vec{q} \rightarrow 0$ we derive explicit microscopic expressions for the effective-charge tensor, the optic modes, the low-frequency dielectric 
constant $\epsilon(\omega)$, the acoustic sum rules, and the elastic and piezoelectric constants. The Lyddane-Sachs-Teller relation is obeyed, and the deviation of the Szigeti charge from the ionic charge is discussed. We discuss the relationship to other models for the dynamics of insulators and semiconductors, and finally present results of explicit calculations for the phonon spectra of silicon and germanium.

A SIMPLE THEORY OF ELECTRONIC GRÜNEISEN CONSTANT AND BULK MODULUS AT LOW TEMPERATURE

M. Shimizu

Phys. Lett. 50A: 93 (1974)

A.bstract--The value of 5/3 for electronic Grüneisen constant is obtained by a simple model of Lang and Ehrenreich. This value is compared with the experimental values for various metals. Bulk modulus at low temperature is also discussed. 


\title{
NT-03-03
}

\section{Materials Chemistry}

\author{
NT-03-03-01
}

\section{Chemical Siructure}

\section{X-ray and Neutron Crystallography}

CRYSTAL AND MOLECULAR STRUCTURE OF DECACOORDINATE COMPLEX TRIS(BICARBONATO)TETRAAQUOHOLMIUM(III) DIHYDRATE, $\mathrm{Ho}\left(\mathrm{H}_{2} \mathrm{O}\right)_{4}\left(\mathrm{H} \mathrm{CO}_{3}\right)_{3} \cdot 2 \mathrm{H}_{2} \mathrm{O}$

W. J. Rohrbaugh and R. A. Jacobson

Inorg. Chem. 13: 2535 (1974)

Abstract--The crystal and molecular structure of tris(bicarbonato)tetraaquoholmium(III) dihydrate $\left(\mathrm{Ho}_{2}\left(\mathrm{H}_{2} \mathrm{O}_{4}\left(\mathrm{HCO}_{3}\right)_{3} \cdot 2 \mathrm{H}_{2} \mathrm{O}\right.\right.$, triclinic, $\underline{\mathrm{p}}$, $\underline{a}=9.18(2) \AA, \underline{b}=11.59(1) \AA, \underline{c}=6.73(1) \AA, \alpha=88.87(6)^{\circ}, \beta=112.45$ $(8)^{\circ}, \gamma=71.54(6)^{n}, \underline{Z}-2$, Mo IKo radiation) has been determined by three-dimensional $\mathrm{x}$-ray analysis. The structure was solved by conventional Patterson and Fourier techniques and refined by full-matrix leastsquares analysis to a final conventional discrepancy factor $\left(\underline{R}=\left[\Sigma \| \underline{F}_{0}|-|-\right.\right.$ $\left.\left.\underline{F}_{C} \|\right] / \Sigma\left|\underline{F}_{0}\right|\right)$ of 0.039 for 1621 observed reflections $\left(\underline{F}_{0}>2 \sigma_{F_{0}}\right)$. The holmium moiety containing four coordinated water molecules and three bidentate bicarbonate groups is 10-coordinate and assumes a distorted

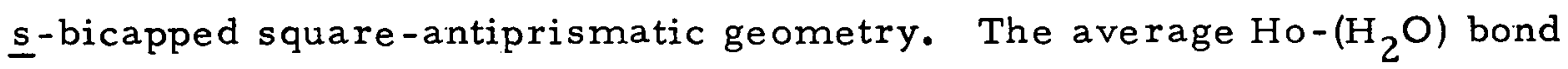
length is $2.36 \AA$ and the Ho-(bicarbonate oxygen) lengths vary from 2.442 (9) 
to 2.557 (9) $\AA$ with the exception of one distance (2.817 (11) $\AA$ ) which appears to have been lengthened due to steric repulsion effects. Extensive intermolecular hydrogen bonding is also prevalent and has been characterized.

CRYSTAL STRUCTURE OF POTASSIUM PENTACHLOROANTIMONATE(III) R. K. Wismer and R. A. Jacobson

Inorg. Chem. 13: 1678 (1974)

Abstract--The crystal structure of potassium pentachloroantimonate(II) $\left(\mathrm{K}_{2} \mathrm{SbCl}_{5}\right.$, monoclinic, $\underline{\mathrm{P}}^{2}{ }_{1} / \underline{\mathrm{c}}, \underline{\mathrm{a}}=8.8686$ (07) $\hat{\mathrm{A}}, \underline{\mathrm{b}}=12.4577$ (13) $\hat{\mathrm{A}}$, $c=8.9280(13) \AA, \beta=110.512(11)^{\circ}, \underline{\underline{Z}}=4$, Mo $\mathrm{K}_{\alpha} \alpha$ radiation) has been determined by three-dimensional $\mathrm{x}$-ray analysis. The structure was solved by conventional Patterson and Fourier techniques and refined by full-matrix least squares to a final conventional discrepancy factor of 0.055 for the 1546 observed reflections. The $\mathrm{SbCl}_{5}{ }^{2}$ - anion displays a distorted square-pyramidal configuration in which the axial antimonychloride bond $(2.385$ (2) $\AA$ ) is shorter than the mean basal antimony chloride bond. Two of the four basal antimony-chloride bonds (2.622 (2), 2.625 (2) $\AA$ ) are undistorted while the other two basal bonds (2.799 (2), $2.509(2) \AA$ ) are distorted by interionic and packing forces.

A NEUTRON-DIFFRACTION STUDY OF HOLMIUM ETHYLSULFATE ENNEAHYDRATE BY THE WHITE-RADIATION METHOD

C. R. Hubbard, C. O. Quicksall and R. A. Jacobson Acta Cryst. B30: 2613 (1974)

Abstract--l'he structure of holmium cthylsulfale ensualiyiliale lias been studied by the white-radiation neutron-diffraction method. Of 703 intensities collected in two days at the Ames Laboratory $5 \mathrm{MW}$ reactor, 300 had $\underline{I}>3 \sigma_{I^{*}}$ Linear programming proved to be an improved technique compared with least-squares procedures for unfolding the observed Laue intensities. The phased Fourier map, calculated using the unfolded 
structure factors, clearly revealed all hydrogen-atom positions, and the resulting peak heights were proportional to the neutron scattering lengths. A subsequent comparison of the Fourier and least-squares hydrogen atomic positions revealed that the average and maximum deviations were 0.17 and $0.28 \AA$. The structure was refined with isotropic thermal parameters to a final $\underline{R I}_{\omega}=0.139$ and $\underline{\mathrm{RI}} \vec{\omega}^{>3 \sigma}=0.111$. Several improvements of the white-radiation method are suggested based on this study and previous results. The space group was confirmed to be $\underline{P} 6 / \mathrm{m}$. The holmium ion is at the center of a slightly distorted tricapped trigonal prism of water molecules. Each water oxygen is hydrogen bonded to two ethylsulfate ions. The hydrogen bonding and oxygen lone pair-lone pair interactions reduce the $\underline{D}_{3 \underline{h}}$ rare-earth ion site symmetry to $\underline{C}_{3 \underline{h}}$. The orientation of the two types of water molecules relative to the holmium is somewhat different as are as sociated $\mathrm{O}-\mathrm{H}$ distances $(0.92$ vs. $1.04 \AA)$.

X-RAY AND WHITE RADIATION NEUTRON DIFFRACTION STUDIES OF OPTICALLY ACTIVE POTASSIUM ANTIMONY TARTRATE, $\mathrm{K}_{2} \mathrm{Sb}_{2}\left(\mathrm{~d}-\mathrm{C}_{4}-\right.$ $\left.\mathrm{H}_{2} \mathrm{O}_{6}\right)_{2} \cdot 3 \mathrm{H}_{2} \mathrm{O}$ (TARTAR EMETIC)

M. E. Gress and R. A. Jacobson

Inorg. Chim. Acta 8: 209 (1974)

Abstract--The crystal structure of dipotassium di- $u$-d-tartrato (4) - bis(antimonate(III) trihydrate has been redetermined by three-dimensional $\mathrm{x}$-ray and white radiation neutron diffraction techniques. $\mathrm{K}_{2} \mathrm{Sb}_{2}-$ $\left(\mathrm{d}-\mathrm{C}_{4} \mathrm{H}_{2} \mathrm{O}_{6}\right)_{2} \cdot 3 \mathrm{H}_{2} \mathrm{O}$ crystallizes in space group $\mathrm{C} 222$ with $\underline{a}=11.192$ (2), $\underline{b}=11.696(3)$, and $\underline{c}=25.932(5) \AA . A$. Full-matrix least-squares refinement of the structure using $2779 \mathrm{x}$-ray intensities resulted in a conventional discrepancy factor of 0.078 . A linear programming technique was used to nbtain approximate neutron structure factors from the Laue intensities. 
The hydrogen atom positions were located by a Fourier map calculated using the derived structure factors phased by the $\mathrm{x}$-ray model.

In the unit cell are eight tartrato-(4)-bridged binuclear anions. The coordination of the quadridentate ligands to antimony is such that the more electronegative carboxyl oxygen atoms occupy axial positions and the hydroxyl oxygen atoms equatorial positions, with average bond lengths 2. 16 and $1.99 \AA$, respectively. The lengthening of the axial antimonyoxygen bond correlates well with similar differences in antimony-halide compounds. The water molecules are hydrogen-bonded to each other and to carboxyl oxygen atoms, and connect the antimony-tartrate anions in infinite sheets parallel to the $a-b$ plane.

\section{Interactions In Solids}

AN EPR STUDY OF $\mathrm{W}^{5+}$ IN A RECENTLY DISCOVERED TRICLINIC TUNGSTEN BRONZE, $\mathrm{Na}_{0 .} 3 \mathrm{WO}_{3}$

H. F. Mollet and B. C. Gerstein

J. Clieiri. Pliys. Co: 1440 (1974)

Abstract--A single crystal EPR study of $\mathrm{W}^{5+}$ in triclinic $\mathrm{Na} 0.33^{-}$ $\mathrm{WO}_{3}$, a recently discovered compound, has been carried out at about $15 \mathrm{~K}$ and $9.2 \mathrm{MHz}$. The EPR spectrum consists of two strong resonances and several weaker resonances whose relative intensities are sampledependent. The total $\mathrm{W}^{5+}$ concentration is approximately 1000 at. ppm. The principal $\mathrm{g}$-tensor components and the ${ }^{183} \mathrm{~W}$ hyperfine splitting constants for the two strong resonances are $\left|g_{1}\right|=1.695 \pm 0.003,\left|g_{2}\right|=$ $1.659 \pm 0.003,\left|\mathrm{~g}_{3}\right|=1.636 \pm 0.003\left[\mid \underline{A}_{2} \approx(61 \pm 8) \times 10^{-4} \mathrm{~cm}^{-1}\right]$ and $\left|\mathrm{g}_{1}\right|=$ $1.676 \pm 0.002,\left|g_{2}\right|=1.630 \pm 0.002,\left|g_{3}\right|=1.593 \pm 0.002\left[\left|\underline{A}_{3}\right| \simeq(52 \pm 4) \times 10^{-4}\right.$ $\mathrm{cm}^{-1}$ ] for resonance 1 and resonance 2 , respectively. The hyperfine 
splitting constants could only be determined in a few orientations because of either lack of resolution or interference of weaker resonances. It is proposed that the observed resonances are due to different $\mathrm{W}^{5+}$ point defects in the $\mathrm{Na}_{0.33} \mathrm{WO}_{3}$ host. This work represents the first evidence of $\mathrm{W}^{5+}$ in the tungsten bronzes.

INITIAL SUSCEPTIBILITY STUDY OF A MAGNETIC TRANSITION IN THE TWO DIMENTIONAL SYSTEM $\left(\mathrm{CH}_{3} \mathrm{NH}_{3}\right)_{2} \mathrm{MnCl}_{4} \cdot$ ABSORPTION AND DISPERSION IN THE NEIGH BORHOOD OF THE CRITICAL TEMPERATURE

B. C. Gerstein, K. Chang and R. D. Willett

J. Chem. Phys. 60: 3454 (1974)

Abstract--Magnetic susceptibility measurements on the layer structured system bis(methylammonium) tetrachloromanganate(II) re vealed a transition centered at $45.3 \mathrm{~K}$ and a broad maximum in the susceptibility at $80 \mathrm{~K}$. The critical exponents for the sharp transition were found to be $\gamma^{\prime}=2.39(7), \underline{T}<\underline{T}_{C^{\prime}}$ and $\gamma=2.90(13), \underline{T}>\underline{T}_{\underline{c}}$. The susceptibility was found to be field dependent below $\underline{\mathrm{T}}_{\underline{c}}$, with $(\partial \mathrm{X} / \partial \underline{\mathrm{H}}) \underline{\mathrm{T}}^{>0}$.

THE LOW-TEMPERATURE HEAT CAPACITY OF 1965-CALORIMETRYCONFERENCE COPPER: A COMPARISON WITH PREVIOUS RESULTS M. Hurley and B. C. Gerstein

J. Chem. Thermorynamics 6: 787 (1974)

A.bstract--The heat capacity of a sample of 1965-CalorimetryConference copper obtained from Argonne National Laboratory (Argonne Designation "T-6.2") has been measured from 0.63 to $27.85 \mathrm{~K}$. The results are compared with those of four previous measurements on copper in this temperature range. 
NT -03

MAGNETIC SUSCEPTIBILITY STUDY OF $\phi_{4} \mathrm{AsCuCl}_{3}$ : AN EXAMPLE OF A. $\mathrm{Cu}_{2} \mathrm{Cl}_{6}^{2-}$ DIMER WITH A. GROUND STATE TRIPLET

C. Chow, R. Caputo, R. D. Willett and B. C. Gerstein

J. Chem. Phys. 61: 271 (1974)

Abstract--The magnetic susceptibility data for $\phi_{4} \mathrm{AsCuCl}_{3}$ is pre-

sented. The data are consistent with the existance of isolated $\mathrm{Cu}_{2} \mathrm{Cl}_{6}^{2-}$ dimers with a $\underline{S}=1$ ground state. A singlet state lies $46 \mathrm{~cm}^{-1}$ above the ground state.

AN X-RAY, SPECTROSCOPIC, AND MAGNETIC STUDY OF THE STRUC-

TURE OF NICKEL SQUARATE DIHYDRATE, $\mathrm{NiC}_{4} \mathrm{O}_{4} \cdot 2 \mathrm{H}_{2} \mathrm{O}$
M. Habenschuss and B. C. Gerstein

J. Chem. Phys. 61: 852 (1974)

Abstract--The structure of nickel squarate dihydrate, $\mathrm{NiC}_{4} \mathrm{O}_{4} \cdot 2 \mathrm{H}_{2} \mathrm{O}$ has been investigated by initial susceptibility measurements, infrared spectroscopy, and single crystal $x$-ray diffraction techniques. The results indicate that the structure consists of $\mathrm{Ni}$ ions situated at the centers of the edges of a cube, with squarate ions in the cube faces. Each nickel is roughly octahedrally coordinated by four squarale oxygens, and by two water oxygens. The lattice constants were found to be $\underline{\mathrm{a}}=\underline{\mathrm{b}}=\underline{\mathrm{c}}=8.068_{5} \mathrm{~A}$. with $\alpha=\beta=\gamma=$ $90^{\circ}$. within experimental accuracy. The structure was found to be noncubic. A. spin-orbit coupling parameter of $-280(30) \mathrm{cm}^{-1}$, which is $86 \%$ of the frec ion value, is obtained from the magnetic and spectroscopic results. The structure of this compound, which is isostructural with the $\mathrm{Mn}$ (II), $\mathrm{Fe}$ (II), and $C O(I I)$ squarates, is different than that proposed by two other sets of workers. All crystals investigated were found to be macroscopically twinned, and a reason for such twinning is proposed. 
III. Low Oxidation State in Solid and Molten Systems

STRUCTURAL DIAGNOSIS OF CHLOROALUMINATE COMPOUNDS BY CHLORINE-35 NUCLEAR QUADRUPOLE RESONANCE SPECT ROSCOPY D. J. Merryman, P. A. Edwards, J. D. Corbett, and R. E. McCarley Inorg. Chem. 13: 1471 (1974)

Abstract--The ${ }^{35} \mathrm{Cl}$ nqr spectra at room temperature are reported for chloroaluminate groups in $\mathrm{Te}_{4}\left(\mathrm{AlCl}_{4}\right)_{2}, \mathrm{ICl}_{2} \mathrm{AlCl}_{4}, \mathrm{Bi}_{5}\left(\mathrm{AlCl}_{4}\right)_{3}$, $\mathrm{Co}\left(\mathrm{AlCl}_{4}\right)_{2}, \mathrm{Hg}\left(\mathrm{AlCl}_{4}\right)_{2}$, and $\mathrm{Te}_{4}\left(\mathrm{Al}_{2} \mathrm{Cl}_{7}\right)^{\prime}$. These and the literature data for $\mathrm{NaAlCl} 4$, GaAlCl 4 , and $\mathrm{SCl}_{3} \mathrm{AlCl}_{4}$ are compared for known and probable structures. The transitions of relatively free $\mathrm{AlCl}_{4}{ }^{-}$groups in "ionic" compounds are found to average $10.6-11.3 \mathrm{MHz}$ with a range of $\leq 1 \mathrm{MHz}$ for the individual compounds. Strong coordination of $\mathrm{AlCl}_{4}{ }^{-}$to the cation (e. g. , $\mathrm{Co}^{2+}, \mathrm{Hg}_{3}{ }^{2+}$ ) or the formation of $\mathrm{Al}_{2} \mathrm{Cl}_{7}$ - anions is reflected in an elongation of the bridging aluminum-chlorine bonds and in appreciable increases in both the range and the average frequency of the chlorine transitions. The effects of bridging on the halogen nqr transitions are considered and compared with those for the aluminum and gallium halide dimers $\mathrm{M}_{2} \mathrm{X}_{6}$.

SYNTHETIC AND NUCLEAR QUADRUPOLE RESONANCE STUDY OF CHLORODIIODINIUM HEXACHLOROANTIMONATE(V), $\mathrm{I}_{2} \mathrm{Cl}^{+} \mathrm{SbCl}_{6}{ }^{-}$ D. J. Merryman and J. D. Corbett Irüg. Chem. 13: 1258 (1974)

Abstract--The work reported herein demonstrates that the only solid phase stable at room temperature in the system $\mathrm{I}_{2}-\mathrm{ICl}-\mathrm{SbCl}_{5}$ is $2 \mathrm{ICl} \cdot \mathrm{SbCl}_{5} \cdot$ This compound exhibits an unusually strong nqr spectrum for all isotopes possible $\left({ }^{35} \mathrm{Cl},{ }^{37} \mathrm{Cl},{ }^{121} \mathrm{Sb},{ }^{123} \mathrm{Sb},{ }^{127} \mathrm{I}\right)$ which allows appreciable information to be deduced regarding not only its formulation as $\mathrm{I}_{2} \mathrm{Cl}^{+} \mathrm{SbCl}_{6}{ }^{-}$but also interactions in the solid structure. 


\section{Chemistry of Heavy Transition Metals}

CHEMISTRY OF POLYNUCLEAR METAL HALIDES. XI. CRYSTAL AND MOLECULAR STRUCTURE OF TRIS(TETRAMETHYLAMMONIUM)

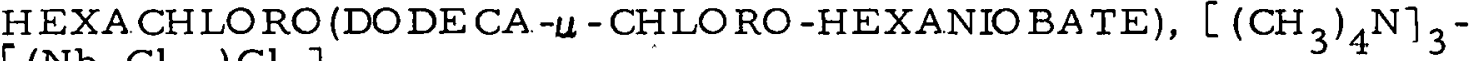
$\left[\left(\mathrm{Nb}_{6} \mathrm{Cl}_{12}\right) \mathrm{Cl}_{6}\right]$

F. W. Koknat and R. E. McCarley

Inorg. Chem. 13: 295 (1974)

Abstract-- The structure of the new compound $\left[\left(\mathrm{CH}_{3}\right)_{4} \mathrm{~N}\right]_{3}\left[\left(\mathrm{Nb}_{6}-\right.\right.$ $\left.\mathrm{Cl}_{12}\right)^{\mathrm{Cl}_{6}} \mathrm{l}$ was determined by single-crystal $\mathrm{X}$-ray methods and refined to a conventional $\underline{\mathrm{R}}$ factor $\underline{\underline{R}}_{1}=0.069$. The compound crystallizes in the trigonal-rhombohedral space group $\underline{\mathrm{R}} 3$ with $\underline{\mathrm{a}}_{\text {trig }}=11.408 \pm 0.005$ and $\underline{c}_{\text {triy }}=30.31 \pm 0.01 \AA$, and three formula units in the trigonal unit cell. It contains a close-packed cubic arrangement of $\left[\left(\mathrm{Nb}_{6} \mathrm{Cl}_{12}\right)_{\mathrm{Cl}_{6}}\right]^{3-}$ complex cluster anions which are based on $\left(\mathrm{Nb}_{6} \mathrm{Cl}_{12}\right)^{3+}$ central cations. The tetramethylammonium cations occupy all tetrahedral and octahedral holes of this arrangement. Slight deviations of the $\left(\mathrm{Nb}_{6} \mathrm{Cl}_{18}\right)^{3-}$ anion from strict octahedral symmetry are apparently caused by the packing of the $\left(\mathrm{Nb}_{6} \mathrm{Cl}_{18}\right)^{3-}$ and $\left(\mathrm{CH}_{3}\right)_{4} \mathrm{~N}^{+}$units. Important average bond distances are

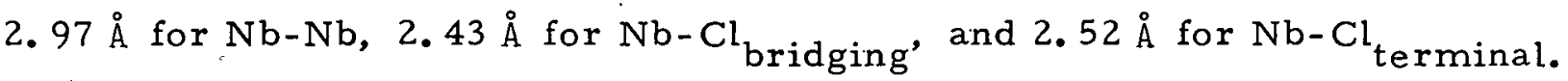
Comparison of these data with values reported for $\mathrm{K}_{4} \mathrm{Nb}_{6} \mathrm{Cl}_{18}$ and $\left[\left(\mathrm{CH}_{3}\right)_{4}^{-}\right.$ $\mathrm{N}]_{2}\left[\left(\mathrm{Nb}_{6} \mathrm{Cl}_{12}\right) \mathrm{Cl}_{6}\right]$ shows that $\mathrm{Nb}-\mathrm{Nb}$ distances increase gradually and that $\mathrm{Nb}-\mathrm{Cl}_{\text {terminal }}$ distances decrease gradually upon stepwise removal of

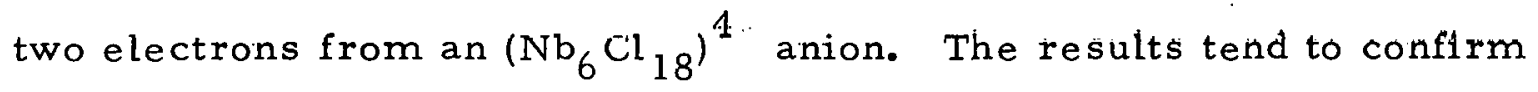
that the two electrons are taken from a bonding MO centered primarily on the metal atoms. 
CHEMISTRY OF THE POL YNU CLEAR METAL HALIDES. XII. PREPARATION OF MOLYBDENUM AND TUNGSTEN $\mathrm{M}_{6} \mathrm{x}_{8}{ }^{4+}$ CLUSTERS BY REDUCTION OF HIGHER HALIDES IN MOLTEN SODIUM HALIDE-ALUMINUM HALIDE MIXTURES

W. C. Dorman and R. E. McCarley

Inorg. Chem. 13: 491 (1974)

Abstract--The aluminum reduction of the higher molybdenum or tungsten halides in the appropriate sodium tetrahaloaluminate melt is reported as a convenient and safe procedure for the preparation of the corresponding molybdenum and tungsten(II) chlorides and bromides in good yields.

\section{NT-03-03-02}

\section{Engineering Chemistry}

THE HIGH TEMPERATURE HEAT CONTENT OF LIQUID YTTRIUM BY LEVITATION CALORIMETRY

L. A. Stretz and R. G. Bautista

Met. Trans. 5: 921 (1974)

A.bstract--A. $15 \mathrm{kva}, 450 \mathrm{khz}$ radio-frequency generator was used to levitate and melt yttrium samples ranging from 0.5 to $2 \mathrm{~g}$ in an inert atmosphere before being dropped into a copper block drop calorimeter contained in is othermal surroundings. The yttrium data were fitted by the following equation where the indicated errors were obtained from the average deviation of the data from the values predicted by the equation:

$$
\underline{\mathrm{H}}_{\mathrm{T} / \mathrm{mol}}-\underline{\mathrm{H}}_{298.15}=[39.725 \pm 0.544](\underline{\mathrm{T}}-1799)+[64,116.655 \pm 163.285]
$$

for $1799<\underline{T}<2360 \mathrm{~K}$. Heat contents measured with the system were corrected for convection and radiation heat losses during the fall of the sample from the levitation chamber into the calorimeter. The maximum estimated error for the levitation calorimetry method was \pm 2.5 pct. 
ANALYTICAL METHODS FOR CHARACTERIZATION OF FLY ASH D. C. Cavin, W. A. Klemm and G. Burnet

Proc. Iowa Acad. Sci. 81: 130 (1974)

Abstract--A typical power plant fly ash was characterized according to its composition and physical properties as a bas is for research on iron and aluminum recovery from the ash. The methods used are standard and require facilities and instruments available in many laboratories today. The procedures include photomicroscopic observation, size separation, magnetic separation, X-ray diffraction, thermal gravimetric analysis, differential thermal analysis, electron microprobe analysis and emission spectroscopy. The results will be useful in determining in what ways and under what conditions a given fly ash may be treated to recover the metals present in a usable form. Preliminary work has been done on a sulfuric acid leaching process and on a lime sintering process patterned after exploratory studies reported from Poland in 1973.

PREDICTING THE SURFACE TENSION OF LIQUID METALS

D. R. Sagentan and $G$. Burnet

J. Inorg. Nucl. Chem. 36: 1105 (1974)

Abstract-- The recent availability of more complete and reliable surface tension data for molten metals has led the authors to seek a general surface tension correlation which would include other fundamental properties of the molten metals. The relationship proposed has a thermodynamic basis and relates the surface tension of a molten metal to its heat of vaporization and ionic radius. Based on data reported by several investigators, the error in the calculated value of surface tensinn is less than ten per cent in the melting point region. 


\title{
NT-03-03-03
}

\section{High Temperature and Surface Chemistry}

\author{
I. High Temperature Chemistry
}

HIGH TEMPERATURE MASS SPECTROMETRY, VAPORIZATION, AND THERMODYNAMICS OF VANADIUM MONOSULFIDE

T. P. Owzarski and H. F. Franzen

J. Chem. Phys. 60: 1113 (1974)

Abstract--A high temperature mass spectrometric investigation of the congruent vaporization of vanadium monosulfide, VS(s), from 1700 to $2000 \mathrm{~K}$ has shown that the two principal vaporization reactions produce $V S(g)$ and $V(g)+S(g)$ with a minor contribution from the reaction to produce $\mathrm{VS}_{2}(\mathrm{~g})+\mathrm{V}(\mathrm{g})$. Thermodynamic results were obtained from th ree investigations of the congruent vaporization of the stoichiometric monosulfide. The second law enthalpy changes for the vaporization reactions at absolute zero were calculated from the experimental data and by use of a measured low temperature heat capacity for VS(s), estimated heat capacities for the solid above room temperature and for the vapor molecules, and literature values for the heat capacities of the atomic species. The $\Delta H_{0}^{\circ}$ values obtained and the estimated uncertainties are: $143 \pm 3 \mathrm{kcal}$ for the reaction to form VS(g), $259 \pm 5 \mathrm{kcal}$ for the reaction to form V(g) $+\mathrm{S}(\mathrm{g})$, and $144 \pm 5$ kcal for the reaction to form $\frac{1}{2} \mathrm{VS}_{2}(g)+\frac{1}{2} \mathrm{~V}(\mathrm{~g})$. Ionic fragmentation of $\mathrm{VS}^{+}$ is considered and shown to be unimportant. Approximate third-law calculations of partial pressures of the important species are reported and the results are shown to be in acceptable agreement with the observed ion intensities. 
PHASE TRANSITIONS BETWEEN NiAs - AND MnP-TYPE PHASES H. F. Franzen, C. Haas, and F. Jellinek

Phys. Rev. B 10: 1248 (1974)

Abstract--The Landau theory of phase transitions is applied to the case of a transition from $\underline{D}_{6}^{4}$ symmetry to $\underline{D}_{2 \underline{h}}^{16}$ symmetry. The restraints placed upon various thermodynamic quantities by the symmetry change are reported. It is shown that the $\mathrm{MnP}$-type structure (space group $\underline{\mathrm{D}}_{2 \mathrm{~h}}^{16}$ ) and the low-temperature form of NbS (space group $\underline{C}_{6}^{4}$ ) are related dis tortions, as both correspond to the same irreducible representation $\mathrm{M}_{4}^{-}$of the NiAs-type structure (space group $\underline{D}_{6 \mathrm{~h}}^{4}$ ).

PREPARATION AND STRUCTURE DETERMINATION OF Ti $\mathrm{S}_{3}$ J. P. Owens and H. F. Franzen

Acta Cryst. B30: 427 (1974)

Abstract-- $\mathrm{Ti}_{8} \mathrm{~S}_{3}$, is monoclinic $\underline{\mathrm{C}} 2 / \underline{\mathrm{m}}$, $\underline{\mathrm{a}}=32 \cdot 69$ (1), $\underline{\mathrm{b}}=3 \cdot 327$

(2), $\underline{c}=19 \cdot 36(2) \AA, \beta=139 \cdot 9(5)^{\circ}, \underline{V}=1356(7) \AA^{3}$. The structure was determined by single-crystal methods and refined to $\underline{R}=0.08$ by leastsquare calculations. The composition was deduced from the structure. There are a great many structural similarities between $\mathrm{Ti}_{8} \mathrm{~S}_{3}$ and $\mathrm{Ti}_{2} \mathrm{~S}$.

EFFECT OF SURFACE CONDITIONS ON THE NORMAL SPECTRAL EMITTANCE OF TITANIUM AND ZIRCONIUM BETWEEN 1000 AND $1800 \mathrm{~K}$ D. N. Baria and R. G. Bautista Met. Trans. 5: 555 (1974)

Abstract--The normal spectral emittance of $\mathrm{Ti}$ and $\mathrm{Zr}$ was obtained in the temperature range 1100 to $1800 \mathrm{~K}$ and wavelength $0.645 u$ for electrochemically polished, mechanically polished and 60 grit ground surfaces at a pressure below $10^{-6} \mathrm{~mm} \mathrm{Hg}$. The emittance at the melting point of both metals was obtained by extrapolation of an empirical equation fitted to the experimental data obtained for the electrochemically polished 
NT -03

surface and was found to be in good agreement with reported values. The considerable grain growth on the surface affected the emittance. The emittance was found to increase with temperature up to $1300 \mathrm{~K}$ and then decrease with further increase in temperature.

THE EFFECT OF SURFACE FINISH ON THE NORMAL SPECTRAL EMITTANCE OF MOLYBDENUM BETWEEN 1000 AND $2400 \mathrm{~K}$

D. N. Baria, T. S. King and R. G. Bautista Met. Trans. 5: 1543 (1974)

Abstract--The normal spectral emittance $(\lambda=0.645 \mathrm{um})$ of molybdenum was determined for electrochemically polished, mechanically polished, and 60 grit ground surfaces between 1000 and $2400 \mathrm{~K}$ at pressures below $10^{-6}$ torr. An empirical equation of the type $\epsilon_{n \lambda}=\underline{A T} \underline{B} \exp \underline{\mathrm{CT}}$ was fitted separately to the data obtained during the heating and the cooling cycles for each of the three surface finishes studied.

NORMAL SPECTRAL EMITTANCE OF VANADIUM AND TANTALUM FOR DIFFERENT SURFACE CONDITIONS AT TEMPERATURES ABOVE $1000 \mathrm{~K}$

D. N. Baria and R. G. Bautista

Met. Trans. 5: 1543 (1974)

Abstract--The normal spectral emittance $(\lambda=0.645 \mu)$ was determined for vanadium between 1100 and $1750 \mathrm{~K}$ and for tantalum between 1200 and $2600 \mathrm{~K}$, at pressures below $10^{-6} \mathrm{~mm} \mathrm{Hg}$ for electrochemically and mechanically polished surfaces. The emittance was found to decrease with increase in temperature. It was also lower for the electrochemically polished surface. An empirical equation was fitted to the experimental data, and it was used to predict the emittances up to the melting points. 


\section{Surface Chernistry}

KINETIC MODEL FOR DISSOCIATIVE ADSORPTION OF A DIATOMIC GAS K. J. Vette, T. W. Orent, D. K. Hoffman, and R. S. Hansen

J. Chem. Phys. 60: 4854 (1974)

Abstract--A general kinetic formulation is given for the adsorption, desorption, and skating of adatoms formed by the dissociative adsorption of a diatom onto a general, two-dimensional lattice. This formulation is then specialized to include only irreversible adsorption without skating or desorption. This problem is solved exactly for the linear array and is solved by successive approximations for primitive lattices of three, four, and sixfold symmetry. For practical purposes, results, which are in satisfactory agreement with limiting results, could be obtained by an analysis limited to the first and second shells of sites around a given site. Limiting fractional surface coverages, which are due to isolated, empty sites surrounded by filled sites, are given for all lattices. Results agree well with Monte Carlo experiments on square lattices. Results for irreversible adsorption without skating are readily adaptable to the problem of irreversible desorption without skating. 


\title{
NT-04 \\ MOLECULAR SCIENCES
}

\section{NT-04-01 \\ Radiation and Separations Research}

\author{
NT-04-01-01 \\ Radiation Sciences
}

I. Photochemistry and Spectroscopy

DEPENDENCE OF IMPURITY ZERO-PHONON BAND THERMAL BROAD- . ENING AND SHIFT ON IMPURITY SITE AND VIBRON LEVEL IN ORGANIC CRYSTALS

F. P. Burke and G. J. Small

Chem. Phys. ㅁ: 198 (1974)

Abstract--Experimental results on the thermal broadening and shifts of impurity zero-phonon bands in some organic mixed crystals are reported and interpreted in terms of the electron-phonon interaction. Attention is focused on the variation of the thermal broadening and line shift parameters with (1) impurity site in a system exhibiting several energetically different impurity sites and with (2) the vibron level in a given final electronic state of the impurity. Experiments were conducted over a temperature range which ensures that hot vibron transitions are negligible. Data from the $5600 \AA^{1} B_{1} \leftarrow{ }^{1} A_{1}$ transition of 2 -phenyl-1monoazaazulene in $\mathrm{p}$-terphenyl show that the variations of the above parameter's with impurity site are as large as the variations of the same between different chemical systems. No dependence of the thermal broadening art 
parameters on the impurity vibron level is observed for the above system or the $7000 \AA{ }^{1} \underline{B}_{1}-{ }^{1} \underline{A}_{1}$ transition of azulene in naphthalene. It is shown that, within the adiabatic (electron-nucleus) and harmonic approximations, the zero-phonon band spectral shape function arising from the electronphonon interaction should be independent of the final vibron level of the impurity transition.

DEPENDENCE OF IMPURITY ZERO-PHONON THERMAL BROADENING ON VIBRON LEVEL IN ORGANIC CRYSTALS: A MANIFESTATION OF THE CRYSTAL ANHARMONICITY

F. P. Burke and G. J. Small

J. Chem. Phys. 61: 4588 (1974)

Abstract--Thermal broadening data on the zelu-pliunun impurity bands in the $4500 \AA{ }^{1} \underline{B}_{1}-{ }^{1} \underline{A}_{1}$ and $3500 \AA{ }^{1} \underline{A}_{1} \div{ }^{l} \underline{A}_{1}$ absorption systems of 1,3-diazaazulene and azulene in a naphthalene host are reported. For both systems, a marked dependence of the thermal broadening on the final impurity vibron level of the transition is observed. The broadening for all fundamental vibron bands studied is smaller than the broadening of the origin or zero-vibron band. This fact allows one to attribute the above vibron level dependence to a specific anharmonic interaction term (a) guartic mixed vibron-phonon term). It is this term which describes the dependence of the quadratic off-diagonal electron-phonon coupling on impurity vibron level. Apparently the vibron-phonon anharmonic terms which lead to temperature dependent vibron relaxation processes are negligible. We report also the unexpected observation of a dependence of zerophonon band the rmal broadening on crystal samples. No correlation between this dependence and residual width is observed. 
VIBRONIC EFFECTS IN THE $7000 \AA$ STATE OF AZULENE G. J. Small and S. Kusserow

J. Chem. Phys. 60: 1558 (1974)

Abstract--Vibronic perturbations in the $7000 \AA \underline{S}_{1}\left(\underline{B}_{1}\right)-\underline{S}_{0}\left(\underline{A}_{1}\right)$ absorption system of azulene due to a large number of $\underline{b}_{1}$ vibrations have been identified. The total induced oscillator strength for this transition is $1.2 \times 10^{-3}$ while the allowed oscillator strength is $7.8 \times 10^{-3}$. Accurate intensities for the $\underline{b}_{1}$ vibronic origins relative to the allowed origin are reported. Calculations are presented which indicate that the two most probable coupling routes for the vibronic interactions (intensity) involve the second excited ${ }^{1} \underline{A}_{1}$ state $\left(\underline{S}_{4}\right)$ and the ground state, $\underline{S}_{0}$. The latter route exists due to the large change in permanent dipole moment between $\underline{S}_{0}$ and $\underline{S}_{1}, \sim 2$ D. Assignments for all 12 of the excited state $\underline{-}_{1}$ fundamentals (excluding $\mathrm{CH}$ ) are given. The differences between the $7000 \AA$ $\underline{B}_{1}-{ }^{1} \underline{A}_{1}$ and $3500 \AA{ }^{1} \underline{A}_{1}-{ }^{1} \underline{A}_{1}$ absorption systems are discussed in relation to the anomalous fluorescence behavior of azulene.

II. Radiation and Solid State Spectroscopy

EVIDENCE FOR EXTENDED INTERACTIONS BETWEEN METAL ATOMS FROM ELECTRONIC SPECTRA OF CRYSTALS WITH SQUARE COMPLEXES D. S. Martin, Jr. Extended Interactions Between Metal Ions in Transition Metal Complexes, ACS Symposium Series No. 5, (A.merican Chemical Society. 1974) pp. $254-275$

Abstract--Frequently, the square-planar molecular or ionic complexes of platinum(II) or palladium(II) in crystals are aligned directly over one another in one dimensional stacks. The electronic absorption spectra of the crystals for polarized light in favorable circumstances provide information about the crystal interactions and possible intermolecular 
electron transfers in the solid state. For crystals with large metalmetal separations, $>4.1 \AA$, the d-d spectra correlate closely in energies and intensities with solution spectra. The spectra of crystals with $\mathrm{Pt}_{2}-$ $\mathrm{Br}_{6}{ }^{2-}$ are consistent with large energy shifts of Frenkel excitons by crystal effects. However, for some molecular complexes with separations of 3.4-3.5 $\AA$, electron transfers to ionic exciton states occur.

PQLARIZED CRYSTAL ABSORPTION SPECTRA AND CRYSTAL STRUCTURE FOR POTASSIUM TETRABROMOPLATINATE(II)

R. F. Kroening, R. M. Rush, D. S. Martin, Jr. and J. C. Clardy Inorg. Chem. I3: 1366 (1974)

Abstract--Crystals of anhydrous $\mathrm{K}_{2} \mathrm{PtBr}_{4}$ have the tetragonal

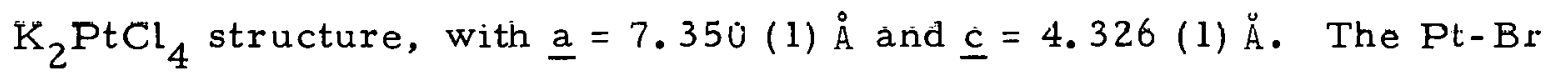
bond length is 2.445 (2) $\AA$. Spectra for single crystals have been recorded at 300 and $15^{\circ} \mathrm{K}$ and in aqueous solution. For $\mathrm{K}_{2} \mathrm{PtBr}{ }_{4}$ crystals the $\mathrm{d} \leftarrow \mathrm{d}$ transitions occur at $1500-2000 \mathrm{~cm}^{-1}$ lower energy than for the corresponding transitions in $\mathrm{K}_{2} \mathrm{PtCl}_{4}$. The ratios of $\underline{a}-\underline{x}, \underline{y}: \underline{c}-\underline{z}$ intensities for the $\mathrm{d}-\mathrm{d}$ transitions are greater for $\mathrm{K}_{2} \mathrm{PtBr}_{4}$ than for $\mathrm{K}_{2} \mathrm{PtCl}_{4}$. Vibrational structure at $15^{\circ} \mathrm{K}$ was resolved for two of the $\mathrm{d}-\mathrm{d}$ bands but for no others. The ${ }^{1} A_{2 g} \leftarrow{ }^{1} A_{1 g}$ transition was identified by its absence from the $\subseteq$ polarization spectrum. The crystal spectra indicate that intense transitions in the solution spectrum at 34,200 and $37,200 \mathrm{~cm}^{-1}$ must occur with a $-\underline{x}, y$ polarization and the first ${ }^{1} A_{2 u}$ state cannot occur below $48,000 \mathrm{~cm}^{-1}$. The two intense bands are attributed to a ${ }^{l} E_{u}$ state and a triplet state whose components in the $E^{\prime} l_{u}$ irreducible representation of the double group, $\underline{D}_{4}^{\prime}$, mix with ${ }^{1} E_{g}$ by spin-orbit coupling. A weak transition at $30,500 \mathrm{~cm}^{-1}$ in both $\underline{a}$ and $\underline{c}$ polarization appears to be dipole allowed by its temperature dependence and has been assigned as ${ }^{3} E_{u}$. 
NT -04

NT-04-01-02

\section{Separations Research}

DISTRIBUTION COEFFICIENT CORRELATIONS FOR PREDICTING THE EXTRA.CTION EQUILIBRIA OF LUTETIUM-YTTERBIUM AND LUTETIUM-THULIUM BINARY RARE EARTH MIXTURES BETWEEN DI(2-ETHYLHEXYL) PHOSPHORIC ACID IN AMSCO AND AQUEOUS HYDROCHLORIC ACID SOLUTIONS

N. E. Thomas and L. E. Burkhart Ind. Eng. Chem. Fundam. 13: 366 (1974)

Abstract--Equilibrium data were obtained for the extraction of the binary rare earth mixtures lutetium-ytterbium and lutetium-thulium from $5 \mathrm{M} \mathrm{HCl-H_{2 }} O$ solutions by $1 \underline{M}$ di(2-ethylhexyl) phosphoric acid in Amsco odorless mineral spirits. The separation factors for the above binary mixtures were substantially constant with respect to mixture composition, the arithmetic averages for $\beta_{\mathrm{Lu}}, \mathrm{Tm}$ and $\beta_{\mathrm{Lu}, \mathrm{Yb}}$ being 6.96 and 1.82, respectively. Empirical correlations for predicting total distribution coefficients for the Lu-Yb and Lu-Tm mixtures were developed. These correlations are comparable to one developed earlier for $\mathrm{Yb}-\mathrm{Tm}$ mixtures and have direct applications in the design and optimal control of heavy rare-earth fractionation columns in which di(2-ethylhexyl) phosphoric acid in Amsco and $\mathrm{HCl}$ in water are employed as liquid solvents.

THE EXTRACTION EQUILIBRIA OF LUTETIUM, YTTERBIUM AND THULIUM BETWEEN DI-(2-ETHYLHEXYL) PHUSPHORIC ACID IN AMSCO AND AQUEOUS HYDROCHLORIC ACID SOLUTIONS

N. E. Thomas and L. E. Burkhart

J. Inorg. Nucl. Chem. 36: 136 9 (1974)

Abstract--Single-component equilibrium data for the extraction of lutetium and ytterbium from aqueous hydrochloric acid solutions by 
$1 \mathrm{M}$ di-(2-ethylhexyl) phosphoric acid in Amsco Odorless Mineral Spirits were obtained over a wide range of equilibrium aqueous rare earth chloride concentrations and at an equilibrium aqueous acidity of $5 \mathrm{M} \mathrm{HCl}$. These data were compared with data taken earlier for thulium. The shapes of the organic-phase loading isotherms (or equilibrium curves) for Lu, Yb, and $\mathrm{Tm}$ are similar and have been interpreted on the basis of several prohable extraction reactions. Under the conditions studied, the extractability of the rare earths increased in the order $\mathrm{Tm}<\mathrm{Yb}<\mathrm{Lu}$. It was possible to correlate the data empirically in terms of total rare-earth metal concentrations.

FORMATION CONST ANTS OF SOME 1:1 AND 2:1 2,3-DIHYDROXY2-METHYLPROPANOATO AND 2, 3-DIHYDROXY - 2-METHYL BUTANOATO COMPLEX SPECIES OF DIVALENT TRANSITION METALS J. E. Powell and S. Kulprathipanja

Inorg. Chim. Acta 11: 31 (1974)

Abstract--Stability constants of the complex species formed between $\mathrm{Co}(\mathrm{II}), \mathrm{Ni}(\mathrm{II}), \mathrm{Cu}(\mathrm{II}), \mathrm{Zn}(\mathrm{II})$ and $\mathrm{Cd}(\mathrm{II})$ and the anions of 2,3 dihydroxy-2-methylpropanoic acid and 2,3 -dihydroxy-2-methylbutarioic acid were determined at an ionic strength of $0.100\left(\mathrm{KNO}_{3}\right)$ and $25^{\circ} \mathrm{C}$.

\section{HYDROMETALLURGY}

R. G. Bautista

T. B. Drew, G. R. Cokelet, J. W. Hoopes, Jr. and T. Vermeulen, eds., Advances in Chemical Engineering Vol. 9, (New York, Academic Press, 1974) pp. 1-110

Abstract--The important developments in the field of hydrometallurgy and its present potential as an active field of process engineering is critically examined. The decreasing supply of high grade ores that is normally used in pyrometallurgical processing of metals has made hydrometallurgical processing of low grade and complex ores a viable 
alternative in the production of metals. The subject matter covered in the review includes raw material preparation, leaching, separation and concentration processes, metal reduction from aqueous solutions, and industrial applications.

A THERMODYNAMIC ACTIVITY MODEL FOR A SINGLE LANTHANIDE NITRATE LIQUID-LIQUID EXTRACTION SYSTEM

W. G. O'Brien and R. G. Bautista

G. V. Jeffreys, ed., Proceedings, International Solvent Extraction Conference, held September 8-14, 1974 at Lyon, France Vol. 2 (London, Society of Chemical Industry, 1974) pp. 1399-1408

Abstract--A thermodynamic model for a single component extraction system has been developed by making use of the thermodynamic activity of the various species, the stability constants of the inorganic complexes formed and by defining the solvent extraction equilibrium constants. The liquid-liquid extraction of a lanthanide from an acidic lanthanide nitrate solution by di (2-ethylhexyl) phosphoric acid can be represented by the equation:

$$
\begin{aligned}
& K_{D}=\frac{\left[(\mathrm{HG})_{2}\right]_{0}}{\left[\mathrm{H}^{+}\right]_{\mathrm{A}}^{3} \quad\left\{1+\mathrm{K}_{1}\left[\mathrm{NO}_{3}^{-}\right]_{\mathrm{A}}+\mathrm{K}_{1} \mathrm{~K}_{2}\left[\mathrm{NO}_{3}^{-}\right]_{\mathrm{A}}^{2}\right\}} \\
& \left\{\mathrm{K}_{1}\left[(\mathrm{HG})_{2}\right]_{0}^{2}+\mathrm{K}_{2} \mathrm{~K}_{1}\left[\mathrm{NO}_{3}^{-}\right]_{A}\left[\mathrm{H}^{+}\right]_{A}\left[(\mathrm{HG})_{2}\right]_{0}+k_{3} \mathrm{~K}_{1} \mathrm{~K}_{2}\left[\mathrm{NO}_{3}^{-}\right]_{A}^{2}\left[\mathrm{H}^{+}\right]_{A}^{2}\right\}
\end{aligned}
$$

where $K_{D}$ is the distribution coefficient of the metallic species between the organic and the aqueous phase, $\left[\mathrm{H}^{+}\right]_{\mathrm{A}}$ the hydrogen ion activity in the aqueous phase, $\left[\mathrm{NO}_{3}^{-}\right]_{\mathrm{A}}$ the nitrate ion activity in the aqueous phase and $\left[(\mathrm{HG})_{2}\right]_{0}$ the activity of the di (2-ethylhexyl) phosphoric acid dimer in the 
the organic phase. The quantities $K_{1}$ and $K_{2}$ are the stability constants for the formation of the following lanthanide-nitrate complexes in the aqueous phase:

$$
\begin{aligned}
& \mathrm{M}^{+3}+\mathrm{NO}_{3}^{-} \stackrel{\mathrm{K}_{1} \longrightarrow \mathrm{MNO}_{3}^{+2}}{\longrightarrow} \mathrm{MNO}_{3}^{+2}+\mathrm{NO}_{3}^{-} \stackrel{\mathrm{K}_{2} \longrightarrow}{\longrightarrow} \mathrm{M}\left(\mathrm{NO}_{3}\right)_{2}^{+1}
\end{aligned}
$$

The quantities $\kappa_{1}, \kappa_{2}$ and $\kappa_{3}$ are the solvent extraction equilibrium constants for the various metallic species existing in the aqueous phase:

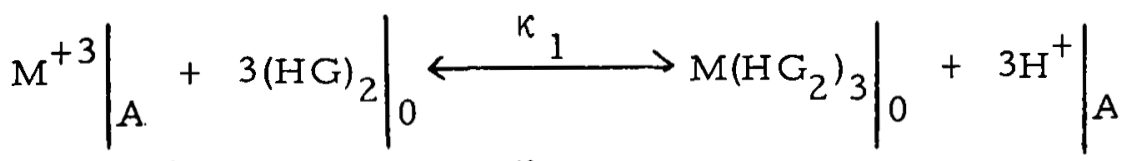

$$
\begin{aligned}
& \left.\mathrm{MNQ}_{3}^{+2}\right|_{\mathrm{A}}+2\left(\left.\left.\mathrm{HG}_{2}\right|_{0} \stackrel{\mathrm{K}_{2}}{\longleftrightarrow} \mathrm{MNO}_{3}\left(\mathrm{HG}_{2}\right)_{2}\right|_{0}+\left.2 \mathrm{H}^{+}\right|_{\mathrm{A}}\right. \\
& \left.\left.\mathrm{M}\left(\mathrm{NO}_{3}\right)_{2}^{+1}\right|_{A} \quad(\mathrm{HG})_{2} \underset{0}{\stackrel{\mathrm{K}_{3}}{\longleftrightarrow}} \mathrm{M}\left(\mathrm{NO}_{3}\right)_{2} \mathrm{HG}_{2}\right|_{0}+\left.\mathrm{H}^{+}\right|_{A}
\end{aligned}
$$




\section{NT-04-02 \\ Chemical and Geophysical Energy}

\section{NT-04-02-01}

\section{Chemical Energy}

I. Reaction Mechanisms of Organic and Bioinorganic Systems

BIMOLECULAR ALKYL TRANSFER BETWEEN CHROMIUM(II) AND THE 4-PYRIDINOMETHYL CH ROMIUM(III) CATION

J. H. Espenson and J. P. Leslie, II

J. A.m. Chem. Soc. 96: 1954 (1974)

Abstract--Radiotracer kinetics have established that the exchange of chromium atoms between $\left(\mathrm{H}_{2} \mathrm{O}\right)_{5} \mathrm{Cr}\left(4-\mathrm{CH}_{2} \mathrm{C}_{6} \mathrm{H}_{4} \mathrm{NH}\right)^{3+}$ (I) and $\mathrm{CR}_{\text {aq }}^{2+}$ takes place according to the second-order rate expression $\underline{\mathrm{R}}_{\mathrm{ex}}=\underline{\mathrm{k}}_{\mathrm{ex}}[\mathrm{I}]\left[\mathrm{Cr}^{2+}\right]$ with $\underline{\mathrm{k}}_{\mathrm{ex}}=5.8 \pm 0.1 \times 10^{-2} \underline{\mathrm{M}}^{-1} \mathrm{sec}^{-1}\left(55.0^{\circ}, 1.00 \mathrm{E} \mathrm{HClO}_{4}\right)$. The synthesis of I by the reaction of 4-pyridiomethylbromide with $\mathrm{Cr}^{2+}$ occurs according to the rate law $\mathrm{d}[\underline{I}] / \mathrm{dt}=\underline{\mathrm{k}}[\mathrm{RBr}]\left[\mathrm{Cr}^{2+}\right]$ with $\underline{\mathrm{k}}=16.9 \pm 0.7 \underline{\mathrm{M}}^{-1}$ $\sec ^{-1}$ under the same conditions. The former results are discussed in terms of an $\mathrm{S}_{\mathrm{H}} 2$ substitution mechanism at the saturated carbon atom for the exchange process, and both studies are related to the homolysis of I here and as a part of the decomposition reaction.

HOMOGENEOUS INORGANIC REACTIONS

J. H. Espenson

E. S. Lewis, ed., Techniques of Chemistry Vol. 6, Pt. 1 Chapter X (New York, John Wiley and Suns, 1974) pp. 541-618

Abstract--This chapter is concerned with the rates of inorganic reactions, including reactions of organometallic compounds, occurring in a homogeneous, liquid phase. The main emphasis has been placed on the methods and interpretations and concepts which have proved of the widest 
general importance and applicability in the study of inorganic reaction mechanisms.

INVERSION AT CARBON IN THE CLEAVAGE OF COBALT - CARBON BONDS BY MERCURIC ION

H. L. Fritz, J. H. Espenson, D. A. Williams, and G. A. Molander J. Am. Chem. Soc. 96: 2378 (1974)

Abstract--Deuterium-decoupled proton $\mathrm{nmr}$ measurements were used to establish the stereochemical course of (a) the conversion of threo- $\left(\mathrm{CH}_{3}\right)_{3} \mathrm{CCHDCHDOH}$ to erythro- $\left(\mathrm{CH}_{3}\right)_{3} \mathrm{CCHDCHDCo}(\mathrm{dmgH})_{2}$ py by reaction of the threo-p-bromobenzenesulfonate derivative with $\mathrm{Co}^{\mathrm{I}}(\mathrm{dmgH})_{2}-$ and (b) the conversion of the alkylcobaloxime to threo- $\left(\mathrm{CH}_{3}\right)_{3} \mathrm{CCHDCHDHgCl}-$ $\left(\underline{k}=1.9 \times 10^{-3} \underline{M}^{-1} \sec ^{-1}\right)$. Both reactions pruced will irversion of configuration at the $\alpha$-carbon atom.

KINETICS AND MECHANISM OF ALKYLCHROMIUM FORMATION IN THE REDUCTIVE COBALT - CARBON BOND CLEAVAGE OF ALKYL CORRINS BY CHROMIUM(II)

J. H. Espenson and T. D. Sellers, Jr.

J. Am. Chem. Soc. 96: 1 (1974)

A.bstract--The stoichiometry and kinctics of reactions of methyl and ethylcobalamin with $\mathrm{Cr}^{2+}$ in aqueous perchloric acid have been examined. These reactions occur with a $1: 1$ stoichiometry, producing $\left(\mathrm{H}_{2} \mathrm{O}\right)_{5} \mathrm{CrCH}_{3}{ }^{2+}$ and $\left(\mathrm{H}_{2} \mathrm{O}_{5} \mathrm{CrC}_{2} \mathrm{H}_{5}{ }^{2+}\right.$ (respectively), and $\mathrm{B}_{12} \mathrm{r}^{\circ}$ The reactions follow secondorder kinetics, the rate constants $\left(298^{\circ} \mathrm{K}, u \sim 1 \mathrm{M}\right)$ being $3.6 \pm 0.3 \times 10^{2}$ and $4.4+0.4 M^{-1}$ sec $^{-1}$. In the same medium $B_{12 a}$ is reduced by $\mathrm{Cr}^{2+}$ at a specific rate of $14.3 \pm 1.0 \underline{\mathrm{M}}^{-1} \mathrm{sec}^{-1}$. The reactions show no dependence upon $\mathrm{pH}$ in the range $0-2.3$. Activation parameters were determined. Two plausible mechanisms are proposed, one of which is a direct bimolecular homolytic attack ( $\left.\mathrm{SH}_{2}\right)$ at the saturated carbon center. 
KINETICS AND MECHANISM OF THE CLEAVAGE REACTIONS OF ALKYLCHROMIUM CATIONS WITH BROMINE

J. H. Espenson and D. A. Williams

J. Am. Chem. Soc. 96: 1008 (1974)

Abstract--Alkylpentaaquoch romium cations $\left(\mathrm{H}_{2} \mathrm{O}_{5} \mathrm{CrR}^{2+}(\mathrm{R}=\right.$ alkyl, haloalkyl, and 4-pyridinomethyl) undergo reaction with molecular bromine in aqueous perchloric acid solutions forming, in a reaction of 1: 1 stoichiometry, $\mathrm{Cr}\left(\mathrm{H}_{2} \mathrm{O}_{6}{ }^{3+}, \mathrm{Br}^{-}\right.$, and the alkyl bromide, $\mathrm{RBr}$. The reaction follows a mixed-second-order rate expression which can be interpreted in terms of an SE2 reaction mechanism, with an "open" transition state because $\mathrm{Cr}\left(\mathrm{H}_{2} \mathrm{O}\right)_{5} \mathrm{Br}^{2+}$ is not a product. On the basis of the variation in the rate constants for the alkyl derivatives, it is suggested that the stereochemical course of the reaction corresponds to inversion of configuration at carbon.

KINETICS OF SUBSTITUTION OF HEXACYANOMETALATES TRANS TO THE CARBON-COBALT BOND IN ETHYLAQUOBIS(DIMETHYLGL YOXIMATO)COBALT

J. H. Espenson and R. Russell

Inorg. Chem. 13: 7 (1974)

Abstract--Kinetic and equilibrium measurements, the former based upon stopped-flow determinations, are reported for the formation of a $1: 1$ adduct between $\mathrm{C}_{2} \mathrm{H}_{5} \mathrm{Co}(\mathrm{dmgH})_{2} \mathrm{H}_{2} \mathrm{O}$ and $\mathrm{M}(\mathrm{CN}) 6^{\underline{\mathrm{n}}-}$ complexes for $\mathrm{M}=\mathrm{Fe}(\mathrm{II})$, Co(III), Fe(III), and $\mathrm{Cr}(\mathrm{III})$. The product in each case corresponds simply to displacement of water, $\left[\mathrm{C}_{2} \mathrm{H}_{5} \mathrm{Co}(\mathrm{dmgH})_{2} \mathrm{NCM}^{\mathrm{CCN})_{5}}{ }^{\underline{n}-}\right]$, except that a slower secondary process was noted for $\mathrm{Cr}(\mathrm{CN})_{6}^{3-}$. The kinetic results are not consistent with a limiting SN 1 mechanism for all four reactions. A mechanism which is applicable to all the reactions involves the prior outer-sphere association of the alkylcobaloxime with $\mathrm{M}\left(\mathrm{CN}_{5}\right)^{-}$; followed by rote-determining loss of water. 
MECHANISM OF HALIDE SUBSTITUTION IN DICHLORO- $\downarrow$-TETRAPROPIONATO -DIRHENIUM(III)

T. R. Webb and J. H. Espenson

J. Am. Chem. Soc. 96: 6289 (1974)

Abstract--Kinetic and equilibrium measurements are reported for the reaction $\mathrm{Re}_{2}\left(\mathrm{C}_{2} \mathrm{H}_{5} \mathrm{CO}_{2}\right)_{4} \mathrm{Cl}_{2}+\mathrm{Br}^{-}=\mathrm{Re}_{2}\left(\mathrm{C}_{2} \mathrm{H}_{5} \mathrm{CO}_{2}\right)_{4} \mathrm{ClBr}+\mathrm{Cl}^{-}$ in acetonitrile. The reaction is reversible with $\underline{K}=(1.1 \pm 0.1) \times 10^{-2}$ at $25.0^{\circ}$. The forward rate constant in the anhydrous solvent is given by the expression $\underline{\mathrm{k}}_{\mathrm{f}}=\underline{\mathrm{A}}\left[\mathrm{Br}^{-}\right] /\left(\left[\mathrm{Cl}^{-}\right]+\underline{B}\left[\mathrm{Br}^{-} 1\right)\right.$ with $\underline{\mathrm{A}}=3.4 \times 10^{-5} \mathrm{sec}^{-1}$ and $\underline{B}=4.1 \times 10^{-2}$ at $25^{\circ}$, which is interpreted in terms of a two-step mechanism involving loss of $\mathrm{Cl}^{-}$prior to entry of $\mathrm{Br}^{-}$. The reaction is subject to strong catalysis by traces of neutral donor molecules including water. The second stepwise replacement of $\mathrm{Cl}^{-}$by $\mathrm{Br}^{-}$has an equilibrium constant determined only approximately as $(4 \pm 2) \times 10^{-3}$.

SUBSTITUENT EFFECTS IN ELECTROPHILIC CLEAVAGE REACTIONS OF FARA-SUBSTITUTED BENZYLPENTA-AQUOCHROMTIUM CATIONS RY MOLECULAR HALOGENS

T. C. Chang and J. H. Espenson

J. G.S. Ghem. rinmm. p. 233 (1974)

Abstract--The kinetics of the reaction of $\mathrm{p}-\mathrm{Z}-\mathrm{C}_{6} \mathrm{H}_{4} \mathrm{CH}_{2} \mathrm{Cr}\left(\mathrm{OH}_{2}\right)_{5}{ }^{2+}$ with halogens in aqueous solution obey a second-order rate expression in which $\underline{\mathrm{k}}_{2}$ follows the Hammett equation for $\mathrm{Br}_{2}(0=-1 \cdot 29)$ and $1_{2}(0=-0.81)$.

\section{Properties of Rare Earth Electrolytes}

APPARENT MOLAL VOLUMES OF SOME DILUTE AQUEOUS RARE EARTH SALT SOLUTIONS AT 25०

F. H. Spedding, P. F. Cullen and A. Habenschuss

J. Phys. Chem. 78: 1106 (1974)

Abstract--The apparent molal volumes, $\phi_{V}$, of aqueous solutions of La, Nd, Gd, and Lu perchlorate, Pr, Sm, Eu, Gd, Tb, Dy, Ho, Tm, 
and Lu nitrate, and Eu, Tm, and Lu chloride were determined from 0.0015 to about $0.15 \mathrm{~m}$ at $25^{\circ}$. The apparent molal volumes were calculated from the specific gravities determined by a magnetically controlled float. The concentration dependences of the apparent molal volumes showed significant deviations from the simple limiting law at the lowest concentrations measured. However, except for the light rare earth nitrates, they could be represented by the extrapolation function of Owen and Brinkley which includes the effect of the $\stackrel{\circ}{a}$ parameter. Including other available $\phi_{\mathrm{V}}$ data on the rare earth salts, La, Pr, Sm, Eu and Gd nitrate required an additional term in the extrapolation function to compensate for positive deviations, probably caused by complex formation. The deviation of $\phi_{\mathrm{V}}$ for $\mathrm{Nd}\left(\mathrm{NO}_{3}\right)_{3}$ was too large to allow use of the extrapolation function. When the apparent molal volumes at infinite dilution of a rare earth anion series are plotted against rare earth ionic radius, $\phi_{\mathrm{V}}{ }^{0}$ decreases from La to $\mathrm{Nd}$ and from $\mathrm{Tb}$ to $\mathrm{Lu}$ but increases from $\mathrm{Nd}$ to $\mathrm{Tb}$ with decreasing ionic radius. This variation was found to be independent of the anion. An analysis of the components comprising $\phi_{\mathrm{V}}{ }^{0}$ indicated that the trend was present in the term reflecting rare earth ion-water interactions. This is in agreement with the suggestion that a shift between two inner water coordination spheres of the rare earth ions occurs in the region from Nd to $\mathrm{Tb}$.

CONDUCTANCES, TRANSFERENCE NUMBERS, AND ACTIVITY COEFFICIENTS OF SOME AOUIEOIIS TFR RITIM HAT.IDF.S AT $25^{\circ} \mathrm{C}$

F. H. Spedding, R. A. Nelson, and J. A. Rard

J. Chem. Eng. Data 19: 379 (1974)

Abstract--The electrical conductances, transference numbers, activity coefficients, and densities of dilute aqueous solutions of $\mathrm{TbCl}_{3}$ 
and $\operatorname{TbBr}_{3}$ were measured at $25^{\circ} \mathrm{C}$. In addition, the dilute solution electrical conductances of aqueous $\mathrm{DyCl}_{3}$ were redetermined. Dilute solution electrical conductance data in the literature were reviewed, and a set of aqueous rare earth cation limiting conductances at $25^{\circ} \mathrm{C}$ is recommended.

ELECTRICAL CONDUCTANCES OF SOME AQUEOUS RARE EARTH ELECTROLYTE SOLUTIONS AT 25०. I. THE RARE EARTH PERCHLORATES

F. H. Spedding and J. A. Rard

J. Phys. Chem. 78: 1435 (1974)

Abstract--The electrical conductances of aqueous solutions of $\mathrm{La}\left(\mathrm{ClO}_{4}\right)_{3}, \mathrm{Nd}\left(\mathrm{ClO}_{4}\right)_{3}, \mathrm{Sm}\left(\mathrm{ClO}_{4}\right)_{3} \mathrm{Gd}\left(\mathrm{ClO}_{4}\right)_{3}, \mathrm{~Tb}\left(\mathrm{ClO}_{4}\right)_{3}, \mathrm{Dy}\left(\mathrm{ClO}_{4}\right)_{3}$, $\mathrm{Ho}\left(\mathrm{ClO}_{4}\right)_{3}, \operatorname{Er}\left(\mathrm{ClO}_{4}\right)_{3}, \operatorname{Tm}\left(\mathrm{ClO}_{4}\right)_{3}$ and $\mathrm{Lu}\left(\mathrm{ClO}_{4}\right)_{3}$ were measured over the concentration range of approximately $0.004 \underline{m}$ to saturation at $25^{\circ}$. The equivalent conductances of the rare earth perchlorates, at constant

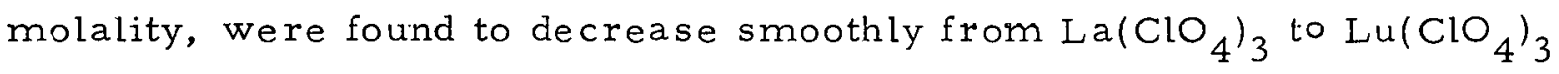
below $2.5 \mathrm{~m}$. A prominent two-series effect appears in the equivalent conductances by $3.0 \mathrm{~m}$ and is discussed in terms of a change in the innersphere cation hydration number and the occurrence of water sharing between the rare earth and perchlorate ions.

ELECTRICAL CONDUCTANCES OF SOME AQUEOUS RARE EARTH ELECTROLYTE SOLUTIONS AT $25^{\circ} \mathrm{C}$. II. RARE EARTH CHLORIDES F. H. Spedding, J. A. Rard, and V. W. Saeger

J. Chem. Eng. Data 19: 373 (1974)

Abstract-- The electrical conductances of aqueous solutions of $\mathrm{LaCl}_{3}, \mathrm{PrCl}_{3}, \mathrm{NdCl}_{3}, \mathrm{SmCl}_{3}, \mathrm{EuCl}_{3}, \mathrm{GdCl}_{3}, \mathrm{TbCl}_{3}, \mathrm{DyCl}_{3}, \mathrm{HoCl}_{3}$, $\mathrm{ErCl}_{3}, \mathrm{TmCl}_{3}, \mathrm{YbCl}_{3}$, and $\mathrm{LuCl}_{3}$ were measured over lhe concentration range of approximately $0.02 \mathrm{~m}$ to saturation at $25^{\circ} \mathrm{C}$. The equivalent conductances of the rare earth chlorides at each molality decreased smoothly from $\mathrm{SmCl}_{3}$ to $\mathrm{LuCl}_{3}$, and $\mathrm{LaCl}_{3}$ through $\mathrm{NdCl}_{3}$ had very similar con- 
ductances. By $0.16 \mathrm{~m}$, the equivalent conductances of the rare earth chlorides dropped below those of the corresponding perchlorates. ... The differences between the chloride and perchlorate systems were discussed in terms of ionic hydration, anion-cation complex formation, the degree of cation hydrolysis, and the effect of these electrolytes on the hydrogen-bonded water structure.

RAMAN SPECTRUM OF HDO IN RARE EARTH PERCHLORATE SOLUTIONS

L. Gutierrez, W. C. Mundy, and F. H. Spedding

J. Chem. Phys. 61: 1953 (1974)

Abstract--Raman data were obtained of the OD stretching vibrations of $\mathrm{HDO}$ at $23.0 \pm 0.5^{\circ} \mathrm{C}$ in nine or ten concentrations of aqueous $\mathrm{La}\left(\mathrm{ClO}_{4}\right)_{3}$, $\mathrm{Gd}\left(\mathrm{ClO}_{4}\right)_{3}$, and $\mathrm{Lu}\left(\mathrm{ClO}_{4}\right)_{3}$ solutions in which the total water content was about 5 mole\% $\mathrm{D}_{2} \mathrm{O}$. The rare earth salt concentration was varied from approximately 0.25 to 4.0 or $4.5 \mathrm{~m}$. A differential analysis technique, previously reported, was used to identify and to correlate changes in the frequency distribution of the $O D$ band with water molecules that are being diversely affected by the rare earth salt ions. At least four general types of water molecules are discernible in solution at various salt concentrations. In dilute solutions, cation-affected, anion-affected, and unaffected free water molecules are clearly distinguished, whereas at high perchlorate salt concentrations water molecules associated with ion pairs are also identified. In addition, results are presented to indicate that the $\mathrm{La}^{3+}$ cation affects water somewhat differently than do either the $\mathrm{Gd}^{3+}$ or $\mathrm{Lu}^{3+}$ cations, and this is interpreted as reflecting a difference in the hydration number between these $\mathrm{RE}^{3+}$ cations. 
RELATIVE VISCOSITIES OF SOME AQUEOUS RARE EARTH CHLORIDE SOLUTIONS AT $25^{\circ} \mathrm{C}$

F. H. Spedding, D. L. Witte, L. E. Shiers, and J. A. Rard

J. Chem. Eng. Data 19: 369 (1974)

Abstract--The relative viscosities of aqueous solutions of $\mathrm{PrCl}_{3}$, $\mathrm{EuCl}_{3}, \mathrm{GdCl}_{3}, \mathrm{TmCl}_{3}, \mathrm{YbCl}_{3}$, and $\mathrm{LuCl}_{3}$ were determined over the concentration range of approximately $0.05 \mathrm{~m}$ to saturation at $25^{\circ} \mathrm{C}$. The JonesDole $P$-coefficients were determined for all of these salts, and the variation of this parameter across the rare earth series is discussed in terms of irn-solvent interactions. The concentration dependence of the relative viscosity is briefly discussed in terms of various quasi theoretical models and in terms of ion-solvent interactions and the modification of the solvent siructure.

\section{NT-04-03}

\section{Molecular and Atomic Sciences}

\section{NT-04-03-01}

\section{Chemical Physics}

I. Crystallography of Organic and Biological Materials

COMPETITIVE REACTIONS OF COORDINATED CARBON MONOXIDE AND METHYL ISOCYANIDE WITH AMINES

R. J. Angelici, P. A. Christian, B. Dombek and G. A. Pfeffer J. Organometallic Chem. 67: 287 (1974)

Abstract--The relative reactivities of $\mathrm{CO}$ and $\mathrm{C} \equiv \mathrm{N}-\mathrm{R}$ ligands with $\mathrm{CH}_{3} \mathrm{NH}_{2}$ were investigated in complexes which contained both ligands. Like $\left(\mathrm{C}_{5} \mathrm{H}_{5}\right) \mathrm{Fe}(\mathrm{CO})_{3}{ }^{\prime}$, the $\left(\mathrm{C}_{5} \mathrm{H}_{5}\right) \mathrm{Fe}(\mathrm{CO})_{2}\left(\mathrm{CNCH}_{3}\right)^{+}$complex reacts with $\mathrm{CH}_{3} \mathrm{NH}_{2}$ to give the carbamoyl complex $\left(\mathrm{C}_{5} \mathrm{H}_{5}\right) \mathrm{Fe}(\mathrm{CO})\left(\mathrm{CNCH}_{3}\right)\left(\mathrm{CONHCH}_{3}\right)$; this is a readily reversible reaction. In contrast, $\left(\mathrm{C}_{5} \mathrm{H}_{5}\right) \mathrm{Fe}(\mathrm{CO})\left(\mathrm{CNCH}_{3}\right)_{2}^{+}$ 
reacts with $\mathrm{CH}_{3} \mathrm{NH}_{2}$ to give the amidinium or carbene complex, $\left(\mathrm{C}_{5} \mathrm{H}_{5}\right)$ $\mathrm{Fe}(\mathrm{CO})\left(\mathrm{CNCH}_{3}\right)\left[\mathrm{C}\left(\mathrm{NHCH}_{3}\right)_{2}\right]^{+}$. In a slow reaction, $\left(\mathrm{C}_{5} \mathrm{H}_{5}\right) \mathrm{Fe}\left(\mathrm{PPh}_{3}\right)(\mathrm{CO})-$ $\left(\mathrm{CNCH}_{3}\right)^{+}$forms the amidinium complex, $\left(\mathrm{C}_{5} \mathrm{H}_{5}\right) \mathrm{Fe}\left(\mathrm{PPh}_{3}\right)(\mathrm{CO})\left[\mathrm{C}\left(\mathrm{NHCH}_{3}\right)_{2}\right]^{+}$. Factors that affect the site of $\mathrm{CH}_{3} \mathrm{NH}_{2}$ reaction are discussed. The complexes have been characterized by IR and NMR spectroscopy; a variable temperature $\mathrm{NMR}$ study of $\left(\mathrm{C}_{5} \mathrm{H}_{5}\right) \mathrm{Fe}(\mathrm{CO})\left(\mathrm{CNCH}_{3}\right)\left[\mathrm{C}\left(\mathrm{NHCH}_{3}\right)_{2}\right]^{+}$indicates restricted rotation around the $\mathrm{C}-\mathrm{N}$ bonds of the amidinium ligand.

OXIDATIVE-ADDITION ACROSS A CARBON-SULFUR BOND: PLATINUM(0) COMPLEXES WITH ETHYLENE TRITHIOCARBONATE AND TRIMETHYLENE TRITHIOCARBONATE

E. D. Dobrzynski and R. J. Angelici

J. Organometallic Chem. 76: C53 (1974)

Abstract--Platinum(0) phosphine complexes $\mathrm{PtL}_{4}$ (where $\mathrm{L}=\mathrm{PPh}_{3}$ or $\mathrm{PMePh}_{2}$ ) undergo oxidative addition reactions with ethylene trithiocarbonate, $\mathrm{C}_{2} \mathrm{H}_{4} \mathrm{CS}_{3}$, to give cis $-\widehat{\mathrm{PCS}_{2} \mathrm{CH}_{2} \mathrm{CH}_{2} \mathrm{~S}}(\mathrm{~L})_{2}$ and with trimethylene trithiocarbonate, $\left(\mathrm{CH}_{2}\right)_{3} \mathrm{CS}_{3}$, to give cis $-\widehat{\mathrm{PtCs}_{2} \mathrm{CH}_{2} \mathrm{CH}_{2} \mathrm{CH}_{2} \mathrm{~S}}\left(\mathrm{PPh}_{3}\right)_{2}$. These bidentate ligands are displaced by $\mathrm{CS}_{2}$ giving the free trithiocarbonates and the known $\mathrm{CS}_{2}$ complex $\mathrm{Pt}\left(\mathrm{CS}_{2}\right)\left(\mathrm{PPh}_{3}\right)_{2}$. Dimethyl trithiocarbonate, $\left(\mathrm{CH}_{3} \mathrm{~S}\right)_{2} \mathrm{CS}$, does not undergo the same type of oxidativeaddition reaction with $\mathrm{Pt}\left(\mathrm{PPh}_{3}\right)$, and ethylene carbonate shows no reactivity toward $\mathrm{Pt}\left(\mathrm{PPh}_{3}\right)_{4}$.

CRYSTAL AND MOLECULAR STRUCTURES OF THE CAGED AMINO PHOSPHORUS MOLECULES OP $\left(\mathrm{NMeCH}_{2}\right)_{3} \mathrm{CMe} \mathrm{AND} \mathrm{H}_{3} \mathrm{BP}\left(\mathrm{NMeCH}_{2}\right)_{3} \mathrm{CMe}$ J. C. Clardy, R. L. Kolpa and J. G. Verkade Phosphorus 4: 133 (1974)

Abstract--Using $x$-ray diffraction techniques the crystal and molecular structures of the title compounds were solved. The OP $\left(\mathrm{NMeCH}_{2}\right)_{3}-$ CMe, 2, 4, 6, 7-tetramethyl-2, 6, 7-triaza-1-phosphabicyclo[2.2.2] octane- 
1 -oxide, crystals belong to the orthorhombic space group having $2 / \mathrm{m}^{2 /} \mathrm{m}^{-}$ $2 / \mathrm{m}$ Laue symmetry with $\underline{a}=12.81(5), \underline{b}=13.19(5)$ and $\underline{c}=12.84(5) \AA$. There are eight molecules in the unit cell. The molecule has near-perfect $\mathrm{C}_{3 \underline{\mathrm{v}}}$ symmetry with the sum of the angles around nitrogen averaging $357^{\circ}$. While the average $\mathrm{P}-\mathrm{N}(1.590(8) \AA)$ is uncommonly short, those of the $\mathrm{N}-\mathrm{CH}_{2}(1.49(1) \AA), \mathrm{N}-\mathrm{CH}_{3}(1.42(1) \AA)$ and $\mathrm{C}-\mathrm{C}(1.55(1) \AA)$ bond distances are normal as is the $O-P$ bond length $(1.545(50) \AA$ ) for compounds of this type. The average $\mathrm{NPN}\left(103.1^{\circ}\right), \operatorname{PNC}\left(\mathrm{H}_{2}\right)\left(115.9^{\circ}\right), \operatorname{PNC}(\mathrm{H})_{3}\left(126.4^{\circ}\right)$, $\operatorname{NCC}\left(107.5^{\circ}\right)$ and $\operatorname{CCC}\left(109.4^{\circ}\right)$ are compared with those of similar compounds whose structures have been reported.

The borane adduct, 2, 4,6,7-tetramethyl-2, 6, 7-triaza-1-phosphabicyclo-[2.2.2]octane-1-borane, is also orthorhombic possessing $2 / \mathrm{m}^{2 /} \mathrm{m}^{2 /} \mathrm{m}$ Laue symmetry with two molecules in the unit cell. The cell constants are $\underline{a}=9.9(2), \underline{h} \equiv 7.18(3)$ and $\underline{c}=8.93(1) \AA$. The molecule has near-perfect $\mathrm{C}_{3 \underline{\mathrm{v}}}$ symmetry with the sum of the angles around the nitrogen averaging $359.7^{\circ}$. 'l'he average $\mathrm{P}-\mathrm{N}(1.66(3) \AA), \mathrm{N}-\mathrm{CH}_{2}(1.49(3) \breve{A})$, and C-C $(1.53(3) \AA)$ bond lengths are within the range of the se lengths in similar compounds as is also the $\mathrm{B}-\mathrm{P}$ bond distance $(1.98(3) \AA)$. The $\mathrm{N}-\mathrm{CH}_{3}$ length of $1.34(3) \AA$ is rather short.

The formation of a $B-N$ as well as a $B-P$ bonded adduct of $P(N M e-$ $\left.\mathrm{CH}_{2}\right)_{3} \mathrm{CMe}$ with $\mathrm{BH}_{3}$ in contrast to $\mathrm{P}(\mathrm{NMeNMe})_{3} \mathrm{P}$ which forms only $\mathrm{H}_{3} \mathrm{BP}-$ $(\mathrm{NMeNMe})_{3} \mathrm{PBH}_{3}$ is rationalized on steric arguments deduced from structural parameters recently published for $P\left(\mathrm{NMeNMe}_{3} \mathrm{P}\right.$ and $\mathrm{OP}(\mathrm{NMeNMe})_{3} \mathrm{PO}$. 
CRYSTAL AND MOLECULAR STRUCTURE OF THE CARCINOSTAT CY CL OPHOSPHAMIDE HYDRATE

J. C. Clardy, J: A. Mosbo and J. G. Verkade

Phosphorus 4: 151 (1974)

Abstract-- The structure of $2-0 \times 0-2-($ bis -8 -chloroethylamino)-

1-hydro-1,3,2-aza-oxaphosphorinane (cyclophos phamide), determined by the $x$-ray diffraction technique, shows that the phosphoryl oxygen is axial and the amino moiety equatorial. The sum of the angles around the exocyclic nitrogen is $360.1 \pm 0.6^{\circ}$ and the plane defined by the atoms attached to this nitrogen very nearly bisects the NPO angle of the ring. A water molecule forms hydrogen bonds to two cyclophosphamide molecules via the phosphoryl oxygen and the proton on the ring nitrogen. The triclinic crystals belong to the space group $\mathrm{P}_{1}$ with two molecules per unit cell. The unit cell parameters are $\underline{a}=8.65(1), \underline{b}=13.39(1), \underline{c}=6.01(1) \AA$, $\alpha=96.3(1), \beta=100.3(1)$ and $\gamma=106.7(1)^{\circ}$. The final $\underline{\mathrm{R}}$ and $\omega \underline{\mathrm{R}}$ factors are 0.072 and 0.092 for the 1601 observed reflections, respectively.

CRYSTAL AND MOLECULAR STRUCTURE OF 1, 3-Bis(p-TOLYL)-2PHENYL - 4, 5-DIHYDRO - 1, 3-DIAZA - 2-PHOSPHO LIDINE J. C. Clardy, R. L. Kolpa, J. G. Verkade and J. J. Zuckerman Phosphorus 4: 145 (1974)

Abstract--The slructure of the title compound determined by $x$-ray diffraction techniques shows that the crystals belong to the orthorhombic space group $\mathrm{Cmc}_{1}$, with two molecules per unit cell. The cell constants

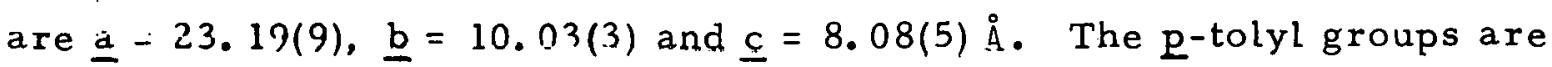
coplanar with the nearly trigonal planar geometries of the nitrogens in the almost planar five-membered phosphorus heterocycle. The phenyl ring attached to the pyramidal phosphorus is perpendicular to the mirror plane of the molecule. The structure is rationalized in terms of nitrogen lone-pair delocalization into the tolyl pi system and the nmr results reported earlier 
are rationalized in terms of the solid state structure with the added feature of rapid inversion about phosphorus in solution.

CRYSTAL STRUCTURE OF (N-CARBOXYMETHYL -L - VALINATO)COPPER(II)

S. K. Porter, R. J. Angelici, and J. Clardy

Inorg. Nucl. Chem. Letters 10: 21 (1974)

Abstract--Previously it was observed that ( $\mathrm{N}$-carboxymethyl-

$\underline{L}$-valinato)copper(II), (N-Cm-L-Val)Cu, forms more stable complexes

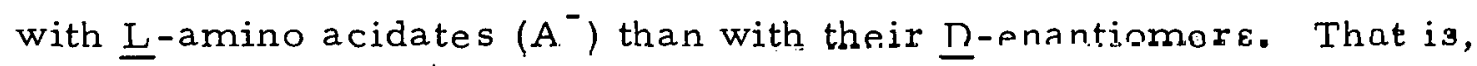
stability constants, $K_{x}$, for the rcaction, (IN-Cm-L-Val)(n+ $A^{-}$ $(\mathrm{N}-\mathrm{Cm}-\mathrm{L}-\mathrm{Val}) \mathrm{Cu}\left(\mathrm{A}^{-}\right)$, are larger for the L-isomers of $\mathrm{A}^{-}$. This prefcrential coordination of $\underline{L}$-amino acids was ulilized in the partial resolution of racemic amino acids. This was done by binding the (N-Cm-LVal)Cu complex to a styrene-divinylbenzene copolymer and chromatographing the racemic amino acids on this resin. The solid state crystal structurc study reported hercin was carried out in order to determine possible structural features of (N-C.m-L-Val) Cu that contribute lu ils stereoselectivity in binding optically active amino acids.

DISSOL VING METAL REDUCTION OF anti-TRICY C.T. [3. ?. .. . 2, 4 .] HEPTANES AND anti-TRICYCLO $\left[3.3 .0 .0^{2}, 4\right]$ OCTANES. INTRAMOLECULAR EPOXIDE CLEAVAGE A.S A ROUTE TO HIGHLY STRAINED TRICYCLIC A.LCOHOLS

L. A. Paquette, K. H. Fuhr, S. Porter and J. C. Clardy

J. Org. Chem. 39: 467 (1974)

Abstract--Reduction of epoxides derived from anti-tricyclo-

$\left[3.2 .0 .0^{2,4}\right]$ hept-6-enes and anti-tricyclo[3.3.0.0 $\left.0^{2,4}\right]$ oct-6-enes with lithium in liquid ammonia affords exo tricyclic alcohols in high yield. The process involves initial reductive cleavage of the internal cyclopropane bond followed by back-side attack on the proximate $\mathrm{C}-\mathrm{O}$ bond with formation 
of a new cyclopropane ring. The value of the synthetic method is revealed by the ready access which is gained to functionalized strained molecules inaccessible by other methods.

OPPOSITOL, A BROMINATED SESQUITERPENE ALCOHOL OF A NEW SKELETAL CLASS FROM THE RED ALGA, LAURENCLA SUBOPPOSITA S. S. Hall, D. J. Faulkner, J. Fayos and J. Clardy

J. Am. Chem. Soc. 95: 7187 (1973)

Abstract--Marine algae of the genus Laurencia (family Rhodomelaceae) have produced many brominated sesquiterpenes. We report here the isolation, from the epiphytic red alga Laurencia subopposita Setchell, a brominated sesquiterpene alcohol, which possesses moderate antibiotic activity vs Staphylococcus aureus. This unusual Laurencia metabolite represents a new sesquiterpene skeletal class.

PHOTOCHEMICAL CYCLOADDITIONS OF TRIPLET 1, 3-DIMETHYLURA CIL TO OLEFINS. STRUCTURAL STUDIES ON THE ADDUCTS

J. S. Swenton, J. A. Hyatt, J. M. Lisy, and J. Clardy

J. Am. Chem. Soc. 96: 4885 (1974)

Abstract--The acetone-sensitized additions of 1,3-dimethyluracil (1) to ketene diethyl acetal (2a), tert-butyl vinyl ether (2b), and vinyl acetate $(2 c)$ have been studied. From excited 1 and $2 \mathrm{a}$ an $85 \%$ yield of cis- and trans-fused 8,8-diellıxy-2,4-diazabicyrln[4.2. U]octane-3, 5= diones in a ratio of $84: 16$ were produced. From cycloaddition of excited 1 to $2 \mathrm{~b}$ and $2 \mathrm{c}$ good yields of cis-fused 8 -substituted 2, 4-diazabicyclo[4.2.0] octa-3,5-diones were formed. The orientation and stereochemistry of all these adducts were rigorously established by a combination of chemical, labeling, and $x$-ray crystallographic studies. 
REGIOSPECIFIC CONSTRU CTION OF POLYOXYGENATED (9, 10 ANTHRAQUINONES. TOTAL SYNTHESIS OF ISLANDICIN AND DIGITOPURPONE

A. S. Kende, J. L. Belletire, J. L. Herrmann, R. F. Romanet, E. L. Hume, R. H. Schlessinger, J. Fayos and J. C. Clardy

Synthetic Comm. 3: 387 (1973)

Abstract--Recent interest in the synthesis of anthraquinones, particularly the antitumor substance adriamycin, has stimulated a re-exploration of synthetic methods for this nucleus. Synthetic approaches have been complicated by the Hyashi rearrangement and the difficulty of properly characterizing materials. This paper explores the extent of rearrangement using $\mathrm{x}$-ray diffraction to unambiguously characterize products.

A REVISED STRUCTURE OF VERMICULINE. A NOVEL MACROLIDE DILACTONE ANTIBIOTIC FROM PENICILLIUM VERMICULATUM R. K. Boeckman, Jr., J. Fayos and J. Clardy

J. Am. Chem. Soc. 96: 5954 (1974)

Abstract--Vermiculine, a highly crystalline antibiotic from Penicillium vermiculatum Dangeard, had previously been assigned the unusual medium ring lactone structure on the basis of spectral information. Certain peculiarities in its chemistry, specifically its great acid stability and resistance to isomerization of the endocyclic double bond prompted a reexamination of the proposed structure. A single crystal $x-r$ ay diffraction experiment revealed the dilactone structure. This structure represents a new type of dilactone macrolide antibiotic and is compatible with the known chemical and spectral information. 
STRUCTURE AND SYNTHESIS OF MONILIFORMIN, A NOVEL CYCLOBUTANE MICROBIAL TOXIN

J. P. Springer, J. Clardy, R. J. Cole, J. W. Kirksey, R. K. Hill, R. M. Carlson and J. L. Isidor

J. Am. Chem. Soc. 96: 2267 (1974)

Abstract--Moniliformin is a recently isolated toxin from Fusarium moniliforme shown to be toxic to cockerels and to possess novel plant growth-regulating and phytotoxic effects on corn and tobacco plants. From chemical and spectroscopic investigations, in which $\mathrm{x}$-ray crystallography was the definitive tool, moniliformin has been found to have the structure of the potassium salt of 1-hydroxy-cyclobut-1-ene-3,4-dione. An independent synthesis was devised and the synthetic material had an identical bioassay.

STRUCTURE OF VERRUCULOGEN, A. TREMOR PRODUCING PEROXIDE FROM PENICILLIUM VERRU CULOSUM. J. Fayos, D. Lokensgard, J. Clardy, R. J. Cole and J. W. Kirksey J. Am. Chem. Soc. 96: 6785 (1974)

Abstract-- Pennicillium verruculosum produces a metabolite, $\mathrm{C}_{27} \mathrm{H}_{33} \mathrm{~N}_{3} \mathrm{O}_{7}$, which is both toxic and tremorgenic. The structure has been established through chemical, spectroscopic and $x$-ray crystallographic techniques. The structure formally can be viewed as the diketopiperazine of 6-0-methyltryptophan and proline, two five carbon mevalonate derived units and four oxygens. The trivial name verruculogen has been previously proposed for this substance. The novel, nonendoperoxide does not appear to be an artifact of the isolation procedure. Verruculogen has an $\mathrm{I}_{\mathrm{H}} \mathrm{D}_{50}$ (i. p., Swiss mice) of $2.4 \mathrm{mg} / \mathrm{kg}$ and elicits tremors with an $E D_{50}$ of $.39 \mathrm{mg} / \mathrm{kg}$ (i. p., Swiss mice). 
STRUCTURES OF SUAVEOLIC ACID AND SUAVEOLOL P. S. Manchand, J. D. White, J. Fayos and J. Clardy J. Org. Chem. 39: 2306 (1974)

Abstract--Several species of $\underline{\text { Hyptis }}$ have been found to possess significant pharmacological properties. An investigation of Hyptis suavolens (L) Point (Labiatae), a species widespread throughout tropical America and reputed to possess medicinal properties has led to the isolation of two novel diterpenes for which the names suaveolic acid and suaveolol are proposed.

The structures were elucidated by chemical, spectral and $X$-ray crystallographic techniques. The crystals of methyl suaveolate are orthorhombic $\left(\mathrm{P}_{2} 2_{1} 2_{1}\right)$ and the final $\mathrm{R}$ is .085 for the 1153 observed reflections.

STUDIES ON VINCA ALKALOIDS. THE STRUCTURE OF VINCARODINE J. P. Kutney, G. Cook, J. Cook, I. Itoh, J. Clardy, J. Fayos, P. Brown, and G. H. Svoboda Heterocycles $\underline{2}: 73$ (1974)

Abstract--The structure and stereochemistry of vincarodine have been determined by an investigation of its spectroscopic properties, particularly NMR, electron impact and field ionization mass spectrometry and finally by $\mathrm{X}$-ray analysis of the hydrobromide derivative.

TRANSITION METAL PROMOTED REDIRECTION OF THE THERMAL BISHOMOCONJUGATIVE BOND REORGANIZATION PATHWAY OF UNSATURATED PROPELLANES

L. A. Paquette, J. M. Photis, J. Fayos and J. Clardy

J. Am. Chem. Soc, 96: 12.17 (1974)

Abstract--In order to check whether or not the $6 \pi$ electron (self Diels-Alder) path of bond reorganization in $[4.2 .0]$ octatrienes could be diverted by transition metals 1 a was heated at reflux with $\mathrm{Mo}(\mathrm{CO})_{6}{ }^{\circ}$ The products, which showed extensive diversion by transition metal, were characterized by $\mathrm{X}$-ray diffraction. 
X-RAY DETERMINATION OF CHONDRIOL; A RE-ASSIGNMENT OF STRUCTURE

W. Fenical, K. B. Gifkins and J. Clardy

Tet. Lett. p. 1507 (1974)

Abstract--A reexamination of the halogenated metabolites from

the marine alga Chondria oppositiclada Dawson revealed that the previously published structure for chondriol was inconsistent with the ${ }^{13} \mathrm{C} \mathrm{nmr}$ spectrum. A single crystal $\mathrm{X}$-ray diffraction study revealed the correct structure as an unusual eight membered cyclic ether with a pentaenyne unit.

II. Statistical Mechanisms of Gaseous Systems

KINETIC MODEL FOR DISSOCIATIVE ADSORPTION OF A DIATOMIC GAS

K. J. Vette, T. W. Orent, D. K. Hoffman, and R. S. Hansen

J. Chem. Phys. 60: 4854 (1974)

For abstract see Materials Science, page 72 .

III. Mass Spectroscopy and Ion Source Chemistry

DIFFUSION OF METALLIC SOLUTES IN VANADIUM USING SPARK SOURCE MASS SPECTROMETRY AS THE METHOD OF ANAL YSIS F. A. Schmidt, R. J. Conzemiue, O. N. Carlson and H. J. Svec Anal. Chem. $46: 810$ (1974)

For abstract see Materials Science, page 13.

A QUADRUPOLE MASS SPECTROMETER FOR THE IDENTIFICATION AND CHARACTERIZATION OF NEUTRAL FRAGMENTS FORMED BY THE INTERACTION OF ELECTRONS WITH GASFOITS MOLECULES J. R. Reeher and H. J. Svec

A. R. West, ed., Advances in Mass Spectrometry Vol. 6, Chapter 58 Proc. of a Conference held in Edinburgh, (Barking, Essex, England, Applied Science Publishers, Ltd. for the Institute of Petroleum, London, 1974) pp. 509-515

Abstract--A quadrupole mass spectrometer with a dual electronbeam ion source has been designed and built for the purpose of obtaining neutral fragment. mass spectra. The instrument includes capabilities 
for automatic scanning of the spectra and provisions for obtaining vertical ionization potentials of neutral fragments. It can also be used to obtain appearance potentials of neutral fragments. Examples of neutral mass spectra obtained for benzene, toluene, m-xylene and mesitylene are given along with traces of typical ionization efficiency data for $\mathrm{CH}_{3}$, $\mathrm{C}_{2} \mathrm{H}_{2}{ }^{0}, \mathrm{C}_{4} \mathrm{H}_{2}{ }^{0}, \mathrm{C}_{4} \mathrm{H}_{3}{ }^{0}$ and $\mathrm{C}_{4} \mathrm{H}_{4}{ }^{0}$ from tolune.

SIMULTANEOUS ION-BEAM COILEETION FOR PRECISE MIEASUREMENT OF NUCLIDIC ION-CURRENT RATIOS IN SPARK-SOURCE MASS SPECTROMETRY R. J. Conzemius and H. J. Svec Talanta 2.1: 171 (1974)

Abetract--Simullaneous lon-beam collection techniques make significant improvement possible in the precision of measurements when electrical ion-detection is used with the spark ion-sourcc. The advantage of reference of specific ion-current signals only to those from dosired regions of the mass spectrum is that reproducible measurements may be made on heterogeneous samples such as oxide-graphite pellets. For example, isotopic ratio measurements from separate samplings of an oxide (pelleted with graphite) are reproducible to better than $\pm 0.5 \%$. The technique is also advantageous when sparking dissimilar clcctrodes, such as a gold probe and a metal bar.

\section{Moles rular Bonding Thcory}

EVF,N-TEMPERED ATOMIC ORBITALS. VI. OPTIMAL ORBIIAL EXPONENTS AND OPTIMAL CONTRACTIONS OF GAUSSIAN PRIMITIVES FOR HYDROGEN, CARBON, AND OXYGEN TN MOLECULES R. D. Bardo and K. Ruedenberg

J. Chem. Phys. 60: 918 (1974)

$$
\text { Abstract--Bases of even-tempered Gaussian primitives are }
$$

optimized with respect to all parameters in the molecules hydrogen, 
methane, acetylene, ethylene, ethane, methyl acetylene, water, carbon monoxide, carbon dioxide, formaldehyde, and carbon suboxide. A method is introduced for constructing contracted atomic orbitals from the optimized molecular orbitals of these molecules. Transferability of the optimal even-tempered primitive and contracted bases between molecules is shown. Certain minimization schemes for the even-tempered basis are discussed which greatly reduce the amount of work involved in molecular optimizations.

EVEN-TEMPERED ATOMIC ORBITALS. VII. THEORETICAL EQUILIBRIUM GEOMETRIES AND REACTION ENERGIES FOR CARBON SUBOXIDE AND OTHER MOLECULES CONTAINING CARBON, OXYGEN, AND HYDROGEN

R. D. Bardo and K. Ruedenberg

J. Chem. Phys. 60: 932 (1974)

Abstract--The quality of molecule-optimized even-tempered Gaussian bases is ascertained from calculations of theoretical equilibrium conformations and of reaction energies for the molecules hydrogen, methane, acetylene, ethylene, ethane, methyl acetylene, water, carbon monoxide, carbon dioxide, and formaldehyde. The equilibrium geometry of $\mathrm{C}_{3} \mathrm{O}_{2}$ is determincd and compared to known results.

GENEALOGICAL ELECTRONIC SPIN EIGENFUNCTIONS AND ANTISYMMETRIC MANY-ELECTRON WAVEFUNCTIONS GENERATED DIRECTLY FROM YOUNG DIAGRAMS W. I. Salmon

Advances in Quantum Chem. 8 : 37 (1274)

No abstract available.

POTENTIAL ENERGY CURVE IN THE TRANS-CIS ISOMERIZATION OF GLYOXAL

K. R. Sundberg and L. M. Cheung

Chem. Phys. Lett. 29: 93 (1974)

Abstract--A series of Hartree-Fock calculations on glyoxal for the trans, cis and five intermediate values of the dihedral angle are 
presented. The molecular geometry is optimized at each point. The energy for the trans-cis isomerization is $4.77 \mathrm{kcal} / \mathrm{mole}$ and the energy barrier is $7.2 .2 \mathrm{kcal} / \mathrm{mole}$. Moment of inertia for the rotation of one of the aldehyde groups about the carbon-carbon bond is calculated.

\section{Analysis}

\section{NT -04-03-03}

THE DETECTION OF PRASEODYMIUM, EUROPIUM, GADOLINIUM AND HOLMIUM CARBONYLS USING MATRIX ISOLATION

J. L. Slater, T. C. DeVore and V. Calder

Inorg. Chem. 13: 1808 (1974)

Abstract--Carbonyl compounds of the rare earth metals praseodymium, gadolinium, and holmium were prepared by codeposition of the metal atoms with carbon monoxide in argon matrices. Infrared absorptions attributable to the species $M(C O)_{\underline{x}} \underline{x}=1-6$, were observed. The final product upon controlled annealing of the matrix was assigned to the hexacarbonyl. The variation of the carbonyl stretching frequency with coordination number is similar to that observed in other carbonyl complexes, namely, the frequency increases with increasing coordination number; however, the variation of the $C O$ stretching frequency for different metals is very small. The spectra of the carbonyl compounds of europium were measured but the assignments were less certain. 
THE TIME EVOLUTION OF DRUGS IN THE BODY. AN APPLICATION OF THE PRINCIPLES OF CHEMICAL KINETICS

G. V. Calder

J. Chem: Educ. 51: 19 (1974)

Abstract--The basic principles of chemical kinetics are applied to the time evolution of drugs in the body. The metabolism of ethanol is used as a specific example because of the social implications of its use in our culture.

\section{Analytical Spectroscopy}

ANALYTICAL APPLICATIONS OF X-RAY EXCITED OPTICAL LUMINESCENCE. DIRECT DETERMINATION OF RARE EARTH NUCLEAR POISONS IN ZIRCONIA

A. P. D'Silva and V. A. Fassel

Anal. Chem. $\underline{46}$ : 996 (1974)

Abstract--An X-ray excited optical luminescence technique for the direct quantitative determination of fractional ppm levels of rare earth "neutron poisons" in $\mathrm{ZrO}_{2}$ and $\mathrm{Zircaloys}$ is described. A blend of $\mathrm{ZrO}_{2}$ ' $\mathrm{K}_{2} \mathrm{CO}_{3}, \operatorname{Sr}\left(\mathrm{NO}_{3}\right)_{2}$, and $\mathrm{WO}_{3}$ is heated to $1050^{\circ} \mathrm{C}$ for 2 hours to yield a quaternary oxide phosphor host with a composition of $\mathrm{K}_{2} \mathrm{O} \cdot 2 \mathrm{SrO} \cdot 2 \mathrm{ZrO}_{2} \cdot 3 \mathrm{WO}_{3}$. The irradiation of this phosphor by $\mathrm{X}$-rays causes the emission of optical line luminescence of the rare earth impurities. When the phosphor sample is irradiated at $150^{\circ} \mathrm{C}$, the intense host band luminescence is quenched yielding improved signal to noise ratios for Sm, Dy, Eu, Pr, and Tb, which is the internal reference element. The Gd luminescence, which is quenched at $150^{\circ} \mathrm{C}$, is observed at ambient temperatures. The detection limits under these conditions are: $0.05 \mathrm{ppm}$ for Gd, Sm, Pr; 0.1 for Eu; and 0.02 ppm for Dy. 
APPLICATIONS OF CATHODOLUMINESCENCE IN ELECTRON MICROPROBE ANALYSIS

R. N. Kniseley and F. C. Laabs

C. Andersen, ed., Electron Microprobe Analysis Chapter 10 (New York, John Wiley and Sons, Inc., 1973) pp. 371-382

Abstract--Electron excited optical fluorescence (cathodoluminescence)

has been shown to be a very useful spectrographic technique for the detection of low concentration impurities and the study of physical properties of various materials such as semiconductors. This paper discusses the basic parameters which give use to cathodoluminescent emissions and the types of applications as well as the instrumental techniques generally used in an attempt to utilize the wealth of physical data contained in cathodoluminescent emissions.

ELECTRICAL DISCHARGE EXTRACTION METHODS

R. K. Winge and V. A. Fassel

L. Melnick, L. Lewis and B. Holt, eds., Determination of Gaseous Elements in Metals, Chapter 5 (New York, John Wiley and Sons, Inc., F974) pp. 221-264

Abstract--Most methods for determining the gaseous elements in metals require that they be extracted in one form or another from the metal before they can be determined. In general, therefore, the apparatus consists of two main sections: the extraction system which converts the oxygen, nitrogen, and hydrogen contents to $\mathrm{CO}, \mathrm{N}_{2}$ : and $\mathrm{H}_{2}$ and the analysis section which separates, if necessary, and quantitatively measures each compunent.

This chapter is subdivided in like manner, with the extraction and analytical systems discussed in separate sections. Only those techniques in which the electrical discharge is used to melt a relatively large sample (approximately 0.1-2 grams) and to extract completely its gaseous element content are discussed. Discharges of this type include the direct current arc, 
the hollow cathode, and, if the electrical discharge is broadly defined, even the electron beam.

AN IMPROVED PNEUMATIC NEBULIZER FOR USE AT LOW NEBULIZING GAS FLOWS

R. N. Kniseley, H. Amenson, C. C. Butler, and V. A. Fassel A.ppl. Spectros copy 28: 285 (1974)

Abstract--A corrosion resistant pneumatic nebulizer is described which operates efficiently at low aerosol gas flow rates (down to 0.8 liters/min.). Details of the construction and alignment of this nebulizer are described. Studies on the stability of the nebulization process and the efficiency of the nebulizing system are also reported.

INDUCTIVELY COUPLED PLASMA--OPTICAL EMISSION SPECTROSCOPY V. A. Fassel and R. N. Kniseley

A.nal. Chem. 46: 11.10A. (1974)

Abstract--With this promising excitation source for optical emission spectroscopy, metals and metalloids can be determined at the ultratrace level on $u l$ or $u g$ samples. Simultaneous multielement determinations can be achieved with minimal interelement effects.

INDUCTIVELY COUPLED PLASMAS

V. A. Fassel and R. N. Kniseley

Anal. Chem. 46: 1155A (1974)

Abstract--This article discusses the formation and stabilization of these plasmas and their unique properties and characteristics that make them very promising atomization-excltation sources.

INDUCTIVELY COUPLED PLASMA-OPTICAL EMISSION ANALYTICAL SPECTROMETRY. A COMPACT FACILITY FOR TRACE ANALYSIS OF SOLUTIONS

R. H. Scott, V. A. Fassel, R. N. Kniseley, and D. E. Nixon Anal. Chem. 46: 75 (1974)

Abstract--This paper describes a compact inductively cúpled plasma-optical emission system for the trace determination of metallic 
elements in solution. Theoretical considerations are presented to determine operating parameters which agree well with the empirically determined values. The aerosol desolvation system commonly used with this type of source has been eliminated, and pneumatic nebulization is employed in place of the more elaborate ultrasonic method. Some characteristics of the plasma are reported. Detection limits are in the range $0.1-10 \mathrm{ng} / \mathrm{ml}$ for most elements studied. The present facility is readily adaptable to simultaneous multielement trace analysis.

INDUCTIVELY COUPLED PLASMA-OPTICAL EMISSION ANALYTICAL SPECTROSCOPY. TANTALUM FILAMENT VAPORIZATION OF MICRO LITER SAMPLES

D. E. Nixon, V. A. Fassel, and R. N. Kniseley

Anal. Chem. 46: 210 (1974)

Abstract--The adaptation of a tantalum filament vaporization sys tem as a sample introduction device for the inductively coupled plasma is described. The potential advantages of this analytical system for simultaneous multielement determinations of elements at the $\mathrm{ng} / \mathrm{ml}$ level are discussed and a comparison of the plasma system with the filament techniques utilized in atomic absorption or fluorescence spectroscopy is presented. For one set of operating conditions, detection limits for 16 elements were in the $\mathrm{ng} / \mathrm{ml}$ to fractional $\mathrm{ng} / \mathrm{ml}$ range for $100-\mu \mathrm{l}$ samples. Typical precision data and an analytical curve for the determination of Be in the range of 0.001 to $10 \mu \mathrm{g} / \mathrm{ml}$ are included.

OPTICAL AND MASS-SPECTROSCOPIC METHODS R. K. Winge and V. A. Fassel L. Melnick, L. Lewis, and B. Holt, eds., Determination of Gaseous Elements in Metals Chapter 6 (New York, John Wiley and Sons, Inc., 1974) pp. 265-287

Abstract--Chapter 6 reviews the application of emission and mass spectroscopic techniques to the determination of gaseous elements in 
metals. Sampling and spectral excitation properties of spark, impulse, dc arc, electrodeless, and hollow cathode discharges are discussed for optical emission techniques. Sampling characteristics of radio frequency discharges and laser extraction techniques are included in the general treatment of mass spectroscopic methods. Operating principles, procedural details, and advantages of isotopic techniques are delineated.

SCANDIUM, YTTRIUM, LANTHANIDE, AND ACTINIDE ELEMENTS W. E. Dallmann and V. A. Fassel L. Melnick, L. Lewis and B. Holt, eds., Determination of Gaseous Elements in Metals Chapter 19 (New York, John Wiley and Sons, Inc., 1974) pp. 631-672

Abstract--Metallurgical aspects, sample handling and preparation procedures, and analytical details for hot extraction, furnace fusion, dc arc, neutron activation, and chemical methods are given for 19 lanthanide (plus scandium and yttrium) and actinide elements. Recommended procedures are outlined for the determination of hydrogen, oxygen, and nitrogen.

SPECTROSCOPIC FLAME TEMPERATURE MEASUREMENTS AND THEIR PHYSICAL SIGNIFICANCE--II. RESULTS FROM FLAME MODEL CALCULATIONS

T. Reif, V. A. F'assel and R. N. Kniseley

Spectrochim. Acta. 29B: 79 (1974)

Abstract--Apparent temperatures have been calculated for several theoretical flame models representing typical laboratory flames. These apparent temperatures correspond to those temperature values which would have been measured by the line reversal, emission-absorption, two-line and slope methods if the theoretical models corresponded to real flames. It is shown that differences as large as $800 \mathrm{~K}$ may arise between the measured values and the average or wcighted average temperatures. Moreover, temperatures measured by the same technique and thermometric species 


\section{NT-04}

but with different spectral lines may differ by as much as $200 \mathrm{~K}$ even if no other errors are involved, such as uncertainties in the transition probabilities. Physical interpretations that go beyond these uncertainties flatter the actual experimental situations and are not justified.

X-RAY EXCITED OPTICAL FLUORESCENCE OF GASEOUS ATMOSPHERIC POLLUTANTS: ANALYTICAL FEASIBILITY STUDY

S. A. Goldstein, A. P. D'Silva and V. A. Fassel

Radiation Research 59: 422 (1974)

Abstract--Optical fluorescence from molecular gases and metallic vapors in argon and helium has been elicited by irradiating gas mixtures with soft $X$-rays. Emission spectra from species of interest in toxicological and environmental studies, e.g., $\mathrm{NO}, \mathrm{NO}_{2}, \mathrm{CO}, \mathrm{SO}_{2}$, and $\mathrm{Hg}$, have been produced and characterized. Probable energy transfer processes accounting for the observed excitation are presented. These include non-selective direct routes involving collisions with photoelectrons, selective indirect routes involving collisions with excited atoms, e.g., sensitized fluorescence, Penning ionization (Jesse effect), and charge transfer, and routes involving relaxation phenomena, e.g., recombination and cascade.

The development of an analytical technique for the determination of the previous molecular species, in addition to $\mathrm{N}_{2}$ and $\mathrm{OH}$, as part per million level impurities in rare gases was found to be highly feasible. The determination of molecular pollutants in air samples, however, was hampered by the process of quenching by ground state nitrogen and oxygen molecules. 
X-RAY EXCITED OPTICAL LUMINESCENCE IN THE YTTRIUMGADOLINIUM - TERBIUM PHOSPHATE SYSTEM

A. P. D'Silva and V. A. Fassel

J. Luminescence $\underline{8}: 375$ (1974)

A.bstract--The X-ray excited optical luminescence of $\mathrm{Tb}$ in $\mathrm{YPO}_{4}$ present at $0.01 \mathrm{~mol} \mathrm{~Tb}_{2} \mathrm{O}_{3} / \mathrm{mol} \mathrm{Y}_{2} \mathrm{O}_{3}$ was found to consist primarily of emission in the 3800-4500 $\AA$ region arising from $5 \mathrm{D}_{3} \rightarrow 7 \mathrm{~F}_{\mathrm{J}}$ transitions. of $\mathrm{Tb}^{3+}$. This luminescence was in addition found to be sensitized by Gd. Preliminary tests on the radiographic properties of the $\mathrm{Y}_{0.8} \mathrm{Gd}_{0.2} \mathrm{PO}_{4}: \mathrm{Tb}^{3+}$ composition show that this phosphor offers promise as an efficient radiographic screen phosphor.

\section{Analytical Separations}

ADSORPTION OF CHLORINATED PESTICIDES FROM RIVER WATER WITH XAD-2 RESIN

J. J. Richard and J. S. Fritz

Talanta 21: 91 (1974)

Abstract--Usually chlorinated pesticides are present in water in such small amounts that using a separatory funnel to carry out the extraction procedure is difficult because of the large volume of water needed to get meaningful data. For the determination of pesticides at lower concentrations two methods are usually used, continuous extraction with an organic solvent, or adsorption on charcoal. These two methods are, however, rather time-consuming, requiring one hour to extract $0.5-1$ litre of wate $r$ in the continuous exlraction procedure and up to $35 \mathrm{hr}$ extraction with chlor oform to recover the pesticide from the charcoal in the charcoal adsorption procedure. Recently several new absorbents have been proposed for the recovery of organics from water. A mixture of Carbowax 4000 monostearate and undecane on a Chromosorb W solid support has been used to recover chlorinated pesticides from water. Amberlite XAD-2 
resin has been used to concentrate dissolved organic materials from seawater. Polyurethane foam coated with a selective adsorbent has been used for the extraction of organochlorine pesticides from water. Finally Amberlite XAD-2 resin has been used to recover trace organics from potable water. Of these absorbents, Amberlite XAD-2 resins seemed to have the most potential and Amberlite XAD- 2 was evaluated as an absorbent for concentration of trace organochlorine pesticides from river water.

CHROMATOGRAPHIC SEPARATION OF METAL IONS ON LOW CAPACITY, MACRORETICULAR RESINS

J. S. Fritz and J. N. Story

Anal. Chem. 46: 825 (1974)

Abotract--Forced-fluw chumalography on partially sulfonated, macroreticular resin beads is used to obtain several rapid metal ion separations. Separations of thorium(IV) from lanthanum(III); thorium(IV) from zirconium(IV); calcium(II) from magnesium(II); zinc(II), lead(II); copper(II), maganese(II), and nickel(II) from each other, and separation of lead(II) from large amounts of other divalent ions are demonstrated. Low-capacity resins provide rapid separations in strongly acidic eluents of moderate concentrations. In-stream addition of color-forming reagent provides continuous detection and accurate quantitation of eluted metals,

\section{DETERMINATION OF BISMUTH BY FORCED-FLOW LIQUID CHROMATOG- RAPHY \\ R. B. Willis and J. S. Fritz}

Talanta $21: 347$ (1974)

Abstract--Bismuth(III) is retained on a cation-exchange column from dilute acid and is then separated from most other metal ions by elution with $0.5 \mathrm{M}$ hydrobromic acid. The elution curve can be measured spectrophotometrically and automatically recorded. This separation method is rapid and is selective for bismuth. 
FORCED-FLOW CHROMATOGRAPHY OF THE LANTHANIDES WITH CONTINUOUS IN -ST REAM DETECTION

J. N. Story and J. S. Fritz

Talanta 2 l: 892 (1974)

Abstract--A method for ion-exchange separation of rare earths is described in which the elements are detected automatically after addition of a colour-forming reagent. A separation of 13 rare-earth elements was accomplished in $4 \mathrm{hr}$.

MACROPOROUS RESINS FOR SORPTION AND CHROMATOGRAPHIC SEPARATION OF GASES

J. S. Fritz and R. C. Chang

Anal. Chem. 46 : 938 (1974)

Abstract--Macroporous resins are used as the sole column packing for gas chromatography. Retention times for inorganic and organic gases are given on macroporous resins of various surface areas and with different functional groups in the resin molecule. Several practical separations are given including an excellent separation of the rare gases.

RAPID EDTA DETERMINATION OF LEAD IN BINARY ALLOYS OF LEAD AND TIN

M. J. Tschetter and R. Z. Bachman

Talanta 21: 106 (1974)

Abstracl-=A simplc, rapid and accurate method for determining lead in lead-tin alloys is described. The lead-tin alloys were dissolved in a mixture of 1:1 nitric acid containing 10\% sodium fluoride. The tetravalent tin was effectively masked by the fluoride. A quick and accurate EDTA. titration of the lead was carried out in a HMTA buffered solution using Xylenol Orange as indicator. 
SELECTIVITY BEHAVIOR OF LOW-CAPACITY, PARTIALLY SULFONATED, MACROPOROUS RESIN BEADS

J. S. Fritz and J. N. Story

J. Chromatography 90: 267 (1974)

Abstract--Cation-exchange resins with capacities ranging from

0.23 to 3.70 mequiv. /g were prepared by sulfonation of highly cross linked macroporous polystyrene resins. Distribution coefficients for exchange of hydrogen-form resin for polyvalent metal cations in $1 \underline{M}$ acid show m14ked 1ncrcases with increasing resin capacity.

SEPARATION AND DETERMINATION OF TIN BY LIQUID-SOLID CHROMATOGRAPHY

J. S. Fritz and L. Goodkin

Anal. Chem. 46: 959 (1974)

Abstract--Tin(IV) is retained selectively on a polyacrylate resin

from $1 \underline{M}$ hydrochloric acid. It is then eluted with $0.1 \mathrm{M}$ hydrochloric acid and detected automatically by UV spectrophotometry. Several standard samples are successfully analysed for tin by the procedure developed.

\section{Analytical Mass Spectroscopy}

CONTAMINATION OF WATER BY SYNTIETIC POLYMER TUBES

G. A. Junk, H. J. Svec, R. D. Vick, and M. J. Avery

Eıvirunmental Sci. \& Tech. 8 : 1100 (1974)

Abstract--Organic contamination ranging from 1-5000 parts per

billion (ppb) by weight was detected in the water which had flnwed through tubes of polyethylene, polypropylene, black latex, six different formulations of polyvinylchloride, and a plastic garden hose. The contaminants in the effluent water were isolated by sorption on macroreticular resin beads contained in a small glass column. The sorbed organic compounds were then eluted with diethylether, the eluate was concentrated by evaporation, 
and the organic contaminants were separated and measured quantitatively by gas chromatography. Identifications of plasticizers and other polymer additives were made by combination gas chromatography-mass spectrometry. The described method is accurate and convenient for testing polymer tubes intended for use in situations which require flowing water or water solutions.

USE OF MACRORETICULAR RESINS IN THE ANALYSIS OF WATER FOR TRACE ORGANIC CONTAMINANTS

G. A. Junk, J. J. Richard, M. D. Grieser, D. Witiak, M. D. Arguello, R. Vick, H. J. Svec, J. S. Fritz and G. V. Calder

J. Chromatography 99: 745 (1974)

A.bstract--Organic impurities in water can be isolated by sorption on a small column of a macroreticular resin. The organics are readily eluted by diethyl ether; the eluate is then concentrated by evaporation, and the organics are separated and determined by gas chromatography. Studies on a large number of model compounds added to water in the $10-$ to $100-\mathrm{ppb}$ range (20 parts per trillion for pesticides) demonstrated that this method is accurate and reliable. An extensive study of the procedure revealed several critical steps where proper technique and conditions are essential to avoid serious error. These include resin purification and handling, preparatinn of standard samples containing organic impurities, and the technique and apparatus used in concentrating the XAD column eluate. 
IV. Activation Analysis and Electroanalytical Chemistry

MIXED-POTENTIAL MECHANISM FOR THE POTENTIOMETRIC RESPONSE OF THE SODIUM TUNGSTEN BRONZE ELECTRODE TO DISSOL VED OXY GEN AND IN CHELOMETRIC TITRATIONS

P. B. Hahn, D. C. Johnson, M. A. Wechter, and A. F. Voigt

Anal. Chem. 46: 553 (1974)

Abstract--Evidence is presented showing that an adsorption mech-

anism which was proposed in earlier work to explain the potentiometric

response of the $\mathrm{Na}{ }_{\underline{x}} \mathrm{WO}_{3}$ electrode in alkaline solution is not correct.

The potential response to dissolved oxygen in alkaline solution and the

potential shift observed at the equivalence point in titrations of metal ions

in ammoniacal solution with EDTA are explained by a mixed-potential

mechanism. The potential is established as a result of the spontaneous oxidation of the $\mathrm{Na}_{\underline{x}} \mathrm{WO}_{3}$ electrode by dissolved oxygen. These responses

were found to be unique to the cubic $\mathrm{Na}{ }_{\underline{x}} \mathrm{WO}_{3}$ among all the highly conducting alkali metal tungsten bronzes.

\section{Lasers in Analytical Chemistry}

INVERSE RAMAN EFFECT: A QUANTITATIVE SPECTROSCOPIC TECHNIQUE

E. S. Yeung

J. Molecular Spectroscopy 53: 379 (1974)

Abstract--The inverse Raman effect extends the general applicability of Raman spectroscopy to unstable species, fluorescing compounds and low pressure gases. A critical examination of the theory leads to optimization of the experimental variables. Interference effects from two-photon absorption processes are discussed. An experimental apparatus based on a giant-pulse ruby laser and a broad-band laser-pumped dye laser is described. Experimental correlations with ordinary Raman scattering 
cross sections are presented. The effects of inhomogeneous laser beams on the measurements are examined.

PREDISSOCIATION MODEL FOR FORMALDEHYDE

E. S. Yeung and C. B. Moore

J. Chem. Phys. 60: 2139 (1974)

Abstract--The collisionless nonradiative decay of single vibronic levels of the first excited singlet state of formaldehyde $\left({ }^{1} \underline{A}_{2}\right)$ is explained in terms of coupling with vibronic levels of the ground $\left({ }^{l} \underline{A}_{1}\right)$ state. Interaction is provided by the breakdown of the Born-Oppenheimer approximation through the nuclear kinetic energy operator. A full, Franck-Condon-factorweighted summation of states calculation is undertaken for both $\mathrm{H}_{2} \mathrm{CO}$ and $\mathrm{D}_{2} \mathrm{CO}$. Harmonic oscillator wavefunctions derived from published spectroscopic studies are used throughout. Anharmonic mixing of the ground state vibrational levels is artificially accounted for by averaging the rate over a range of final state energies. The bound-to-bound state calculation is consistent with a two-step dissociation process, in which the excited state is less strongly coupled to the ground state than the ground state is. coupled to the continuum. Direct coupling to the continuum is neglected. The results are in good agreement with experiment as regards the dependence of rate on total energy and on vibrational modes, the absolute magnitude of the rates, and the effect of isotopic substitution. Rates for levels with $\mathrm{CH}$ stretches excited are underestimated. The largest contributions to the rates come from coupling to ground state levels with the CO stretch and the out-of-plane bend highly excited. 


\title{
NT-04-04 \\ Mathematical and Computer Sciences
}

\author{
NT-04-04-01
}

\section{Mathematical Sciences}

\section{$\triangle N A L Y T I C A L$ CONTINUATION OF THE EULER TRANSFORM} D. C. Carlsui

SIAM. J. Math. Anal. 5: 252 (1974)

Abstract--The Euler transform is defined by an integral over the unit interval $[0,1]$ if the transform variables have positive real parts. If the function to be transformed is holomorphic on a neighborhood of $[0,1]$, its transform can be represented for all complex values of the transform variables by an integral around a contour which encircles $[0,17$. The integrand contains a ${ }_{2} \underline{F}_{1}$-function. This type of contour integral represents the principal branch of Appell's double hypergeometric function $\underline{F}_{1}$ for all values of the parameters and variables.

\section{EXPANSION OF ANALYTIC FUNCTIONS IN JACOBI SERIES}

R. r. Ciarlson

SIAM. J. Math. Anal. 모 797 (1974)

Abstract--A classical theorem on expansion of an analytic function in a series of Jacobi polynomials $\underline{\mathrm{P}}_{\underline{n}}^{(\alpha, \beta)}$ is extended so that $\alpha$ and $\beta$, instead of being assumed real, may have any complex values provided $\alpha+\beta \neq-2$, $-3,-4, \ldots$. . The function to be expanded may be analytic inside an arbitrary ellipse in the complex plane, since we use notation which does not fit the foci at -1 and 1 . If the ellipse is a circle, Jacobi's series reduces to Taylor's series as a special case, not a limiting case. Cauchy's inequality for the coefficients of Taylor's series has an analogue for Jacobi's 
series. The coefficients are determined uniquely by the analytic function. Some special series are listed.

INEQUALITIES FOR JACOBI POLYNOMIALS AND DIRICHLET AVERAGES B. C. Carlson SIAM. J. Math. Anal. ㅁ: 586 (1974)

Abstract--Upper approximations are derived for the absolute values of single and double Dirichlet averages of $\underline{x}^{n}$. These averages are homogeneous polynomials of degree $\underline{n}$ in several complex variables. Special cases yield upper approximations to the absolute value of a Jacobi polynomial with any complex values of the indices and argument. A Jacobi polynomial is represented in a new way by a triple sum. 